\title{
Desenvolvimento de meio quimicamente definido para produção de polissacarídeo capsular em cultivo de Streptococcus pneumoniae sorotipo 14
}

Dissertação apresentada ao Programa de PósGraduação Interunidades em Biotecnologia USP/Instituto Butantan/IPT, para obtenção do Título de Mestre em Biotecnologia. 


\section{Desenvolvimento de meio quimicamente definido para produção de polissacarídeo capsular em cultivo de Streptococcus pneumoniae sorotipo 14}

Dissertação apresentada ao Programa de PósGraduação Interunidades em Biotecnologia USP/Instituto Butantan/IPT, para obtenção do Título de Mestre em Biotecnologia.

Área de concentração: Biotecnologia

Orientadora: Dra. Viviane Maimoni Gonçalves

Versão original 
DADOS DE CATALOGAÇÃO NA PUBLICAÇÃO (CIP)

Serviço de Biblioteca e Informação Biomédica do

Instituto de Ciências Biomédicas da Universidade de São Paulo

(c) reprodução total

Ferri, Anne Letícia Silva.

Desenvolvimento de meio quimicamente definido para produção de polissacarídeo capsular em cultivo de Streptococcus pneumoniae sorotipo 14 / Anne Letícia Silva Ferri. -- São Paulo, 2013.

Orientador: Profa. Dra. Viviane Maimoni Gonçalves.

Dissertação (Mestrado) - Universidade de São Paulo. Instituto de Ciências Biomédicas. Departamento de Biologia Celular e do Desenvolvimento. Área de concentração: Biotecnologia. Linha de pesquisa: Estudo de meio de cultura para produção de polissacarídeo capsular Streptococcus pneumoniae.

Versão do título para o inglês: Development of a chemically defined medium for capsular polysaccharide production by Streptococcus pneumoniae serotype 14 .

$\begin{array}{lll}\text { 1. Fermentação anaeróbica } & \text { 2. Meios de cultura } 3 \text {. Cultura de }\end{array}$ microrganismos 4. Metabolismo celular 5. Polissacarídeos bacterianos 6. Pneumonia I. Gonçalves, Profa. Dra. Viviane Maimoni II. Universidade de São Paulo. Instituto de Ciências Biomédicas. Programa de Pós-Graduação Interunidades em Biotecnologia USP/IPT/Instituto Butantan III. Título. 
Candidato(a):

Título da Dissertação:

Orientador(a):
Anne Letícia Silva Ferri.

Desenvolvimento de meio quimicamente definido para produção de polissacarídeo capsular em cultivo de Streptococcus pneumoniae sorotipo 14.

Profa. Dra. Viviane Maimoni Gonçalves.

A Comissão Julgadora dos trabalhos de Defesa da Dissertação de Mestrado, em sessão pública realizada a considerou
( ) Aprovado(a)
( ) Reprovado(a)
Examinador(a): Assinatura:
Nome:
Instituição:
Examinador(a): Assinatura:
Nome:
Instituição:
Presidente: Assinatura:
Nome:
Instituição:




\section{AGRADECIMENTOS}

Foram dois anos de trabalho, de muito trabalho, mas também de muito aprendizado e descobertas. Nesses dois anos tive o apoio de muitas pessoas maravilhosas a quem eu gostaria de fazer um agradecimento especial.

Em primeiro lugar, gostaria de agradecer a Dra. Viviane Maimoni Gonçalves pela enorme contribuição neste trabalho, pelos ensinamentos, pela paciência, pela companhia nas imensas noites de cultivo, pela companhia nos congressos, pelo carinho, confiança e amizade, sem você este sonho não teria sido realizado.

Aos meus pais, Edméa e Walmir, por serem meu alicerce, minha estrutura, meu conforto, meu refúgio. A minha mãe por ter me dado tanta força pra encarar uma cidade nova, pessoas novas, uma vida nova e meu pai, sempre com tanto carinho, querendo sempre o melhor pra mim. Ao meu irmão Cassiano, meus primos e tios pelos tantos momentos de descontração em Machado. Aos meus tios e primos que moram longe, mas eu sei que estão sempre torcendo por mim. Aos meus avós Wilma, Laís e Ivo pelos momentos de oração que eu sinto daqui, de tão sinceros e protetores, sem vocês não teria energia para continuar A minha pequena princesa Bianca que com seu sorriso e sua inocência de criança consegue transmitir seu amor e deixar meus feriados muito mais felizes.

E o que falar dos meus companheiros de laboratório? Dos que passaram e também tiveram uma importância neste trabalho, a Verônica, Matheus, Grazieli, Bruno, Silvia, Juliano Buba, e dos que aqui ainda estão e neste tempo se tornaram muito mais que companheiros, cada um com seu jeito, formamos sim uma família, e eu gostaria de agradecer cada um em especial: A Vivi com seu jeito maluquinho, sempre assustada e estabanada, mas com um coração gigante, a Paola com seu jeito calmo e meigo, o Felipe (eterno kbeção) com sua mega inteligência e sua "boa vontade" pra resolver qualquer coisa que dê errado no laboratório, ao Douglas pela amizade, pelas caminhadas, pelas madrugadas de cultivo e pela disponibilidade para ajudar a qualquer hora, a Rafa, minha companheira de stress e segredinhos, ao Juliano Buba pelas conversas e pela ajuda sempre que preciso. Cada um de vocês vai fazer uma falta imensa, e eu nem sei se vou conseguir almoçar sem vocês. Aos nossos queridos técnicos Sr. Louri, Sr. Helio, Kdu em especial a Ana, que se tornou uma amiga e a quem sentirei muitas saudades.

Aos pesquisadores Dra Bete, Dra Mickie e Dr. Joaquin pelos ensinamentos e pela disponibilidade para ajudar no que for preciso. 
Ao Bruno e sua linda família pelo apoio, por todos os finais de semana de diversão, conversas, momentos agradáveis e felizes, vocês se tornaram minha segunda família e a quem eu tenho muito a agradecer por estarem sempre comigo.

As minhas amigas de casa Ana e Hadassa pela companhia e conversas no final das tardes para aliviar o stress do dia a dia. As minha amigas de Alfenas Priscila, Natalia, Geovana, Marina e Letícia que apesar da distância e da correria do dia- dia, não deixaram de participar da minha vida, me aconselhar e me apoiar em todas as minhas decisões.

Ao meu querido ex-orientador Prof. Dr. Masaharu Ikegaki a quem tenho profunda admiração e respeito, meu muito Obrigado pelos ensinamentos e pelo encorajamento para que eu pudesse enfrentar um "mundo novo".

Não poderia deixar de falar de meus amigos de Machado, principalmente as meninas Gabi, Fernanda e Isabelli, que me divertem e me fazem esquecer por algumas horas quanto trabalho ainda tenho a fazer.

Agradeço ao laboratório de Bioprocessos e aos demais laboratórios do Centro de Biotecnologia do Instituto Butantan pela estrutura disponibilizada e a Fundação de amparo à pesquisa do Estado de São Paulo (FAPESP) pelo apoio financeiro.

Enfim, gostaria de agradecer a Deus por permitir a realização deste sonho e por estar presente na minha vida todo segundo olhando e intercedendo por mim.

Obrigada de coração a todas as pessoas que em algum momento destes dois anos me ajudaram e estiveram comigo, todos serão lembrados com muita saudade e carinho. 
"E se o mundo não corresponde em todos os aspectos a nossos desejos, é culpa da ciência ou dos que querem impor seus desejos ao mundo?" 


\section{RESUMO}

FERRI, A. L. S. Desenvolvimento de meio quimicamente definido para produção de polissacarídeo capsular em cultivo de Streptococcus pneumoniae sorotipo 14. 2013. 109 f. Dissertação (Mestrado em Biotecnologia) - Instituto de Ciências Biomédicas, Universidade de São Paulo, São Paulo, 2013.

Streptococcus pneumoniae é a maior causa de meningite, pneumonia e bacteremia, especialmente em crianças e idosos. A cápsula polissacarídica é indispensável para a virulência desta bactéria e sua síntese depende da regulação de diversas vias metabólicas. $\mathrm{O}$ pneumococo pode catabolizar vários açúcares como glicose, sacarose e lactose, há inúmeras rotas metabólicas deficientes e ausentes, levando a uma elevada exigência nutricional. Os objetivos do trabalho foram: i) avaliar a influência das fontes de carbono glicose, sacarose e frutose e ii) de diversas composições de meio quimicamente definido no crescimento celular e produção do polissacarídeo 14 (PS14) em cultivos descontínuos; iii) identificar a melhor vazão específica de alimentação (D) e iv) avaliar a influência das bases nitrogenadas em cultivos contínuos. Glicose na concentração de $10 \mathrm{~g} / \mathrm{L}$, glicose $10 \mathrm{~g} / \mathrm{L}$ com pulso de mais 10 $\mathrm{g} / \mathrm{L}$, glicose $20 \mathrm{~g} / \mathrm{L}$, frutose $10 \mathrm{~g} / \mathrm{L}$, sacarose $10 \mathrm{~g} / \mathrm{L}$ e sacarose $20 \mathrm{~g} / \mathrm{L}$ foram avaliadas. Avaliou-se a retirada dos aminoácidos do meio de cultura asparagina, ácido aspártico, fenilalanina, serina, alanina, treonina, triptofano, lisina e tirosina, das vitaminas/cofatores ácido fólico, piridoxamina, ácido $p$-aminobenzóico, $\beta$-NAD e riboflavina, de ambos os grupos de compostos de uma só vez, além de acrescentar o dobro de glicina, isoleucina, leucina, valina e o triplo de glutamina ao meio de cultura sem os aminoácidos e vitaminas citados acima. Em cultivo contínuo avaliou-se D $0,15 \mathrm{~h}^{-1}$ a $0,5 \mathrm{~h}^{-1}$ e, depois de estabelecida $\mathrm{D}$, testaram-se as bases nitrogenadas adenina, guanina e uracila em limitação e excesso de glicose, além de concentrações crescentes da base identificada como limitante. $\mathrm{O}$ crescimento do microrganismo foi acompanhado pela DO e a produção de PS14 por ELISA de captura. O consumo de açúcar e a produção de ácidos orgânicos foram medidos por CLAE. Entre as fontes de carbono testadas, sacarose apresentou maior quantidade de PS14 livre no sobrenadante chegando a $228 \mathrm{mg} / \mathrm{L}$ em meio completo. A retirada dos aminoácidos asparagina, ácido aspártico, fenilalanina, serina, alanina, treonina, triptofano, lisina e tirosina $\mathrm{e}$ as vitaminas/cofatores ácido fólico, piridoxamina, ácido $p$-aminobenzóico, $\beta$-NAD e riboflavina não levou à diminuição acentuada da produção de PS14. O uso do meio de cultura com ausência dos aminoácidos e das vitaminas descritos acima e adição do dobro de glicina, isoleucina, leucina, valina e o triplo de glutamina, utilizando sacarose como fonte de carbono, levou ao aumento da produção total de PS14 (441 mg/L), sendo esse meio mais econômico devido à retirada de 14 componentes. Além disso, a utilização da sacarose como fonte de carbono é inovadora, pois, até onde sabemos, ela ainda não havia sido empregada como fonte de carbono para produção de PS por S. pneumoniae. A maior produtividade de PS14 em cultivo contínuo foi alcançada com $\mathrm{D}=0,4 \mathrm{~h}^{-1}$. Apesar de a injeção de adenina ao reator em estado estacionário ter provocado aumento da quantidade de PS14 produzido, a realização de cultivo contínuo com concentrações crescentes deste composto indicou que a maior produção total de PS14 foi obtida com a concentração original de adenina do meio de cultura.

Palavras-chave: Streptococcus pneumoniae. Meio de cultura quimicamente definido. Metabolismo. Polissacarídeo capsular sorotipo 14. Cultivo contínuo. 


\begin{abstract}
FERRI, A. L. S. Development of a chemically defined medium for capsular polysaccharide production by Streptococcus pneumoniae serotype 14. 2013. 109 p. Masters thesis (Biotechnology) - Instituto de Ciências Biomédicas, Universidade de São Paulo, São Paulo, 2013.
\end{abstract}

Streptococcus pneumoniae is the major cause of meningitis, pneumonia, and bacteremia, especially among young children and older adults. The capsular polysaccharides (PS) of pneumococci have been shown to be essential for their virulence and, their production depends on regulation of several metabolic pathways. Sugars are the most preferred source of carbon and energy and several amino acids and vitamins should be supplied by the culture medium, since pneumococci are fastidious microorganisms with many metabolic deficiencies. The objectives of this thesis were: i) evaluate the influence of different carbon sources (glucose, fructose and sucrose) and ii) the effect of several compositions of culture medium on the cell growth and PS14 production by S. pneumoniae in batch cultures; iii) determine the most adequate flow rate (D) and iv) evaluate the influence of nitrogenous bases in continuous cultures. In batch, glucose $10 \mathrm{~g} / \mathrm{L}$, glucose $10 \mathrm{~g} / \mathrm{L}$ with pulse of additional $10 \mathrm{~g} / \mathrm{L}$, glucose 20 $\mathrm{g} / \mathrm{L}$, fructose $10 \mathrm{~g} / \mathrm{L}$, sucrose $10 \mathrm{~g} / \mathrm{L}$ and sucrose $20 \mathrm{~g} / \mathrm{L}$ were tested as carbon sources. The medium was modified by removing the following components: the amino acids asparagine, aspartic acid, phenylalanine, serine, alanine, threonine, tryptophan, lysine, and tyrosine, the vitamins folic acid, pyridoxamine, p-aminobenzoic acid, $\beta$-NAD and riboflavin and all aforementioned amino acids and vitamins at a time. In addition, the concentration of isoleucine, leucine, valine and glycine was doubled and glutamine was tripled. In continuous cultivation, D $0.15 \mathrm{~h}^{-1}$ to $0.5 \mathrm{~h}^{-1}$ were evaluated and, after the $\mathrm{D}$ was established, the nitrogenous bases adenine, guanine and uracil were tested in limitation and excess of glucose. Also, increasing concentrations of the nitrogenous base identified as important were tested in continuous culture. The biomass was measured by optical density (OD). The production of PS14 was measured by capture ELISA. Sugar consumption and production of organic acids were determined by HPLC. Among the carbon sources tested, the use of sucrose produced the highest value $228 \mathrm{mg} / \mathrm{L}$ of PS14 free in supernatant. The exclusion of amino acids asparagine, aspartic acid, phenylalanine, serine, alanine, threonine, tryptophan, tyrosine and lysine and vitamins/cofactors folic acid, pyridoxamine, p-aminobenzoic acid, riboflavin and $\beta$-NAD from the culture medium had little impact on the production of PS14. The use of the culture medium without the amino acids and the vitamins described above and addition of twice glycine, isoleucine, leucine, valine and threefold of glutamine, using sucrose as carbon source, resulted in a greater production of PS14 (441 mg/L). This medium was more economical due to the withdrawal of 14 components. Furthermore, it is the first time that sucrose was used as carbon source for PS production by $S$. pneumoniae. The maximum PS14 productivity was reached with $D=0.4 \mathrm{~h}^{-1}$. Although the pulse of adenine into the reactor during the steady state in a continuous culture had increased the PS14 production, the results of the continuous culture with increasing concentrations of adenine indicated that the original concentration of this compound produced the highest amount of PS14.

Key-words: Streptococcus pneumoniae. Chemically defined medium. Metabolism. Capsular polysaccharide serotype 14 . Continuous cultivation. 


\section{LISTA DE FIGURAS}

Figura 1 - Desenho da superfície da bactéria Streptococcus pneumoniae.

Figura 2 - Biossíntese do polissacarídeo capsular Streptococcus pneumoniae.

Figura 3 - Visão simplificada do metabolismo de S. pneumoniae sorotipo 14.

Figura 4 - Perfil da síntese de aminoácidos em $S$. pneumoniae D394cps com base na incorporação de ${ }^{13} \mathrm{C}_{6}$ da glicose nos aminoácidos.

Figura 5 - Esquema do cultivo contínuo

Figura 6 - Esquema do cultivo contínuo para determinação da concentração não-limitante de adenina.

Figura 7 - Esquema do ELISA DE CAPTURA

Figura 8 - Produção de biomassa, PS14 $\mathrm{L}, \mathrm{PS} 14_{\mathrm{C}}$ e glicose residual em cultivo descontínuo em reator com meio CG10.

Figura 9 - Produção de lactato, acetato e biomassa em cultivo descontínuo em reator com meio CG10.

Figura 10 - Produção de biomassa, PS14 L e glicose residual em cultivo descontínuo em reator com meio CG10P10.

Figura 11 - Produção de lactato, acetato e biomassa em cultivo descontínuo em reator com meio CG10P10

Figura 12 - Produção de biomassa, PS14 L, PS14 em reator com meio CG20.

Figura 13 - Produção de lactato, acetato e biomassa em cultivo descontínuo em reator com meio CG20.

Figura 14 - Produção de biomassa, PS14 ${ }_{L}, P S 14_{C}$, e sacarose residual em cultivo descontínuo em reator com meio CS10.

Figura 15 - Produção de lactato, acetato e biomassa em cultivo descontínuo em reator com meio CS10

Figura 16 - Produção de lactato, acetato, glicose e sacarose residual em cultivo descontínuo em frasco com meio CG5S5.

Figura 17 - Produção de biomassa e PS14 ${ }_{L}$ em cultivo descontínuo em frasco com meio CG5F5. 
Figura 18 - Produção de biomassa, PS14 $\mathrm{L}_{\mathrm{L}}, \mathrm{PS} 14_{\mathrm{C}}$, e glicose residual em cultivo descontínuo em reator com meio contendo apenas 6 vitaminas/cofatores (M1G20).

Figura 19 - Produção de lactato, acetato e biomassa em cultivo descontínuo em reator com meio contendo apenas 6 vitaminas/cofatores (M1G20)

Figura 20 - Produção de biomassa, PS14 L, PS14 $\mathrm{C}$, e glicose residual em cultivo descontínuo em reator com meio apenas 11 aminoácidos (M2G20).

Figura 21 - Produção de lactato, acetato e biomassa em cultivo descontínuo em reator com meio contendo apenas 11 aminoácidos (M2G20).

Figura 22 - Produção de biomassa, PS14 $4_{\mathrm{L}}, \mathrm{PS} 14_{\mathrm{C}}$, e glicose residual em cultivo descontínuo em reator com meio $\mathrm{M} 3 \mathrm{G} 20$

Figura 23 - Produção de lactato, acetato e biomassa em cultivo descontínuo em reator com meio M3G20.

Figura 24 - Produção de biomassa, PS14 $4_{\mathrm{L}}, \mathrm{PS} 14_{\mathrm{C}}$, e glicose residual em cultivo descontínuo em reator com meio $\mathrm{M} 4 \mathrm{G} 20$.

Figura 25 - Produção de lactato, acetato e biomassa em cultivo descontínuo em reator com meio M4G20.

Figura 26 - Produção de biomassa, PS14 $\mathrm{L}, \mathrm{PS} 14_{\mathrm{C}}$, e glicose residual em cultivo descontínuo em reator com meio M4S10.

Figura 27 - Produção de lactato, acetato e biomassa em cultivo descontínuo em reator com meio M4S10

Figura 28 - Produção de biomassa, PS14, PS14 , e sacarose residual em cultivo descontínuo em reator com meio M4S20.

Figura 29 - Produção de lactato, acetato e biomassa em cultivo descontínuo em reator com meio M4S20.

Figura 30 - Produção de biomassa, PS14 $L$, PS14 $\mathrm{C}$, glicose e frutose residual em cultivo descontínuo em reator com meio M4G10F10.

Figura 31 - Produção de lactato, acetato e biomassa em cultivo descontínuo em reator com meio M4G10F10.

Figura 32 - Esquema da via metabólica da frutose até o PS14, após sacarose ser transportada para dentro da célula..

Figura 33 - Esquema da via metabólica da frutose até a glicólise, após frutose ser transportado para dentro da célula.

Figura 34 - Produção de biomassa, PS14 $\mathrm{L}, \mathrm{PS} 14_{\mathrm{C}}$, sacarose residual em cultivo descontínuo em reator com meio M5S20. 
Figura 35 - Produção de lactato, acetato e biomassa em cultivo descontínuo em reator com meio M5S20.

Figura 36- Produção de biomassa, PS14 $4_{\mathrm{L}}, \mathrm{PS} 14_{\mathrm{C}}$ e PS14 $14_{\mathrm{T}}$ em cultivo contínuo em reator e meio M1G10 variando as vazões específicas de alimentação de $0,15 h^{-1}$ a $0,5 h^{-1} \ldots$

Figura 37 - Produção de biomassa, glicose residual, lactato e acetato em cultivo contínuo em reator e meio M1G10 variando as vazões específicas de alimentação de $0,15 h^{-1}$ a $0,5 h^{-1} \ldots . .84$

Figura 38 - Determinação do $\mu_{\text {máx }}$ pelo método dinâmico em cultivo contínuo em reator com $\mathrm{D}=1,0 \mathrm{~h}^{-1}$ em meio M1G10.

Figura 39 - Determinação do coeficiente de manutenção $\left(m_{s}\right)$ e do fator de conversão verdadeiro $\left(\mathrm{Y}_{\mathrm{G}}\right)$ em cultivo contínuo em reator de $S$. pneumoniae sorotipo 14 em meio M1G10.

Figura 40 - Relação de $\mu_{\mathrm{L}}$ com as vazões específicas de alimentação em cultivo contínuo em reator de S. pneumoniae sorotipo 14 em meio M1G10.....

Figura 41 - Relação de $\mu_{\mathrm{PS} 14 \mathrm{C}}(\mathrm{A})$ e $\mu_{\mathrm{PS} 14 \mathrm{~T}}$ (B) com as vazões específicas de alimentação em cultivo contínuo em reator de $S$. pneumoniae sorotipo 14 em meio M1G10 .

Figura 42 - Relação de $\mu \mathrm{PS} 14_{L}$ com as vazões específicas de alimentação em cultivo contínuo em reator de S. pneumoniae sorotipo 14 em meio M1G10 .

Figura 43 - Cápsula de S. pneumoniae sorotipo 14 corada com India Ink

Figura 44 - Produção de biomassa, glicose residual, lactato e acetato em cultivo contínuo em reator e em meio M1G10 e adição de bases nitrogenadas

Figura 45 - Produção de biomassa, glicose residual, lactato e acetato em cultivo contínuo em reator e em meio M1G20 e adição de bases nitrogenadas.

Figura 46 - Produção de PS14 ${ }_{L}$ em cultivo contínuo em reator e em meio M1G10 e M1G20 e adição de bases nitrogenadas.

Figura 47 - Produção de biomassa, glicose residual, lactato e acetato em cultivo contínuo em reator e em meio M1G20 com $20 \mathrm{~g} / \mathrm{L}$ de glicose e cinco concentrações diferentes de adenina. 98

Figura 48 - Produção de PS14 ${ }_{L}$ em cultivo contínuo em reator e em meio M1G20 e cinco concentrações diferentes de adenina. 


\section{LISTA DE TABELAS}

Tabela 1 - Composição do meio completo descrito po Van der Djin e Kessler (1980)

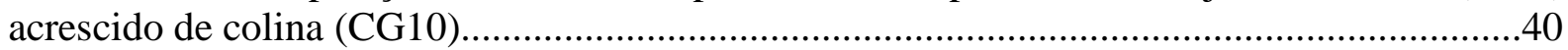

Tabela 2 - Equações para cálculo dos parâmetros de cultivos em batelada e contínuos

Tabela 3 - Parâmetros dos cultivos batelada em reator com glicose $10 \mathrm{~g} / \mathrm{L}$, glicose $10 \mathrm{~g} / \mathrm{L}$ mais pulso, glicose $20 \mathrm{~g} / \mathrm{L}$ e sacarose $10 \mathrm{~g} / \mathrm{L}$

Tabela 4 - Parâmetros dos cultivos M1G20, M2G20, M3G20, M4G20 comparados ao meio completo com $20 \mathrm{~g} / \mathrm{L}$ de glicose inicial (CG20).

Tabela 5 - Parâmetros dos cultivos M4S10, M4S20, M4G10F10, M5S20 comparados ao meio completo com $10 \mathrm{~g} / \mathrm{L}$ de sacarose inicial (CS10).

Tabela 6 - Composição do meio M5S20. .82

Tabela 7 - Parâmetros do cultivo contínuo alterando as vazões específicas de alimentação...85

Tabela 8 - Parâmetros do cultivo contínuo com adição de bases nitrogenadas com glicose 10 $\mathrm{g} / \mathrm{L}(\mathrm{M} 1 \mathrm{G} 10)$.

Tabela 9 - Parâmetros do cultivo contínuo com adição de bases nitrogenadas com glicose 20 $\mathrm{g} / \mathrm{L}(\mathrm{M} 1 \mathrm{G} 20)$

Tabela 10 - Parâmetros do cultivo contínuo com adição de adenina em cinco concentrações diferentes e glicose $20 \mathrm{~g} / \mathrm{L}$ 100

Quadro 1 - Composição dos meios de cultura modificados .41 


\section{LISTA DE SÍMBOLOS}

A - acetato

$\mathrm{L}$ - lactato

$\mathrm{S}$ - substrato (glicose, frutose ou sacarose)

$\mathrm{X}-$ biomassa

$\mathrm{D}$ - vazão específica de alimentação ou taxa de diluição $\left(\mathrm{h}^{-1}\right)$

$\mathrm{m}_{\mathrm{s}}-$ coeficiente de manutenção $\left(\mathrm{g}_{\text {glicose }} \cdot \mathrm{g}_{\text {célula }}{ }^{1} \cdot \mathrm{h}^{-1}\right)$

$\mathrm{Q}_{\mathrm{x}}$ - produtividade em células $\left(\mathrm{g}_{\text {célula }} \cdot \mathrm{L}^{-1} \cdot \mathrm{h}^{-1}\right)$

$\mathrm{Q}_{\mathrm{PS} 14 \mathrm{~T}}$ - produtividade em PS14 $\left(\mathrm{g}_{\mathrm{PS} 14 \mathrm{~T}} \cdot \mathrm{L}^{-1} \cdot \mathrm{h}^{-1}\right)$

Q $_{\text {PS14L }}$ - produtividade em PS14 $\left(\right.$ g $\left._{P S 14 L} \cdot \mathrm{L}^{-1} \cdot \mathrm{h}^{-1}\right)$

QPS14C - produtividade em PS14 $\left(\right.$ g $\left._{\mathrm{PS} 14 \mathrm{C}} \cdot \mathrm{L}^{-1} \cdot \mathrm{h}^{-1}\right)$

$\mathrm{Q}_{\mathrm{L}}$ - produtividade em lactato $\left(\mathrm{g}_{\text {lactato }} \cdot \mathrm{L}^{-1} \cdot \mathrm{h}^{-1}\right)$

$\mathrm{Q}_{\mathrm{A}}$ - produtividade em acetato $\left(\mathrm{g}_{\text {acetato. }} \cdot \mathrm{L}^{-1} \cdot \mathrm{h}^{-1}\right)$

$\mu$ - velocidade específica de crescimento $\left(\mathrm{h}^{-1}\right)$

$\mu_{\text {máx }}$ - velocidade específica de crescimento máxima $\left(\mathrm{h}^{-1}\right)$

$\mu_{\mathrm{A}}$ - velocidade específica de produção de acetato $\left(\mathrm{g}_{\text {acetato. }} \cdot \mathrm{g}_{\text {célula }} \cdot \mathrm{h}^{-1}\right)$

$\mu_{\mathrm{L}}$ - velocidade específica de produção de lactato $\left(\mathrm{gl}_{\mathrm{actato}} \cdot \mathrm{g}_{\text {célula }}{ }^{1} \cdot \mathrm{h}^{-1}\right)$

$\mu_{\mathrm{S}}-$ velocidade específica de consumo de substrato $\left(\mathrm{g}_{\text {glicose }} \cdot \mathrm{g}_{\text {célula }} \cdot \mathrm{h}^{-1}\right.$ )

$\mu_{\mathrm{PS} 14 \mathrm{~L}}$ - velocidade específica de produção de PS14 $\left(\mathrm{mg}_{\mathrm{PS} 14 \mathrm{~L}} \cdot \mathrm{g}_{\text {célula }} \cdot \mathrm{h}^{-1}\right)$

$\mu_{\mathrm{PS} 14 \mathrm{C}}$-velocidade específica de produção dePS14 $\mathrm{C}\left(\mathrm{mg}_{\mathrm{PS} 14 \mathrm{C}} \cdot \mathrm{g}_{\text {célula }} \cdot \mathrm{h}^{-1}\right)$

$\mu_{\mathrm{PS} 14 \mathrm{~T}}$ - velocidade específica de produção de PS14 $\left(\mathrm{mg}_{\mathrm{PS} 14 \mathrm{C}} \cdot \mathrm{g}_{\text {célula }}{ }^{1} \cdot \mathrm{h}^{-1}\right)$

$\mathrm{Y}_{\mathrm{X} / \mathrm{S}}-$ Fator de conversão de substrato a células ( $\mathrm{g}_{\text {célula }} / \mathrm{g}_{\text {substrato }}$ )

$\mathrm{Y}_{\mathrm{PS} 14 / \mathrm{S}}$ - Fator de conversão de substrato a PS14 $\left(\mathrm{mg}_{\mathrm{ps} 14} / \mathrm{g}_{\text {substrato }}\right)$

$\mathrm{Y}_{\mathrm{L} / \mathrm{S}}-$ Fator de conversão de substrato a lactato $\left(\mathrm{g}_{\text {lactato }} / \mathrm{g}_{\text {substrato }}\right)$

$\mathrm{Y}_{\mathrm{A} / \mathrm{S}}$ - Fator de conversão de substrato a acetato ( $\left.\mathrm{g}_{\text {acetato }} / \mathrm{g}_{\text {substrato }}\right)$

$\mathrm{Y}_{\mathrm{PS} 14 \mathrm{~L} / \mathrm{S}}$ - Fator de conversão de substrato a PS14L $\left(\mathrm{mg}_{\mathrm{ps} 14} / \mathrm{g}_{\text {substrato }}\right)$ 
$\mathrm{Y}_{\mathrm{PS} 14 \mathrm{~L} / \mathrm{X}}$ - Fator de conversão de células a PS14L $\left(\mathrm{mg}_{\mathrm{ps} 14} / \mathrm{g}_{\text {célula }}\right)$

$\mathrm{Y}_{\mathrm{PS} 14 \mathrm{C} / \mathrm{S}}$ - Fator de conversão de substrato a PS14C $\left(\mathrm{mg}_{\mathrm{ps} 14} / \mathrm{g}_{\text {substrato }}\right)$

$\mathrm{Y}_{\mathrm{PS} 14 \mathrm{C} / \mathrm{X}}$ - Fator de conversão de células a PS14C $\left(\mathrm{mg}_{\mathrm{ps} 14} / \mathrm{g}_{\text {célula }}\right)$

$\mathrm{Y}_{\mathrm{PS} 14 \mathrm{~T} / \mathrm{S}}$ - Fator de conversão de substrato a PS14T $\left(\mathrm{mg}_{\mathrm{ps} 14} / \mathrm{g}_{\text {substrato }}\right)$

$\mathrm{Y}_{\mathrm{PS} 14 \mathrm{~T} / \mathrm{X}}$ - Fator de conversão de células a PS14T $\left(\mathrm{mg}_{\mathrm{ps} 14} / \mathrm{g}_{\text {célula }}\right)$

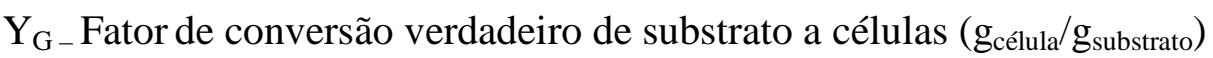

CI - Intervalo de confiança

v - população média estimada (90\% de confiança)

$\bar{a}$ - média das amostras

$t$ - valor descrito pela distribuição $t$-Student (tabelado)

$\sigma-$ desvio padrão

$\mathrm{n}$ - quantidade de amostras (espaço amostral) 


\section{LISTA DE ABREVIATURAS}

$\mathrm{AK}$ - acetato quinase

ATCC - American Type Culture Collection

ATP - Adenina trifosfato

BHI -Brain and heart infusion

CcpA - Catabolite Control Protein A (Proteína A do Regulador global do CCR)

CCR - Carbon Catabolite Repression (Repressão catabólica do carbono)

CG10 - meio completo com glicose 10g/L

CG10P10 - meio completo com glicose $10 \mathrm{~g} / \mathrm{L}$ e pulso de $10 \mathrm{~g} / \mathrm{L}$ de glicose

CG20 - meio completo com glicose 20g/L

CG5S5 - meiocompleto com glicose 5g/L e sacarose 5/L

CS10 - meio completo com sacarose $10 \mathrm{~g} / \mathrm{L}$

CLAE - Cromatografia líquida de alta eficiência

DHAP - diidroxicetona fosfato

DO - Densidade ótica a 600nm

ELISA - Enzyme-linked immunosorbent assay

EMP - Embden-Meyerhof-Parnas (via glicolítica)

EPS - Exopolissacarídeo

FBP - frutose - 1,6 - bifosfato

GAP - gliceraldeído-3-fosfato

GC - guanina/citosina

GC/MS - cromatografia gasosa com espectrômetro de massa

LDH - lactato desidrogenase 
M1G10 - meio modificado 1 com glicose 10g/L, composição no APÊNDICE A M1G20 - meio modificado 1 com glicose 20g/L, composição no APÊNDICE A M2G20 - meio modificado 2 com glicose 20g/L, composição no APÊNDICE A M3G20 - meio modificado 3 com glicose 20g/L, composição no APÊNDICE A M4G20 - meio modificado 4 com glicose 20g/L, composição no APÊNDICE A M4S10 - meio modificado 4 com sacarose 10g/L, composição no APÊNDICE A M4S20 - meio modificado 4 com sacarose 20g/L, composição no APÊNDICE A M4G10S10 - meio modificado 4 com glicose $10 \mathrm{~g} / \mathrm{L}$ e sacarose $10 \mathrm{~g} / \mathrm{L}$, composição no APÊNDICE A

M5S20 - meio modificado 5 com sacarose 20g/L, composição no APÊNDICE A

$\mathrm{NAD}^{+}$- Molécula de nicotinamida oxidada

$\mathrm{NADH}$ - Molécula de nicotinamida reduzida

OPD - ácido $o$-fenilenodiacético (da sigla em inglês)

OMS - Organização Mundial da Saúde

PBS - solução salina tamponada com fosfato

PBS-T - Tween 20 a 0,05\% em solução salina tamponada com fosfato

PBS-T-BSA - Tween 20 a $0,05 \%$ e albumina bovina a $0,5 \%$ em solução salina tamponada com fosfato

PCV7 - vacina pneumocócica 7-valente conjugada

PCV10 - vacina pneumocócica 10 -valente conjugada

PCV13 - vacina pneumocócica 13-valente conjugada

$\mathrm{PDH}_{\mathrm{C}}-$ complexo piruvato desidrogenase

PFL - piruvato formiato liase

PLY - toxina pneumolisina 
PPP - via pentose fosfato

PS - Polissacarídeo capsular

PS14 - Polissacarídeo capsular produzido pelo S. pneumoniae sorotipo 14

PS14 $\mathrm{C}$ - Polissacarídeo capsular produzido pelo $S$. pneumoniae sorotipo 14 associado às células

PS14 1 - Polissacarídeo capsular produzido pelo $S$. pneumoniae sorotipo 14 livre no sobrenadante da cultura

PS14 14 - Polissacarídeo capsular produzido pelo $S$. pneumoniae sorotipo 14 total, ou seja, a soma do polissacarídeo capsular livre e associado à célula

PspA - Pneumococcal surface protein A

Sistema ABC - Sistema transportador dependente de ATP

Sistema PTS - Sistema transportador dependente de fosfotransferase

THY - meio de cultura Todd e Hewitt com adição de 0,5\% de extrato de levedura

Wzd/ Wze - Proteínas reguladoras da síntese de PS

Wzy/Wzx - proteínas flipase e polimerase da via de síntese de PS 


\section{SUMÁRIO}

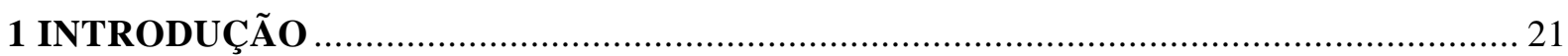

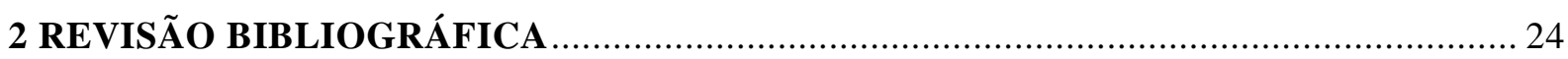

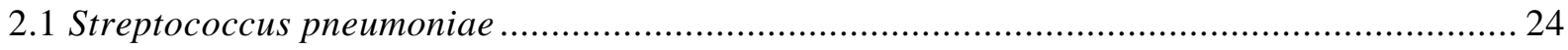

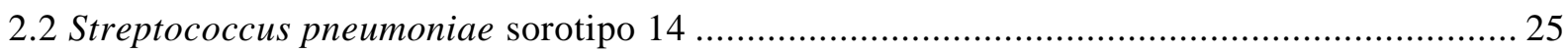

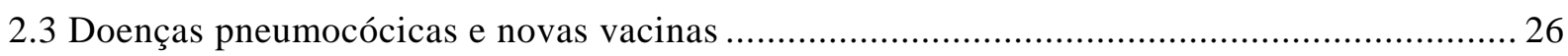

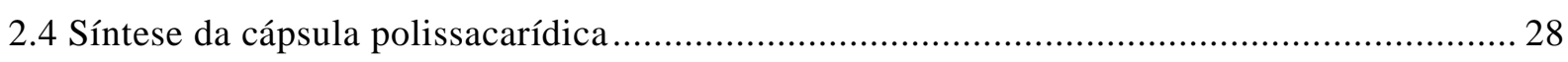

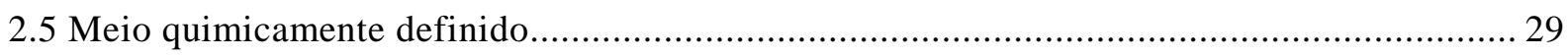

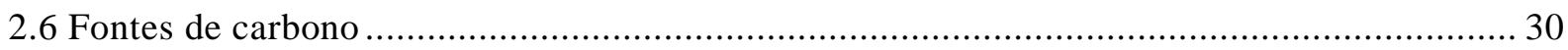

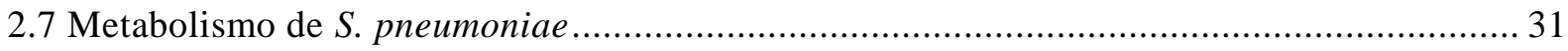

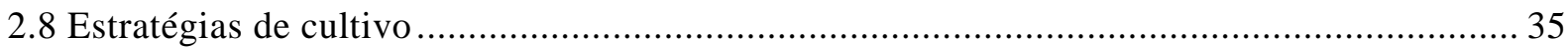

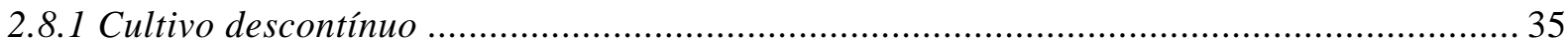

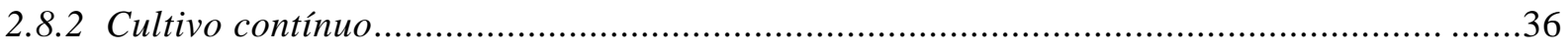

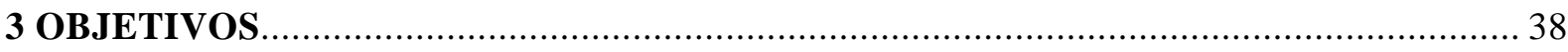

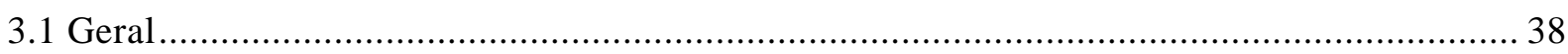

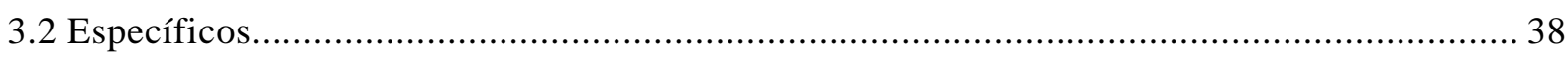

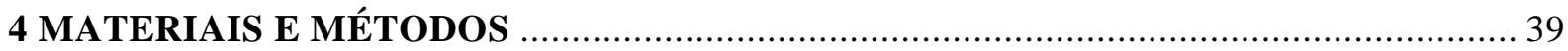

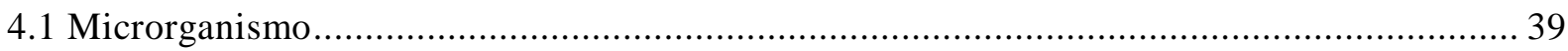

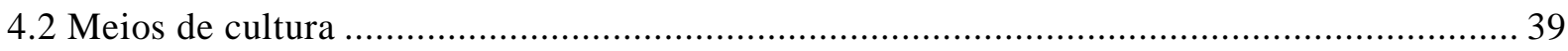

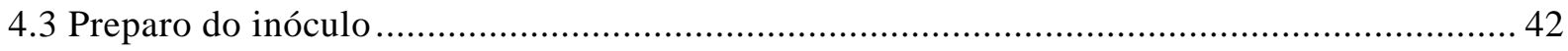

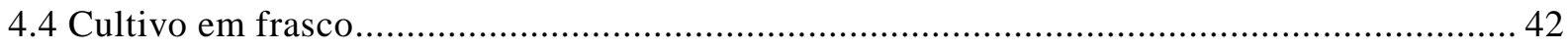

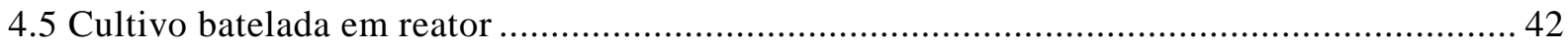

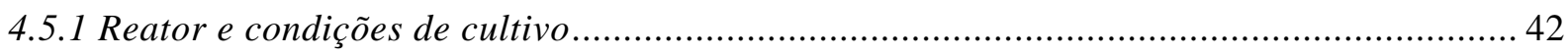

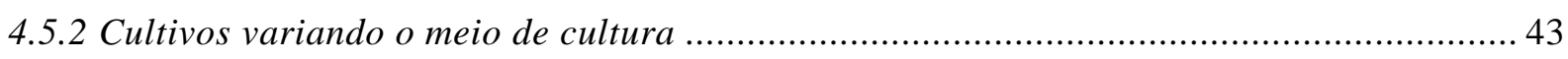

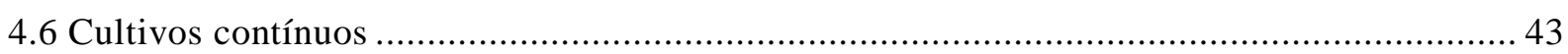

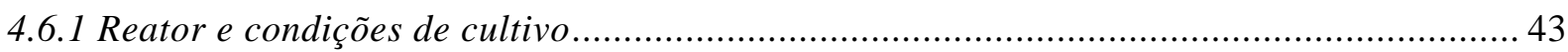

4.6.2 Determinação da vazão específica de alimentação ........................................................... 44

4.6.3 Determinação das concentrações não limitantes das bases nitrogenadas adenina,

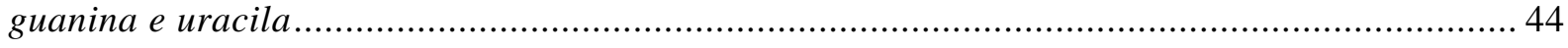

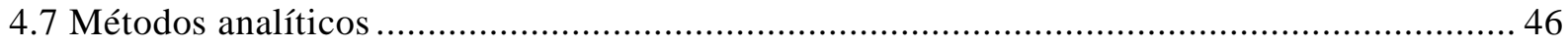

4.7.1 ELISA DE CAPTURA para determinação da concentração de ps14 nas células e no

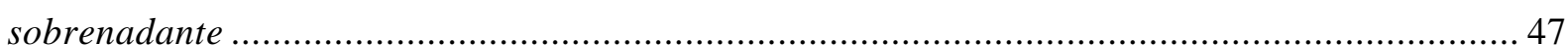

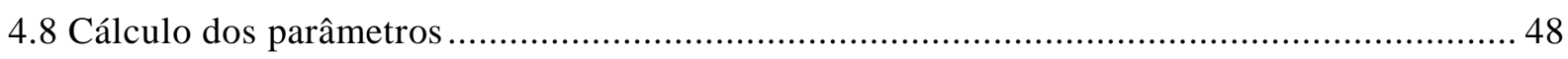

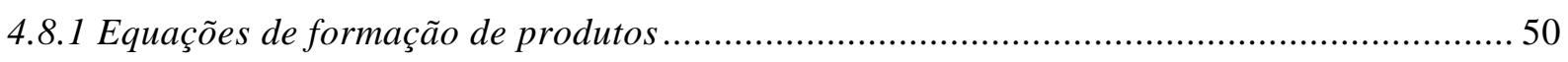

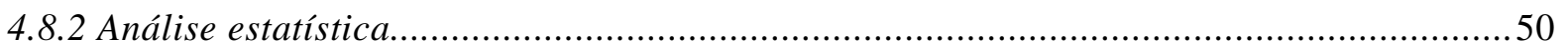

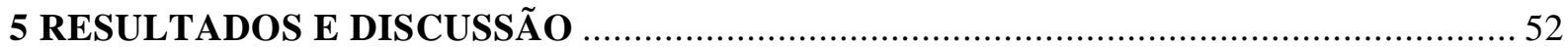


5.1 Cultivos em batelada. 52

5.1.1 Influência de glicose e sacarose na produção de ps 14, biomassa e ácidos orgânicos........ 52

5.1.1.1 Cultivo em meio definido contendo $10 \mathrm{~g} / \mathrm{l}$ de glicose inicial(CG10)

5.1.1.2 Cultivo em meio definido contendo $10 \mathrm{~g} / \mathrm{l}$ de glicose inicial mais pulso de glicose

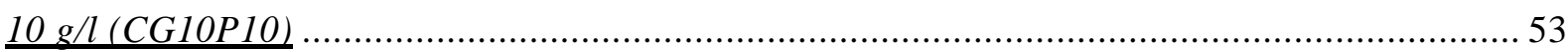

5.1.1.3 Cultivo em meio definido contendo $20 \mathrm{~g} / \mathrm{l}$ de glicose inicial(CG20) ................................ 55

5.1.1.4 Cultivo em meio definido contendo $10 \mathrm{~g} / \mathrm{l}$ de sacarose inicial(CS10) .............................. 57

5.1.1.5 Utilizacão de glicose e sacarose concomitantes como fonte de carbono(CG5S5)

5.1.1.6 Comparação dos dados dos cultivos glicose $10 \mathrm{~g} / \mathrm{l}$ (CG10). glicose $10 \mathrm{~g} / \mathrm{l}$ mais pulso(CG10P10), glicose $20 \mathrm{~g} / \mathrm{l}(\mathrm{CG} 20)$ e sacarose $10 \mathrm{~g} / \mathrm{ll}(\mathrm{CS} 10)$.

5.1.2 Influência da retirada de vitaminas (M1G20) na produção de PS14, biomassa e ácidos orgânicos.....

5.1.3 Influência da retirada de aminoácidos (M2G20) na produção de ps14, biomassa e ácidos orgânicos.....

5.1.4 Influência da retirada de aminoácidos e vitaminas (M3G20) na produção de PS14, biomassa e ácidos orgânicos .

5.1.5 Influência da retirada da riboflavina (M4G20) na produção de PS14, biomassa e ácidos orgânicos.

5.1.6 Cultivo em meio definido com retirada de aminoácidos e vitaminas contendo $10 \mathrm{~g} / \mathrm{l}$ de sacarose inicial (M4S10)

5.1.7 Cultivo em meio definido com retirada de aminoácidos e vitaminas contendo $20 \mathrm{~g} / \mathrm{l}$ de sacarose inicial (M4S20)

5.1.8 Cultivo em meio definido com retiada de aminoácidos e vitaminas contendo $10 \mathrm{~g} / \mathrm{l}$ de glicose e $10 \mathrm{~g} / \mathrm{l}$ de frutose (M4G10F10).

5.1.9 Cultivo em meio definido com retirada de aminoácidos e vitaminas contendo $20 \mathrm{~g} / \mathrm{l}$ de sacarose inicial e o dobro dos aminoácidos glicina, isoleucina, leucina, valina e três vezes glutamina (M5S20).

5.2 Cultivos contínuos

5.2.1 Determinação da vazão específica de alimentação mais adequada para produção de ps14

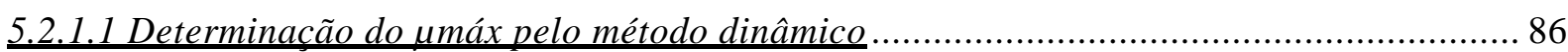

5.2.1.2 Determinação do coeficiente de manutenção e do fator de conversão verdadeiro ........... 86

5.2.1.3 Determinacão do $\mu l, \mu p s 14 c, \mu p s 14 t$ e $\mu p s 14 l$.

5.2.2 Influência da adição de bases nitrogenadas em cultivo contínuo na produção de ps14t, biomassa e ácidos orgânicos em meio cdm completo com $10 \mathrm{~g} / \mathrm{l}$ (M1G10) ou $20 \mathrm{~g} / \mathrm{l}$ de glicose (M1G20) 
5.2.3 Influência do aumento gradativo da concentração de adenina em cultivo contínuo, na produção de PS14t, biomassa e ácidos orgânicos em meio M1G20 ........................................ 97

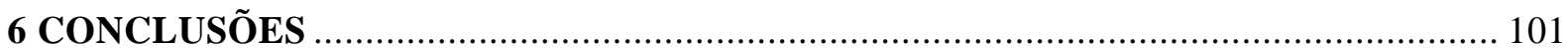

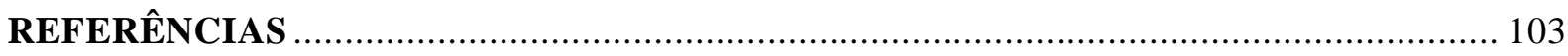

APENDICE A:. Diferentes composições de meio de cultura utilizados nos experimentos.........109 


\section{INTRODUÇÃO}

O Instituto Butantan, vinculado à Secretaria de Saúde do Estado de São Paulo, é um dos maiores centros de pesquisa biomédica do mundo, responsável por mais de $93 \%$ do total de soros e vacinas produzidos no Brasil, das quais se destacam as vacinas contra difteria, tétano, coqueluche, hepatite B, influenza sazonal e H1N1. O Instituto desenvolve estudos e pesquisas na área de Biotecnologia, relacionados, direta ou indiretamente, com a saúde pública.

Segundo a Organização Mundial de Saúde (OMS) a pneumonia é o maior problema de saúde pública do mundo. Estima-se que no ano 2000, ocorreram cerca de 14,5 milhões de casos de doenças pneumocócicas invasivas, resultando em 826.000 mortes de crianças menores de 5 anos (O'BRIEN, 2009).

Streptococcus pneumoniae, popularmente chamado de pneumococo, é um dos principais agentes causadores de diversas infecções como pneumonia, otite aguda do ouvido médio e sinusite, e infecções invasivas, como a meningite, bacteremia e sepse. São descritos mais de 90 sorotipos que diferem na estrutura do polissacarídeo da cápsula (PS). Dentre esses, cerca de 20 sorotipos são prevalentes na população. As vacinas atualmente em uso são constituídas de polissacarídeos livres ou conjugados a uma proteína carregadora. A conjugação do polissacarídeo a uma proteína o transforma de um antígeno que induz uma resposta imune timo-independente para timo-dependente, e que, portanto, induz resposta imune em crianças abaixo de 2 anos, que é o principal grupo de risco. Atualmente, três vacinas conjugadas, contendo 7, 10 e 13 sorotipos (PCV7, PCV10 e PCV13) e uma vacina não conjugada contendo 23 sorotipos (PPV23) são comercializadas internacionalmente, porém a PPV23 não dá proteção para menores de 2 anos e a proteção é questionável para menores de 5 e maiores de 65 anos, enquanto que as vacinas conjugadas têm baixa cobertura de sorotipos e alto custo.

Uma vacina conjugada contendo PS de poucos sorotipos conjugados a proteínas do pneumococo como carregadoras poderia aumentar a cobertura vacinal com poucos componentes antigênicos. Uma das proteínas candidatas é a "pneumococcal surface protein A, PspA", uma vez que ela é bastante conservada entre as cepas e tem apresentado boa imunogenicidade e proteção em ensaios em animais. Assim, um projeto temático foi proposto pelo Centro de Biotecnologia do Instituto Butantan para o estudo de diferentes aspectos relacionados ao desenvolvimento de uma vacina pneumocócica composta de conjugados PSPspA. 
Segundo informe SIREVA II 2011, o sorotipo 14 representa cerca de 14\% do total de sorotipos existentes no Brasil, responsável por 39,8\% dos casos de doenças pneumocócicas em crianças menores que 5 anos, e também é o que apresenta maior resistência a antibióticos, sendo portanto, objeto de estudo deste trabalho e um dos componentes da vacina proposta pelo projeto temático.

Os sorotipos 23F, 6B, 1 e 14 já foram estudados no Laboratório de Bioprocessos. Estudou-se a influência da composição do meio de cultura e das condições de cultivo sobre a produção do PS do sorotipo 23F, caseína e hidrolisado de soja foram testados como fonte de nitrogênio, além da influência da concentração inicial de glicose. Caseína mostrou-se a fonte de nitrogênio mais eficiente, a glicose tornou-se inibitória a partir de $30 \mathrm{~g} / \mathrm{L}$, e em condições anaeróbias, foi obtido $240 \mathrm{mg} / \mathrm{L}$ de PS23F solúvel (GONÇALVES et al., 2002). O método de purificação do PS23F produzido foi estabelecido e o produto obtido atendeu aos requisitos de pureza (GONÇALVES et al., 2003). Além disso, a introdução de ar na fase estacionária do cultivo anaeróbio provocou a liberação do PS ligado às células para o sobrenadante da cultura, alcançando-se $400 \mathrm{mg} / \mathrm{L}$ de PS23F solúvel (GONÇALVES et al., 2006).

Para o sorotipo 6B, estudou-se a influência da densidade ótica (DO) do inóculo e da concentração residual de glicose no momento do pulso para produção de PS6B, sendo que o pulso de glicose quando a concentração residual da fonte de carbono era de $15 \mathrm{~g} / \mathrm{L}$ (somente 50\% havia sido consumido) levou a maior concentração de PS6B (390 mg/L) (CARMO, 2010). O método para purificação do PS6B também foi estabelecido com sucesso (GONÇALVES et al., 2007).

Para o sorotipo 1, selecionou-se a melhor cepa produtora de PS1 (ST595/01) e estudou-se a influência de diferentes peptonas também na produção de PS1, além de terem sido estabelecidos dois método de dosagem deste PS, colorimétrico e ELISA de captura com anticorpo biotinilado. Um novo meio de cultura complexo foi elaborado contendo a peptona Phytone e sem a adição dos aminoácidos glutamina e asparagina, já fornecidos em quantidades suficientes pela Phytone. Utilizando este novo meio, a estratégia de batelada alimentada aumentou a produção de PS1, chegando a 375 mg/L (FIGUEIREDO, 2012; MARTHOS, 2012).

O sorotipo 14 foi estudado anteriormente quanto à produção de PS14 em cultivos contínuos em meio complexo e em meio definido com adição de diferentes concentrações de glicose, glutamina e colina. Verificou-se que em meio definido a glicose deixou de ser limitante acima de $15 \mathrm{~g} / \mathrm{L}$, a colina acima de $25 \mathrm{mg} / \mathrm{L}$ e a glutamina em 0,2 g/L (GOGOLA, 
2011). Um método de dosagem de PS14 através do ELISA de captura também foi estabelecido (GOGOLA et al., 2012).

Neste trabalho, será apresentada uma continuação dos estudos de produção de PS14, através do desenvolvimento de um meio de cultura quimicamente definido adequado para Streptococcus pneumoniae sorotipo 14, possibilitando assim maior compreensão do metabolismo deste microrganismo a fim de melhorar o processo de produção de PS14 para futura aplicação em uma vacina pneumocócica conjugada. 


\section{REVISÃO BIBLIOGRÁFICA}

\subsection{Streptococcus pneumoniae}

S. pneumoniae é um microrganismo que pertence ao grupo das bactérias láticas, é Gram-positivo e se apresenta na forma de diplococos lanceolados ou em cadeias curtas. É uma bactéria nutricionalmente fastidiosa e anaeróbia aerotolerante. Também chamado

pneumococo, S. pneumoniae é um patógeno que reside assintomaticamente no trato respiratório superior de humanos, entretanto também causa doenças graves que apresentam alta taxa de mortalidade, como pneumonia, septicemia e meningite (MUSHER, 1992).

A superfície desta bactéria consiste em três estruturas distintas: membrana plasmática, parede celular e cápsula polissacarídica. A membrana plasmática apresenta estrutura conservada, com moléculas de ácido lipoteicóico inseridas na bicamada lipídica. A parede celular de bactérias Gram-positivas é composta por peptidoglicanos, contém os ácidos teicóico e lipoteicóico e ancora diversas proteínas de superfície. O ácido teicóico contém resíduos de colina, onde as proteínas ligantes de colina ancoram-se, e é um dos responsáveis pela resposta inflamatória intensa observada na infecção por pneumococo. O PS da cápsula do S. pneumoniae é formado por oligossacarídeos repetitivos, constituídos de 2 a 10 unidades monossacarídicas, e possui papel importante na patogenia microbiana, incluindo a inibição da fagocitose, a prevenção da deposição do complemento, a aderência a células do hospedeiro e a contribuição para processos inflamatórios (VENTURA et al., 2006).

Uma enorme variedade de estruturas polissacarídicas pode ser formada visto que há um variado número de diferentes monossacarídeos que podem ser ligados de diferentes formas dentro de uma subunidade, incluindo ramificações na cadeia e substituição por moléculas orgânicas e inorgânicas (KOLKMAN et al., 1997).

O pneumococo produz uma série de fatores de virulência, incluindo o polissacarídeo capsular (PS), proteínas de superfície, enzimas e a toxina pneumolisina (PLY), sendo que destes o PS é o mais importante (MITCHELL; MITCHELL, 2010). Além disso, cada estrutura de PS é reconhecida de maneira diferente pelo sistema imune do hospedeiro, o que permite a classificação do pneumococo em sorotipos, cada um deles correspondendo então a uma estrutura química e imunologicamente distinta de PS da cápsula (GARAU; CALBO, 2007). Por exemplo, os polissacarídeos dos sorotipos 6A e 6B diferem somente na maneira 
em que ramnose é ligada ao ribitol e isso é suficiente para que sejam diferenciados pelo sistema imune (ELBERSE et al., 2011).

Entre os microrganismos que colonizam as vias respiratórias Haemophilus influenzae, Neisseria meningitidis e Moraxella catarrhalis, o $S$. pneumoniae é a única espécie estritamente dependente dos carboidratos como fonte de carbono, esta diferença decisiva na utilização do carbono provavelmente garante vantagem competitiva para o pneumococco na nasofaringe (BUCKWALTER; KING, 2012).

Figura 1- Desenho da superfície da bactéria Streptococcus pneumoniae

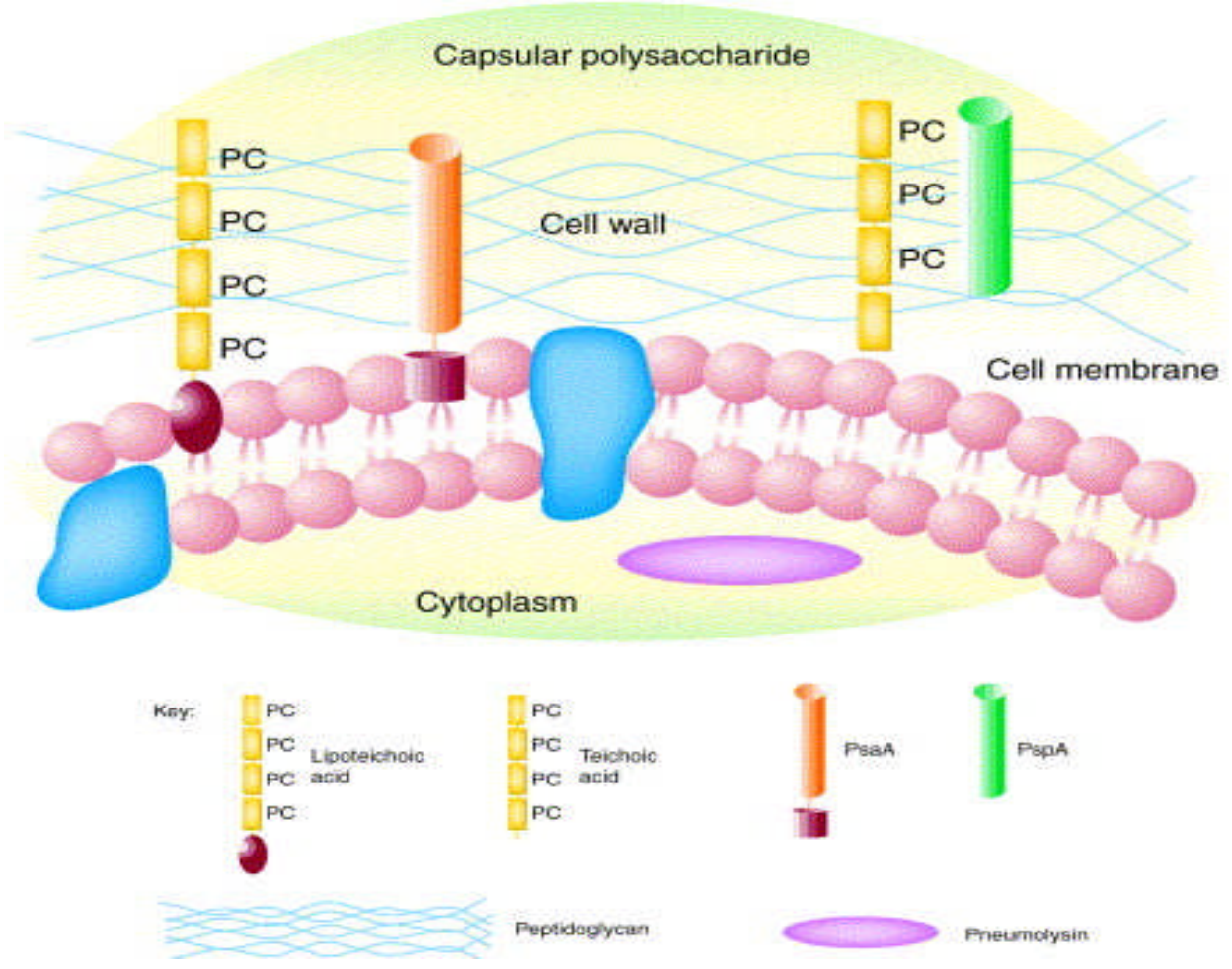

Fonte: (SNAPPER et al., 2001).

\subsection{Streptococcus pneumoniae sorotipo 14}

Na era pré-vacina, S. pneumoniae sorotipo 14 era um dos principais causadores de doenças invasivas no mundo, atualmente, o sorotipo 14 continua sendo o de maior prevalência entre crianças de 0-6 anos no Brasil (INFORME REGIONAL DE SIREVAII, 2011) e um dos que apresenta maior incidência no mundo. Ele foi responsável por 39,8\% da doença pneumocócica no Brasil na faixa etária de 0-6 anos e por 10,8\% dos casos da doença em crianças de 6-14 anos (BRADILEONE et al., 2003). Uma pesquisa feita com amostras de 
crianças menores de 5 anos no Brasil indicou que entre 1999 e 2008 os sorotipos prevalentes eram, nesta ordem, 14, 5, 6B, 1, 6A, 18C, 19A, 3, 9V, 19F, 23F, 9N e 10A (MANTESE et al., 2009).

O sorotipo 14 expressa resistência a uma variedade de agentes antimicrobianos incluindo penicilina e eritromicina. Estudos prévios mostraram que o genoma de $S$. pneumoniae é rico em sequências de inserção. Na cepa multirresistente CGSP14, sequenciada por Ding et al. (2009), foram identificadas 80 sequências de inserção, a maioria delas parecia estar degenerada devido a inserções, deleções ou mutações pontuais e somente 20 estavam intactas no genoma. Embora esses elementos degenerados possam ser inativos e não funcionais, eles podem levar a sítios potenciais para recombinação homóloga. Análises de alinhamento revelaram que pelo menos oito clusters "estrangeiros" estão presentes no genoma dessa cepa, a maioria dos genes estão relacionados à virulência e à resistência aos antimicrobianos. Há indícios (através de diferentes quantidades de GC), que estes genes podem ter sido adquiridos recentemente através da transferência horizontal, na qual os genes são transferidos de um organismo ao outro. Aproximadamente metade dos genes de resistência aos antimicrobianos em CGSP14 estão associados a elementos genéticos móveis (DING et al., 2009).

O PS14 é formado por unidades repetitivas de: $\rightarrow 6)-\beta-D-N$-acetilglicosamina-( $1 \rightarrow 3)$ $\beta$-D-Galactose- $(1 \rightarrow 4)$ - $\beta$-D-Glicose- $(1 \rightarrow$, com uma cadeia lateral de $\beta$-D-Galactose- $(1 \rightarrow$ ligada ao $\mathrm{C} 4$ de cada resíduo de $\mathrm{N}$-acetilglicosamina (LINDERBERG; LONNGREN; POWELL, 1977) e devido a sua carga neutra, é de difícil detecção quando comparado aos PS carregados.

\subsection{Doenças pneumocócicas e novas vacinas}

As doenças pneumocócicas podem ser não invasivas e menos graves, tais como sinusite, otite e pneumonia, ou doenças pneumocócicas invasivas, por exemplo, bacteremia, pneumonia necrosante, meningite e sepse, que são muito graves e matam 1,6 milhões de pessoas no mundo a cada ano principalmente em países em desenvolvimento. Os indivíduos mais susceptíveis a essas doenças são crianças menores de dois anos e idosos com mais de 65 anos e portadores de algumas doenças crônicas ou imunossupressoras (WHO, 2011).

Uma vez que são conhecidos mais de 90 sorotipos diferentes de pneumococo, cada um deles com um PS quimicamente distinto, a disponibilidade das vacinas existentes não garante que a população esteja protegida a longo prazo, pois nos países que as introduziram em sua 
rotina de vacinação já aparecem casos de substituição dos sorotipos vacinais na população por outros não incluídos nas vacinas (SINGLETON et al., 2007).

Apesar deste fato, as vacinas continuam sendo o método mais eficiente e econômico para prevenir as doenças pneumocócicas (WHO, 2011). Existem dois tipos de vacinas disponíveis atualmente, ambas baseadas na proteção dada pelo PS capsular: vacina 23valente, composta por $23 \mathrm{PS}$ de sorotipos diferentes $(1,2,3,4,5,6 \mathrm{~B}, 7 \mathrm{~F}, 8,9 \mathrm{~N}, 9 \mathrm{~V}, 10 \mathrm{~A}$, $11 \mathrm{~A}, 12 \mathrm{~F}, 14,15 \mathrm{~B}, 17 \mathrm{~F}, 18 \mathrm{C}, 19 \mathrm{~A}, 20,22 \mathrm{~F}, 23 \mathrm{~F}$ e $33 \mathrm{~F}$ ) e as vacinas conjugadas, ou de segunda geração, compostas por 7, 10 ou 13 PS de diferentes sorotipos, cada um deles ligados quimicamente a uma proteína carregadora não relacionada à doença. Nas vacinas conjugadas, a imunogenicidade do PS é alterada pela ligação covalente com a molécula proteica, passando a gerar uma resposta imune dependente de linfócitos $\mathrm{T}$ e efeito de reforço, permitindo então seu uso em crianças menores de dois anos de idade (MANTESE et al., 2003).

O sistema público de saúde do Brasil promove a vacinação de idosos de mais de 60 anos com a vacina 23-valente (BRASIL, 2011). Em 2009, a Fiocruz (Fundação Oswaldo Cruz) assinou um contrato de transferência de tecnologia com o laboratório inglês GlaxoSmithKline (GSK) para produção da vacina 10-valente, na qual os PS 1, 4, 5, 6B, 7F, $9 \mathrm{~V}, 14$ e 23F foram conjugados independentemente à proteína D de H. Influenzae, o PS18C foi conjugado ao toxoide tetânico e o PS19F ao toxoide diftérico. Durante o período de transferência de tecnologia a vacina será distribuída pelo Sistema Único de Saúde (FIOCRUZ, 2011), substituindo a PCV7, que é a vacina 7 valente conjugada ao toxoide diftérico CRM $_{197}$. Entretanto, as projeções apontam que a vacina 10-valente dará cobertura de apenas cerca de $60 \%$ dos casos das doenças pneumocócicas invasivas no Brasil, enquanto que a vacina 13valente daria $72 \%$ de cobertura (FRANCO et al., 2010).

Uma alternativa para aumentar a cobertura e ao mesmo tempo para reduzir o custo seria a obtenção de uma vacina conjugada utilizando como carregadoras proteínas do próprio pneumococo, que seriam então ligadas covalentemente aos PS dos sorotipos mais importantes no Brasil. Assim, pode-se incluir um menor número de PS na vacina, pois as proteínas carregadoras induziriam uma proteção independente do sorotipo. O menor número de PS conjugados consequentemente reduziria o custo da vacina. Por isso, o Instituto Butantan desenvolve atualmente um projeto financiado pela FAPESP para estudo da viabilidade de uma vacina pneumocócica conjugada contendo PS dos três principais sorotipos no Brasil (14, 1 e 6B) ligados a proteínas recombinantes de pneumococo. 


\subsection{Síntese da cápsula polissacarídica}

Polissacarídeos capsulares têm um papel importante na estratégia de sobrevivência de bactérias, sua função é proteger a superfície bacteriana da dessecação e das interações com o sistema imune do hospedeiro e prevenir a opsonofagocitose, além de alguns terem aplicações médicas e industriais (MUSHER, 1992).

Uma imensa variedade de açúcares e ligações glicosídicas levam a uma grande diversidade de estruturas polissacarídicas. Apesar desta diversidade, o lócus genético e o mecanismo responsável pela biossíntese de PS exibem características conservadas. Os mais de 90 sorotipos capsulares de pneumococo, exceto 3 e 37, são sintetizados pela via dependente de flipase (Wzx) e polimerase (Wzy). Estas enzimas estão envolvidas na translocação de unidades repetitivas do PS para a outra face da membrana plasmática (Wzx) e na polimerização da cápsula (Wzy) (BENTLEY et al., 2006). Os genes da biossíntese da

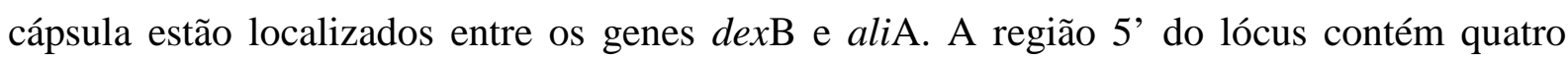
sequências conservadas $(w z g, w z h, w z d, w z e)$ que são importantes para modulação da síntese da cápsula, o gene seguinte codifica um glicosiltransferase inicial (YOTHER, 2011).

Segundo Henriques et al. (2011), as proteínas Wzd e Wze, são reguladoras da síntese de PS e, em presença de ATP, localizam-se no sítio de divisão celular, garantindo que a cápsula seja produzida juntamente com a parede celular, resultando em uma encapsulação total das células de $S$. pneumoniae.

O PS é sintetizado pela transferência de um monossacarídeo fosfato de um açúcar nucleotídeo difosfato (na maioria das vezes UDP-glicose) para um carregador lipídico ligado à membrana da célula, a partir daí, é feita uma série de transferências de monossacarídeos para dar origem à unidade repetitiva. Esta unidade repetitiva formada é então transferida para a face externa da membrana e polimerizada para formar o PS maduro que é finalmente anexado a peptideoglicana (BENTLEY et al., 2006). A Figura 2 ilustra este processo de formação e amadurecimento do PS. 
Figura 2 - Biossíntese do polissacarídeo capsular de Streptococcus pneumoniae

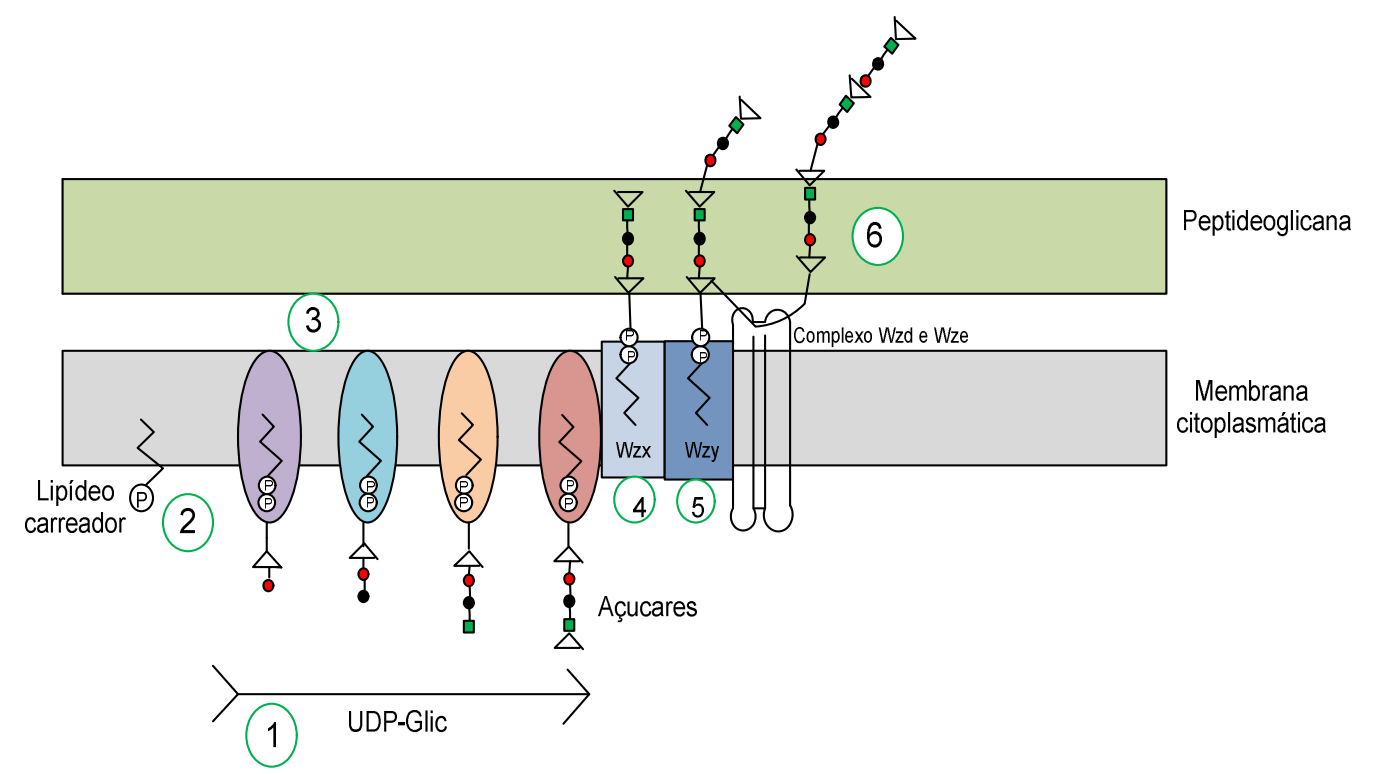

1- Biossíntese dos açúcar-nucleotídicos

2- A transferase inicial liga o açúcar inicial com açúcar fosfato associado a um lipídeo carreador

3- As glicosiltranferases ligam os açúcares sequencialmente para formar a unidade repetitiva

4- A flipase Wzx transporta a unidade repetitiva através da membrana citoplasmática

5- A polimerase Wzy liga as unidades repetitivas para formar o PS maduro

6- O complexo Wzd/Wze desloca o PS maduro para a superfície celular

Fonte: Adaptado de Bentley et al., 2006 e Yother, 2011.

2.5 Meio quimicamente definido

$\mathrm{Na}$ indústria farmacêutica, meios de cultura complexos são muito utilizados porque geralmente são baratos e apresentam produtividades elevadas. Meios sintéticos ou quimicamente definidos, por sua vez, são empregados para estudos de metabolismo microbiano, pois oferecem condições de cultura reprodutíveis para determinar com precisão os requisitos para o crescimento e a formação do produto.

Via de regra, os meios definidos não são elaborados para aplicações industriais, mas algumas de suas características são vantajosas quando comparadas às dos meios complexos. Meios definidos permitem maior consistência do processo, pois não estão sujeitos à variação de lote a lote; o controle e monitoramento são facilitados, pois não estão presentes fontes de carbono alternativas; costumam ser mais solúveis e menos sensíveis às condições de esterilização que os meios complexos, o que o facilita o aumento de escala, a recuperação e a purificação do produto (ZHANG; GREASHAM, 1999).

Um meio quimicamente definido, que foi inicialmente descrito para Streptococcus do grupo A (VAN DE RJIN; KESSLER, 1980), tem sido usado para o cultivo de $S$. pneumoniae. 
Este meio contém todos os 20 aminoácidos, vitaminas do complexo B, além de guanina, uracila e adenina e, para o crescimento do S. pneumoniae, deve ser acrescido do fator de crescimento colina (RANE; SUBBAROW, 1940). Esse meio definido, de acordo com os autores, não é um meio mínimo, pois nele foram incluídas substâncias que permitem o crescimento dos diferentes sorotipos de estreptococo do grupo A (VAN DE RJIN; KESSLER, 1980). Ele tem mais de 40 componentes e é mais caro que os meios baseados em hidrolisados de caseína ou soja e extrato de levedura, porém seu emprego tem permitido o estudo do metabolismo e da produção da cápsula em nosso laboratório (GOGOLA, 2011), o que tem possibilitado uma melhor compreensão das interações entre o metabolismo central e a produção do PS capsular, a exemplo do que foi feito para a produção de ácido hialurônico pelo Streptococcus zooepidemicus (BLANK et al., 2005).

\subsection{Fontes de carbono}

A análise do genoma do $S$. pneumoniae sugere que ele possui vias para o catabolismo de várias pentoses pela via pentose fosfato, e também para outros açúcares como glicose, celobiose, frutose, galactose, lactose, sacarose, entre outros (TETTELIN et al., 2001). Os mais abundantes transportadores do pneumococo para estes açúcares são os transportadores dependentes de ATP (“ATP binding cassette transporters" ou "ABC-transporters") e o sistema dependente de fosfotransferase (PTS), sendo que destes dois, o sistema PTS está em maior quantidade, havendo um total de 21 sistemas PTS e 7 transportadores ABC. O principal transportador de glicose em S. pneumoniae é o PTS SPO282-3-4 tipo manose, pois em todos os mutantes gerados no trabalho de Bidosse et al. (2012), a deleção deste PTS foi a única que afetou a utilização da glicose. Além do mais, a mutação neste PTS afetou o crescimento em manose, galactose, $\mathrm{N}$-acetilglicosamina e glicosamina quando usadas como única fonte de carbono (BIDOSSI et al., 2012).

Os dois transportadores de sacarose, chamados de sus e scr, foram caracterizados por Iyer e Camilli (2007), segundo os autores, o dissacarídeo sacarose é a maior fonte de carbono utilizada pelo $S$. pneumoniae durante a colonização e a infecção da superfície da mucosa da nasofaringe. A sacarose é internalizada e fosforilada pelo sistema PTS e uma vez dentro da célula, fosfohidrolases clivam o dissacarídeo fosfato em um monossacarídeo livre e um monossacarídeo fosfato (SALMINEN et al., 2004). Interessantemente, segundo Shelborne et al., (2008) o sistema transportador sus não se encontra presente no genoma de Streptococcus tipo A e B e $S$. mutans, organismos que raramente causam pneumonia. 
Apesar destas informações, não há na literatura trabalhos para S. pneumoniae utilizando sacarose como fonte de carbono para produção de PS, por isso o interesse deste trabalho em avaliar este dissacarídeo.

Devido a esta ampla capacidade de utilização de açúcares, quando exposta a mais de uma fonte de carbono, a bactéria precisa tomar decisões metabólicas, optando pela utilização concomitante dos açúcares ou pelo uso preferencial de uma fonte ao invés de outra com o intuito de manter o crescimento ótimo. A habilidade de utilizar o açúcar preferencial depende de um processo regulatório chamado repressão catabólica do carbono (CCR), que causa o silenciamento dos genes específicos para utilização dos açúcares não preferenciais até que a célula tenha consumido todo o açúcar preferencial.

O principal regulador global do CCR é a proteína A (CcpA) que já foi amplamente estudada na bactéria Gram-positiva Bacillus subtilis e foi identificada como funcional na regulação de operons catabólicos em Streptococcus spp. Curiosamente, a deleção do CcpA comprometeu severamente a virulência e a colonização da nasofaringe em $S$. pneumoniae. A caracterização do proteoma da parede celular revelou que a CcpA atua na ativação da expressão de algumas proteínas enquanto regula outras negativamente, portanto a atenuação da colonização e da virulência da cepa com deleção da CcpA sugere que esta proteína está direta ou indiretamente relacionada a regulação de genes que são requeridos para colonização in vivo (GORKE; STULKE, 2008; IYER et al., 2005).

\subsection{Metabolismo de S. pneumoniae}

Comparado com o aspecto de virulência, pouca atenção é dada à fisiologia e ao metabolismo de bactérias patogênicas. A ligação entre o metabolismo bacteriano e sua virulência já foi citada em várias bactérias patogênicas como Listeria, Legionella, Mycobacteria, Staphylococcus, comprovando a necessidade de mais estudos nesta área (MUNOZ-ELIAS; MCKINNEY, 2006).

O pneumococo possui um grande número de enzimas e sistemas transportadores envolvidos na utilização de carboidratos, aminoácidos e outros compostos. Trinta por cento destes sistemas transportadores, incluindo o sistema ABC e PTS estão envolvidos de absorção de aproximadamente vinte diferentes carboidratos, os quais podem ser metabolizados via Embden-Meyerhof-Parnas (EMP) ou via das pentoses fosfato (PPP). A análise do genoma do pneumococo revelou a perda de genes que codificam enzimas das vias Entner-Doudoroff 
(ED) e o ciclo de Krebs (TCA) e também da cadeia transportadora de elétrons para respiração aeróbica e anaeróbica (TETTELIN et al., 2001). Além do mais, o pneumococo não tem capacidade de sintetizar todos os vinte aminoácidos e possui vias incompletas para biossíntese de cisteína, glicina, glutamina, histidina e provavelmente lisina e prolina (HARTEL et al., 2011). Para compensar esta deficiência, a bactéria produz peptidases e proteases localizadas na parede celular para digerir as proteínas e transportadores para aminoácidos e oligopeptídeos (TETTELIN et al., 2001).

S. pneumoniae faz parte do grupo das bactérias láticas e, sob condição de anaerobiose, acredita-se que seja dependente da fermentação homolática para obtenção da energia necessária para o crescimento, onde a glicose é metabolizada a piruvato e o lactato é o produto final do metabolismo. Sob aerobiose, o piruvato é convertido a acetato, sendo o acetil-fosfato um intermediário capaz de fosforilar ADP gerando ATP pela ação da enzima acetato quinase (AK). Nesta reação também ocorre formação de $\mathrm{CO}_{2}$, acetil-fosfato e peróxido de hidrogênio, que é tóxico para as células, por isso o pneumococo tolera apenas baixas tensões de $\mathrm{O}_{2}$ na cultura (SPELLERBERG et al., 1996).

O catabolismo da glicose no pneumococo ocorre pela via clássica de EbdenMeyerhof- Parnas (EMP) com rendimento de duas moléculas de piruvato, duas de ATP e duas de NADH para cada molécula de glicose oxidada. Uma vez que o piruvato é formado, o NADH gerado na glicólise precisa ser reoxidado, o que ocorre através da catálise por lactato desidrogenase (LDH) que converte piruvato a lactato. O piruvato também pode ser convertido a acetil-CoA através da enzima piruvato formato liase (PFL) que leva a produção de acetato com a produção de um ATP sendo, portanto, um processo energeticamente favorável (SPELLERBERG et al., 1996).

Os estreptococos quando expostos a altas concentrações de glicose no meio (o que significa uma elevada razão $\mathrm{NADH} / \mathrm{NAD}^{+}$), produzem altos níveis de intermediários glicolíticos como frutose 1,6-bifosfato (FBP), dihidroxiacetona fosfato (DHAP) e gliceraldeído 3-fosfato (GAP). A FBP ativa a enzima LDH e altos níveis de DHAP ou GAP inibem a PFL. Estes dois efeitos combinados geram um fluxo maior de carbono direcionado ao lactato. Quando a glicose está limitada no meio de cultura (baixa razão NADH/NAD+), a concentração intracelular destes intermediários glicolíticos é baixa, resultando na separação do fluxo metabólico a partir do piruvato para fermentação mista (NEIJSSEL; SNOEP; TEIXEIRA DE MATTOS, 1997).

A Figura 3 ilustra a entrada do açúcar na célula de $S$. pneumoniae com posterior formação do polissacarídeo (PS14) e dos ácidos orgânicos através do metabolismo 
homofermentativo (produção de lactato) e heterofermentativo (produção de formiato, acetato e etanol).

Figura 3- Visão simplificada do metabolismo de S. pneumoniae sorotipo 14

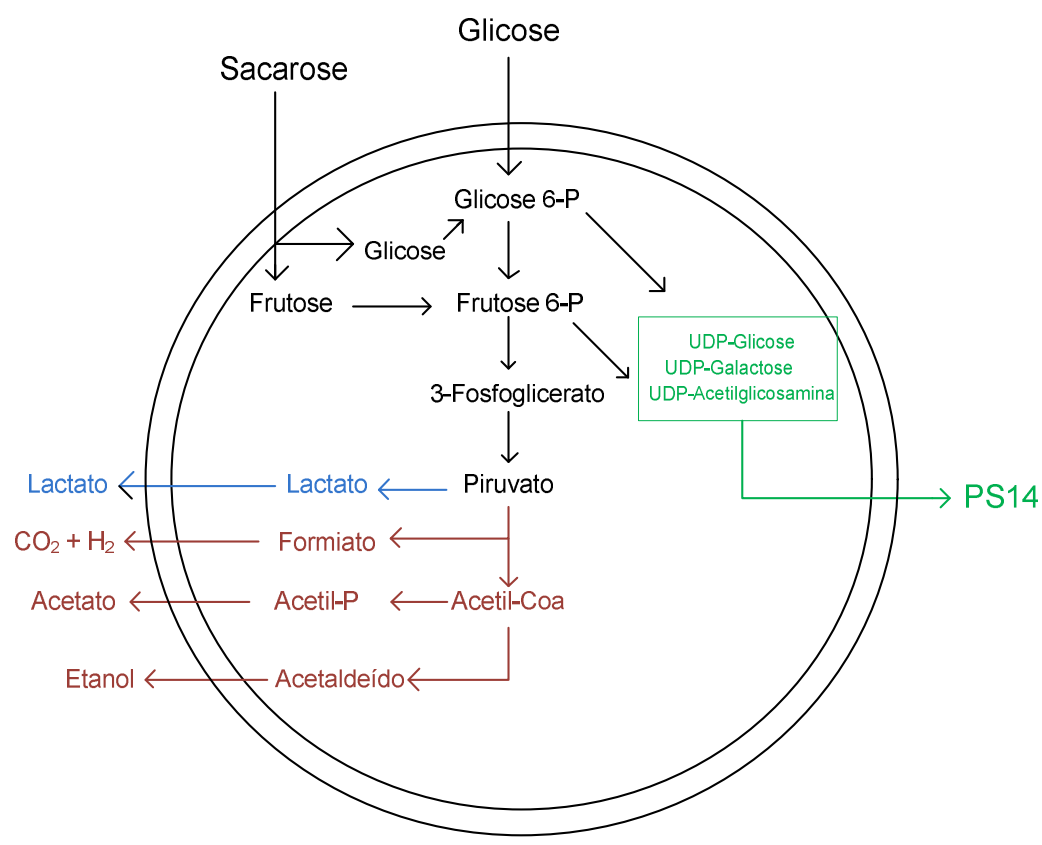

Em azul: Metabolismo homofermentativo

Em vermelho: Metabolismo heterofermentativo

Em verde: Monossacarídeos que formam a unidade repetitiva de PS14

Fonte: Adaptado de Neijssel, Snoep e Teixeira de Mattos (1997) e Tetellin et al. (2001).

Hartel et al. (2011) estudaram o metabolismo da cepa acapsulada de S. pneumoniae D39scps em meio quimicamente definido suplementado com glicose. Omitindo separadamente cada um dos 20 aminoácidos, demonstrou-se que os aminoácidos essenciais para o pneumococo são arginina, cistina, histidina, glicina, ácido glutâmico, isoleucina, leucina e valina, enquanto que a retirada dos aminoácidos treonina, serina, asparagina, alanina, aspartato, lisina, fenilalanina, tirosina e triptofano, não afetou o crescimento em condições in vitro. Para investigar a síntese de aminoácidos pela cepa D39 $c$ cps, os autores analisaram o metabolismo do carbono através da marcação do ${ }^{13} \mathrm{C}_{6}$ da glicose. A incorporação do carbono marcado nas proteínas derivadas dos aminoácidos recém-sintetizados foi medida por cromatografia gasosa e espectrometria de massas (GC/MS). O perfil de síntese de aminoácidos está representado na Figura 4. Este estudo demonstrou que o pneumococo utiliza uma via não convencional para síntese da serina, através da hidroximetilação da glicina. 
Figura 4 - Perfil da síntese de aminoácidos em S. pneumoniae D39 incorporação de ${ }^{13} \mathrm{C}_{6}$ da glicose nos aminoácidos

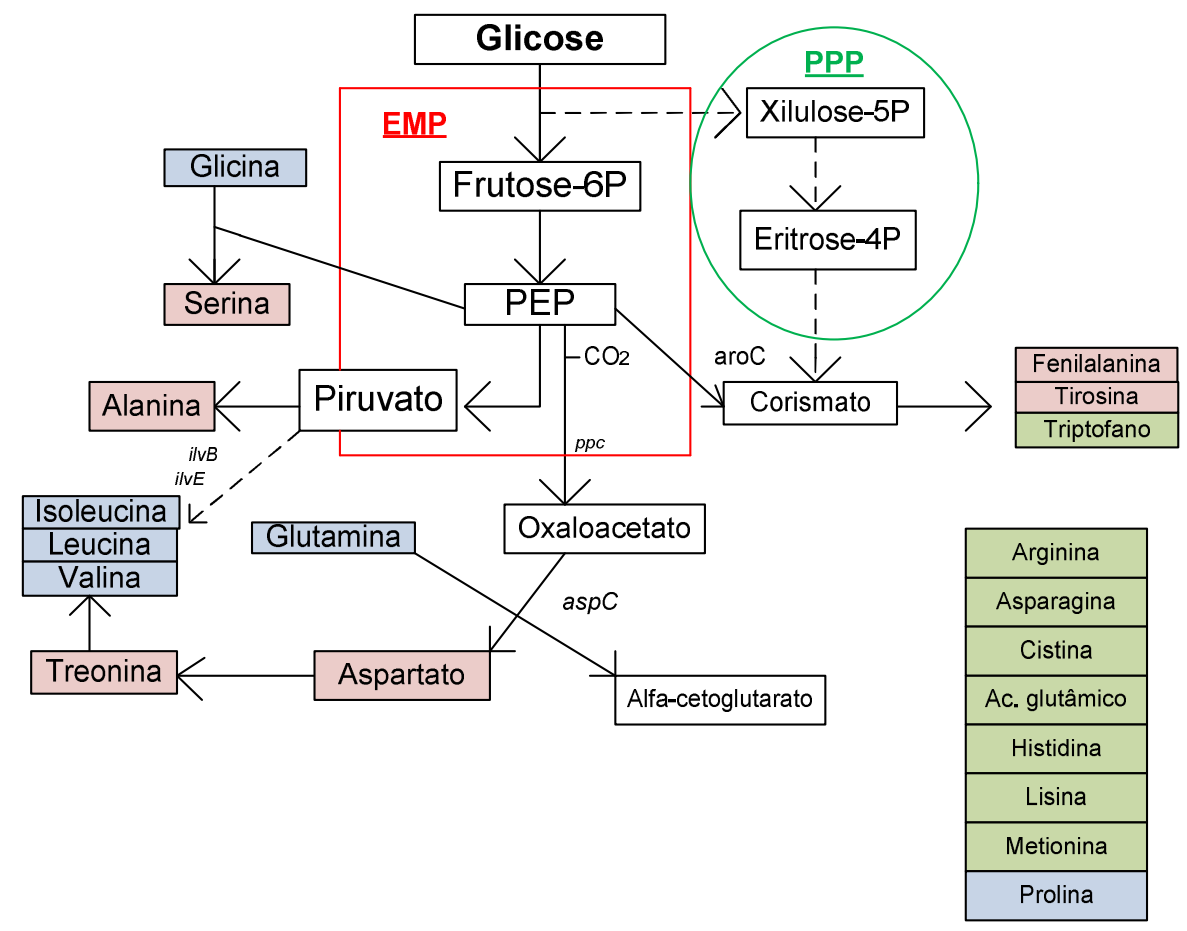

EMP: via Ebden-Meyerhof-Parnas

PPP: via pentose fosfato

Em branco: intermediários importantes e produtos dessas vias

Em rosa: aminoácidos que incorporaram o carbono marcado da glicose

Em azul: aminoácidos que não incorporaram quantidades significativas de carbono da glicose

Em verde: aminoácidos que não foram detectados por GC/MS devido à degradação destes aminoácidos durante hidrólise ácida das proteínas.

Fonte: Adaptado de Hartel et al. (2011)

Observa-se que o experimento com carbono marcado teve resultado similar ao experimento com retirada dos aminoácidos separadamente. Os aminoácidos assinalados em rosa no desenho acima, ou seja, aminoácidos que incorporam carbono marcado da glicose e, portanto poderiam ser retirados do meio, também mostraram não ser essenciais no experimento com retirada dos aminoácidos. Alguns aminoácidos marcados em verde, ou seja, que não foram detectados por cromatografia gasosa, também mostraram ser dispensáveis para cultivo de Streptococcus pneumoniae.

O grande número de sistemas transportadores de açúcares e as vias de biossíntese simplificadas podem colaborar para a fácil adaptação do patógeno em diferentes nichos do hospedeiro. No pneumococo, a utilização de carboidratos e aminoácidos como fontes de carbono parece ser um pré-requisito para o sucesso do patógeno em se adaptar aos vários nichos no hospedeiro e causar doenças graves. Ao que parece, o pneumococo prefere captar e catabolizar os nutrientes, peptídeos e aminoácidos do que sintetizá-los (HARTEL et al., 
2011). Segundo Neijssel; Snoep; Teixeira de Mattos (1997) variações nas condições de cultura podem levar a mudanças no metabolismo da bactéria, portanto, para entender o comportamento do microrganismo no ambiente natural é importante prestar mais atenção na variabilidade fenotípica da bactéria frente a diferentes condições in vitro.

\subsection{Estratégias de cultivo}

Os cultivos podem ser realizados de quatro maneiras principais: a mais simples é o cultivo descontínuo ou batelada, onde o meio de cultura é adicionado no começo do processo e os produtos retirados no final; o chamado descontínuo alimentado, no qual há uma alimentação contínua de substrato sem retirada de produtos durante o processo com consequente aumento do volume de meio no reator; o semicontínuo, no qual o meio de fermentação e o inóculo são colocados no reator e após o término da fermentação, retira-se parte do caldo fermentado e é adicionada no reator a mesma quantidade de meio de fermentação; e o cultivo contínuo, no qual também realiza-se alimentação contínua, porém o caldo fermentado é retirado do reator durante o processo, na mesma vazão de alimentação, mantendo um volume constante no reator (DORAN, 1998). A seguir, estão detalhadas as duas estratégias empregadas neste trabalho.

\subsubsection{Cultivo descontínuo}

O cultivo descontínuo ocorre quando não há mudança no volume do meio fermentado, o inóculo é adicionado ao meio de cultura estéril e no final do cultivo o reator é descarregado e o meio fermentado segue para a purificação.

Este tipo de cultivo é o mais utilizado na indústria alimentícia apesar de poder levar a baixos rendimentos e/ou produtividades e também levar à inibição por substrato já que o substrato é adicionado de uma só vez no início do experimento. Por outro lado, apresenta menores riscos de contaminação, grande flexibilidade de operação, além de melhores condições de controle da estabilidade genética do microrganismo (SCHMIDELL et al., 2001). 


\subsubsection{Cultivo contínuo}

Considera-se que no cultivo contínuo o ambiente seja constante e definido, pois com a manutenção do volume constante, o sistema pode atingir a condição de estado estacionário, na qual as variáveis de estado (concentração de células, substrato e produto) permanecem constantes ao longo de todo o tempo de cultivo (FACCIOTTI, 2001). A manutenção das células em um mesmo estado fisiológico faz com que o cultivo contínuo seja uma excelente ferramenta para estudos do metabolismo e de melhoramento das condições do meio de cultura. Através deste tipo de cultivo, é possível observar a atividade do microrganismo mudando a vazão de alimentação ou a composição do meio de alimentação (HOSKISSON; HOBBS, 2005; TODA, 2003).

A vazão específica de alimentação (D) é a relação entre a vazão volumétrica de alimentação e o volume do reator. O tempo de residência hidráulica do biorreator é dado por 1/D. Considerando que se tenha atingido o estado estacionário, tem-se que $\mu=D$, o que significa que no estado estacionário a concentração celular se mantém constante devido a um equilíbrio entre a velocidade de crescimento celular e a velocidade de retirada de células do fermentador (FACCIOTTI, 2001).

Para uma grande faixa de $\mathrm{D}$, os valores de biomassa permanecem praticamente constantes, sendo que quando D se aproxima de $\mu_{\text {máx }}$, ocorre uma queda brusca até zero. Neste momento, a concentração de substrato tende ao maior valor possível. Esta condição é conhecida como 'lavagem do reator', é quando ocorre um arraste de células para fora do biorreator (FACCIOTTI, 2001). A lavagem do reator pode ser empregada para a determinação da velocidade máxima de crescimento $\left(\mu_{\text {máx }}\right)$ pelo método conhecido como método dinâmico. Neste método, coloca-se um $\mathrm{D}$ bem maior que o $\mu_{\text {máx }}$ de modo que haja um arraste de células do reator. Plotando-se $\ln (\mathrm{X} / \mathrm{Xi})$ em função do tempo, obtém-se uma reta na qual o coeficiente angular é igual à $\mu_{\text {máx }}-\mathrm{D}$. Como D é um valor conhecido, consegue-se calcular o valor de $\mu_{\text {máx. }}$

Segundo Mateles e Battat (1974), o uso do cultivo contínuo em condições de limitação de nutrientes pode levar a uma eficiente otimização do meio de cultura em termos de aumento da concentração celular que o meio é capaz de suportar. Como consequência, é possível estimar a necessidade quantitativa de diferentes nutrientes para a célula.

Mateles e Battat (1974), também descreveram uma técnica que identifica os nutrientes limitantes do crescimento, injetando o componente suspeito diretamente no meio de cultura durante o estado estacionário. A técnica é conhecida como pulso e mudança de meio. 
O cultivo contínuo com pulso e mudança de meio é realizado injetando sequencialmente no reator os compostos que se deseja testar. Um novo meio é então preparado com uma concentração maior do(s) composto(s) cuja resposta foi significativa e o processo é repetido. No próximo passo, os compostos que não deram resposta são retirados do meio de alimentação e o processo todo repetido até que todos os componentes não essenciais sejam removidos. Utilizando essa estratégia, San Martin et al. (1992) desenvolveram um meio sintético para Bacillus stearothermophilus e com crescimento comparável ao obtido em meio complexo reduzindo de 18 para apenas 04 aminoácidos na composição do meio de cultura definido. 


\section{OBJETIVOS}

\subsection{Geral}

Estudar o comportamento de S. pneumoniae sorotipo 14 e a cinética de produção do PS capsular em cultivos descontínuos e contínuos, frente a diferentes composições do meio de cultura, utilizando meios quimicamente definidos a fim de compreender as interações entre a via glicolítica e a formação de biomassa, e aumentar a produção de PS14 através da elaboração de um meio quimicamente definido mais apropriado.

\subsection{Específicos}

- Escolher entre glicose, sacarose e frutose, a melhor fonte de carbono para produção de PS14 e avaliar a existência de uma fonte preferencial em cultivos descontínuos.

- Avaliar a influência de aminoácidos e vitaminas sobre o metabolismo celular e a produção de PS14 em cultivos descontínuos.

- Determinar a vazão específica de alimentação mais adequada para produção de PS14 em cultivo contínuo.

- Determinar os efeitos da adição das bases nitrogenadas em condições de excesso ou limitação de glicose como fonte de carbono em cultivos contínuos empregando a vazão previamente definida e determinar a concentração não-limitante da(s) base(s) nitrogenada(s) que exerceu(ram) efeito positivo. 


\section{MATERIAIS E MÉTODOS}

4.1 Microrganismo

O microrganismo utilizado foi $S$. pneumoniae sorotipo 14 cepa 5287, fornecido pelo Instituto Adolfo Lutz e previamente selecionado devido à maior produção de PS14 (GOGOLA et al., 2012).

\subsection{Meios de cultura}

O meio de cultura quimicamente definido descrito originalmente por Van de Rjin; Kessler (1980), acrescentado de 25mg/L de colina, foi utilizado para os cultivos com meio completo (CG10), como mostrado na Tabela 1. Este meio foi modificado dando um pulso de glicose 10g/L (CG10P10), alterando-se a concentração da glicose para 20g/L (CG20), substituindo glicose por sacarose (CS10), colocando glicose e sacarose juntas (CG5S5), além de retirando alguns aminoácidos e algumas vitaminas e acrescentando maiores concentrações dos aminoácidos que não foram retirados (Quadro 1). 
Tabela 1 - Composição do meio completo descrito por Van de Rjin; Kessler, (1980) acrescido de colina (CG10).

\begin{tabular}{|c|c|c|c|c|c|}
\hline Reagente & $\mathrm{g} / \mathrm{L}$ & Reagente & $\mathrm{g} / \mathrm{L}$ & Reagente & $\mathrm{mg} / \mathrm{L}$ \\
\hline L-Fenilalanina & 0,1 & $\mathrm{NaHCO}_{3}$ & 2,5 & Ácido Fólico & 0,8 \\
\hline L-Serina & 0,1 & $\mathrm{Na}_{2} \mathrm{HPO}_{4}$ & 7,35 & Ác. aminobenzóico & 0,4 \\
\hline L-Tirosina & 0,1 & $\mathrm{NaH}_{2} \mathrm{PO}_{4} \cdot \mathrm{H}_{2} \mathrm{O}$ & 3,195 & Piridoxamina $2 \mathrm{HCl}$ & 1,4 \\
\hline L-Treonina & 0,2 & Acetato de Sódio & 4,5 & $\beta$-NAD & 2,5 \\
\hline L-Triptofano & 0,1 & $\mathrm{KH}_{2} \mathrm{PO}_{4}$ & 0,2 & Riboflavina & 2 \\
\hline Asparagina & 0,1 & $\mathrm{~K}_{2} \mathrm{PO}_{4}$ & 1 & Piridoxal $\mathrm{HCl}$ & 1 \\
\hline L-Lisina & 0,14 & $\mathrm{MgSO}_{4} \cdot 7 \mathrm{H}_{2} \mathrm{O}$ & 0,7 & Biotina & 0,2 \\
\hline L-Ácido aspartico & 0,1 & Glicose & 10 & Nicotinamida & 10 \\
\hline DL-Alanina & 0,1 & & & Tiamina $\mathrm{HCl}$ & 2 \\
\hline L-Glutamina & 0,2 & & & Ácido pantotenico & 4 \\
\hline L-Isoleucina & 0,1 & & & Colina & 25 \\
\hline L-Leucina & 0,2 & & & $\mathrm{CaCl}_{2} \cdot 2 \mathrm{H}_{2} \mathrm{O}$ & 6,7 \\
\hline Glicina & 0,2 & & & $\mathrm{Fe}\left(\mathrm{NO}_{3}\right)_{3} \cdot 9 \mathrm{H}_{2} \mathrm{O}$ & 1 \\
\hline L-Valina & 0,1 & & & $\mathrm{FeSO}_{4} \cdot 7 \mathrm{H}_{2} \mathrm{O}$ & 5 \\
\hline L-Cistina & 0,05 & & & $\mathrm{MnSO}_{4} \cdot \mathrm{H}_{2} \mathrm{O}$ & 5,6 \\
\hline L-Metionina & 0,1 & & & Adenina Sulfato & 38,3 \\
\hline L-Histidina $\mathrm{HCl} \mathrm{H}_{2} \mathrm{O}$ & 0,14 & & & Guanina $\mathrm{HCl}$ & 27,3 \\
\hline L-Ácido Glutâmico & 0,1 & & & Uracil & 22 \\
\hline L-Prolina & 0,2 & & & & \\
\hline L-Arginina $\mathrm{HCl}$ & 0,12 & & & & \\
\hline L-Hidroxiprolina & 0,2 & & & & \\
\hline Cisteína & 0,5 & & & & \\
\hline
\end{tabular}

Em vermelho: aminoácidos que foram retirados no meio modificado

Em azul: vitaminas que foram retiradas no meio modificado

Em laranja: vitamina que foi retirada posteriormente

Em verde: aminoácidos que permaneceram no meio de cultura e foram adicionados em maiores concentrações

Fonte: Adaptado de Van de Rjin e Kessler, 1980

Devido à grande quantidade de componentes dos meios utilizados, foram preparadas soluções estoques, filtradas a $0,22 \mu \mathrm{m}$ e armazenadas em local fresco e livre de luz até o momento do uso. A fonte de carbono (glicose, sacarose ou frutose), fosfatos de sódio bibásico e monobásico, acetato de sódio, piridoxal, $\beta-\mathrm{NAD}$, colina, bicarbonato e cisteína, foram 
solubilizados apenas no momento de preparação do meio. Ao final, o pH foi ajustado para 7,0 e o meio de cultura completo foi esterilizado por filtração a $0,22 \mu \mathrm{m}$.

No Quadro 1, estão representados os meios de cultura modificados utilizados nos experimentos em cultivos descontínuos. A composição detalhada de cada meio de cultura empregado está no APÊNDICE A.

Quadro1 - Composição dos meios de cultura modificados

\begin{tabular}{|c|c|}
\hline M1G10 e M1G20 & M2G20 \\
\hline $\begin{array}{l}\text { Meio definido sem as vitaminas: } \\
\text { ácido fólico, piridoxamina, ácido } \\
\text { aminobenzóico e } \beta \text {-NAD }\end{array}$ & $\begin{array}{l}\text { Meio definido sem os aminoácidos: } \\
\text { asparagina, ácido aspártico, fenilalanina, serina, } \\
\text { alanina, treonina, triptofano, lisina e tirosina }\end{array}$ \\
\hline $\begin{array}{l}\text { Fonte de carbono: Glicose } 10 \mathrm{~g} / \mathrm{L} \text { e Glicose } \\
20 \mathrm{~g} / \mathrm{L}\end{array}$ & Fonte de carbono: Glicose $20 \mathrm{~g} / \mathrm{L}$ \\
\hline M3G20 & M4G20 \\
\hline $\begin{array}{l}\text { Meio definido sem os aminoácidos: } \\
\text { asparagina, ácido aspártico, fenilalanina, } \\
\text { serina, alanina, treonina, triptofano, lisina e } \\
\text { tirosina }\end{array}$ & $\begin{array}{l}\text { Meio M3G20 com a retirada da vitamina } \\
\text { Riboflavina }\end{array}$ \\
\hline $\begin{array}{l}\text { e sem as vitaminas: } \\
\text { ácido fólico, piridoxamina, ácido } \\
\text { aminobenzóico e } \beta \text {-NAD }\end{array}$ & \\
\hline Fonte de carbono: Glicose $20 \mathrm{~g} / \mathrm{L}$ & Fonte de carbono: Glicose $20 \mathrm{~g} / \mathrm{L}$ \\
\hline $\begin{array}{l}\text { Meio M4G20 } \\
\text { Fonte de carbono: sacarose } 10 \mathrm{~g} / \mathrm{L} \text { e sacarose } 2\end{array}$ & e M4S20 \\
\hline $\begin{array}{l}\qquad \text { M4G10F10 } \\
\text { Meio M4G20 } \\
\text { Fonte de carbono: Glicose } 10 \mathrm{~g} / \mathrm{L} \text { e frutose } 10 \\
\mathrm{~g} / \mathrm{L}\end{array}$ & $\begin{array}{l}\qquad \text { M5S20 } \\
\text { Meio modificado M4G20 com 3x Glutamina, 2x } \\
\text { glicina, 2x isoleucina, 2x leucina e 2x valina } \\
\text { Fonte de carbono: sacarose } 20 \mathrm{~g} / \mathrm{L}\end{array}$ \\
\hline
\end{tabular}

O meio ágar BHI Sangue foi utilizado para o controle de contaminação. Este meio é composto de $50 \mathrm{~mL} / \mathrm{L}$ de sangue de carneiro desfibrinado, $37 \mathrm{~g} / \mathrm{L}$ de infusão de cérebro e coração e 20 g/L de agar. 


\subsection{Preparo do inóculo}

Em todos os experimentos foram inoculados $150 \mu \mathrm{L}$ de um lote trabalho preparado previamente no laboratório com a cepa ST 5287 (GOGOLA, 2011) e armazenado em nitrogênio líquido. Este volume foi semeado em tubos de centrífuga contendo $50 \mathrm{~mL}$ do meio de interesse (completo ou modificado) e os tubos foram incubados a $37^{\circ} \mathrm{C}$ em regime estático sob atmosfera de aproximadamente $3 \% \mathrm{CO}_{2}$. O crescimento celular foi monitorado através da densidade ótica a $600 \mathrm{~nm}$ (DO) e o volume da cultura $(50 \mathrm{~mL})$ foi transferido para o reator com $500 \mathrm{~mL}$ de volume útil quando o crescimento bacteriano estava no meio da fase exponencial $(\mathrm{DO}=1,0)$, permitindo que uma $\mathrm{DO}$ inicial de 0,1 fosse alcançada.

\subsection{Cultivo em frasco}

Para avaliação da fonte preferencial de carbono, foi realizado um cultivo estático, em duplicata, em frasco com $100 \mathrm{~mL}$ de volume útil, contendo 5,0 g/L de glicose e 5,0 g/L sacarose simultaneamente em meio CG5S5. Foram inoculados $300 \mu \mathrm{L}$ do estoque congelado em cada frasco e o cultivo foi amostrado de hora em hora para acompanhamento do crescimento celular e posteriores análises de consumo de carboidratos e produção de ácidos orgânicos e PS14 livre no sobrenadante da cultura (PS14L).

\subsection{Cultivos descontínuos em reator}

\subsubsection{Reator e condições de cultivo}

Os cultivos foram realizados em reator R'ALF Plus (Bioengineering) com dorna de 1,0 litro de capacidade, contendo $500 \mathrm{~mL}$ de meio de cultura (completo ou modificado). Os cultivos foram realizados em anaerobiose mantida por atmosfera de $\mathrm{N}_{2}(0,05 \mathrm{~L} / \mathrm{min})$, a 300 rpm, pH 7,0 e $36{ }^{\circ} \mathrm{C}$. O controle de $\mathrm{pH}$ foi feito pela adição automática de $\mathrm{NaOH} 5 \mathrm{M}$ e polipropilenoglicol $30 \%$ foi empregado como antiespumante quando necessário. Amostras de 3,0 $\mathrm{mL}$ foram retiradas para análises, deste volume, $1,0 \mathrm{~mL}$ foi retirado para medida de $\mathrm{DO}$ e 2,0 mL foram centrifugados a $20.000 \mathrm{~g}, 10$ minutos a $4{ }^{\circ} \mathrm{C}$ e o sobrenadante utilizado para medida de PS14L, produção de ácidos orgânicos e consumo de carboidratos. O pellet foi utilizado para quantificação de PS14 associado às células (PS14 $)$. 


\subsubsection{Cultivos variando o meio de cultura}

Uma série de composições do meio de cultura foi testada, sempre mantendo as demais condições fixas (descritas no item 4.5.1) para avaliação da produção do PS14. Primeiramente, foram realizados cultivos variando a concentração de glicose: i) 10 g/L (CG10), ii) 10 g/L inicial mais um pulso $10 \mathrm{~g} / \mathrm{L}$ no meio da fase exponencial (CG10P10), iii) $20 \mathrm{~g} / \mathrm{L}$ desde o início do cultivo (CG20). Foi testada também sacarose $10 \mathrm{~g} / \mathrm{L}$ (CS10) ao invés de glicose como fonte de carbono e glicose $10 \mathrm{~g} / \mathrm{L}$ mais frutose $10 \mathrm{~g} / \mathrm{L}$ em meio modificado (M4G10F10). Foram comparados também o meio contendo seis vitaminas ao invés de dez (M1G10 e M1G20), onze dos vinte aminoácidos propostos inicialmente (M2G20), retirando tanto os aminoácidos como as vitaminas (M3G20), além da retirada de mais uma vitamina reduzindo assim para cinco vitaminas ao invés de dez (M4G20). Após este experimento testou-se a retirada dos aminoácidos e vitaminas utilizando sacarose como fonte de carbono (M4S10 e M4S20) e avaliou-se também o efeito da adição de maior concentração dos aminoácidos que permaneceram no meio de cultura (M5S20). As composições de todos os meios utilizados estão no APÊNDICE A.

\subsection{Cultivos contínuos}

\subsubsection{Reator e condições de cultivo}

As condições de cultivo foram as mesmas descritas no item 4.5.1., com a diferença de que em cultivo contínuo foi utilizada um bomba Watson Marlow U323 na saída do meio com vazão bem maior do que a vazão de entrada para garantir a saída constante do meio de cultura e a manutenção do volume constante. A remoção do meio foi controlada por um pescador, mantendo o volume em 0,5 litros. Uma balança Sartorius (capacidade de $34 \mathrm{~kg}$ ) foi utilizada com o meio de entrada para determinação da vazão de alimentação através da diferença do peso da balança. Para amostragem, coletou-se 3,0 mL de cultura na linha de saída de meio do fermentador (Figura 5). 
Figura 5 - Esquema do cultivo contínuo

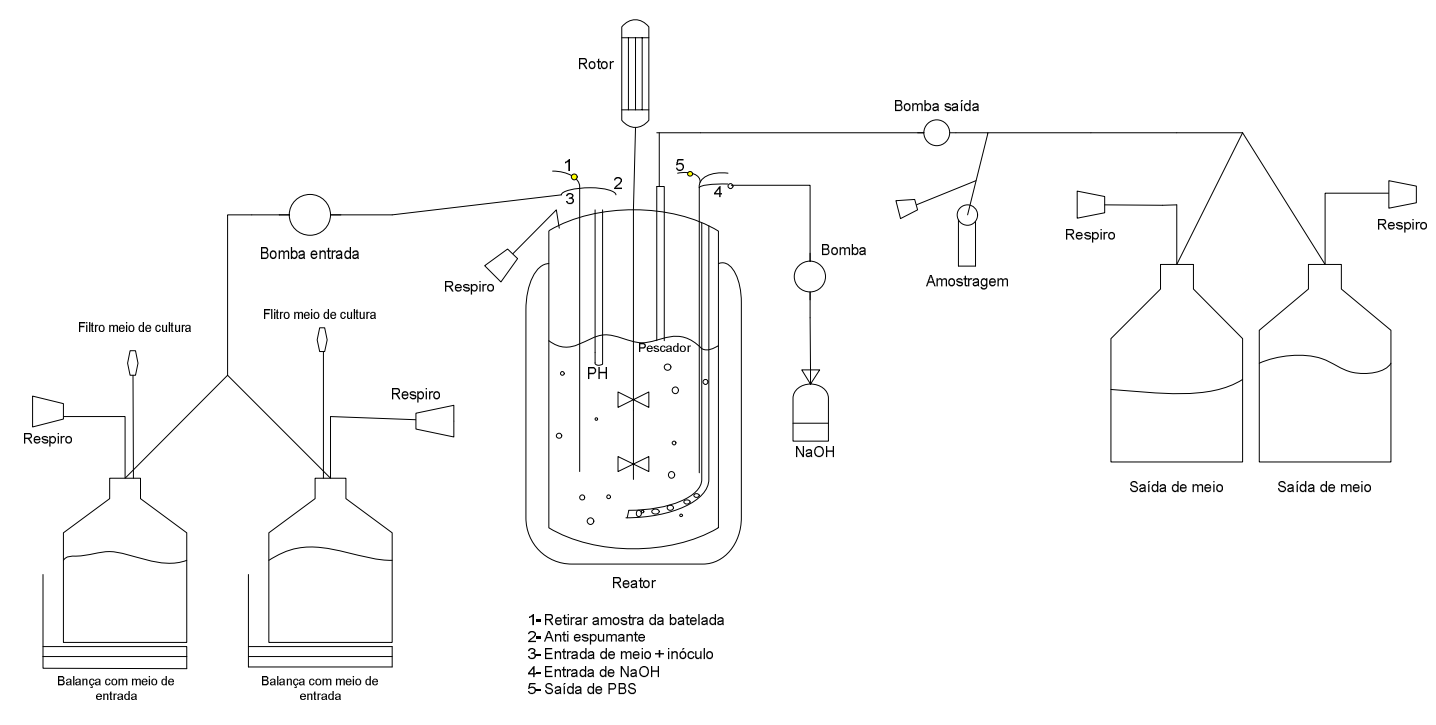

\subsubsection{Determinação da vazão específica de alimentação}

Para determinação da vazão específica de alimentação (D) com maior produção de PS14, D foi aumentada gradativamente de $0,15 \mathrm{~h}^{-1}$ para $0,3 \mathrm{~h}^{-1}, 0,4 \mathrm{~h}^{-1}, 0,5 \mathrm{~h}^{-1}$ e $1,0 \mathrm{~h}^{-1}$ com o intuito de se lavar o reator e calcular o $\mu_{\text {máx }}$ pelo método dinâmico (como descrito no item 2.8.1). O cultivo contínuo iniciou-se com um cultivo descontínuo (item 4.5.1) e com o crescimento ainda em fase exponencial, deu-se início à adição de meio de cultura fresco e a retirada do caldo fermentado. Após cada alteração de vazão, o volume do reator foi trocado por no mínimo sete vezes, ou seja, sete tempos de residência decorreram-se para garantir que o cultivo havia entrado em estado estacionário, após este período foram retiradas amostras por pelo menos três tempos de residência para avaliar se a concentração celular estava constante. Adotou-se como critério um desvio padrão inferior a 10\% para as medidas de DO. O meio de cultura utilizado neste experimento foi o meio modificado M1G20, ou seja, o meio definido sem as seis vitaminas e $20 \mathrm{~g} / \mathrm{L}$ de glicose (Quadro 1 e APÊNDICE A).

\subsubsection{Determinação das concentrações não limitantes das bases nitrogenadas adenina, guanina e uracila}

Dois experimentos foram realizados para determinar se as bases nitrogenadas estavam limitantes no meio de cultura original, no primeiro a concentração de glicose foi $10 \mathrm{~g} / \mathrm{L}$ (limitação) e no segundo foi $20 \mathrm{~g} / \mathrm{L}$ (excesso). Em ambos, iniciou-se com uma batelada. Após 
adição contínua de meio e verificação do estado estacionário com o meio definido completo (CG10 ou CG20), para verificar se não havia limitação destes compostos, cada uma das bases nitrogenadas foi injetada com uma seringa diretamente dentro do reator de modo que sua concentração ficasse duas vezes maior do que no meio completo. Novamente foi esperado no mínimo sete tempos de residência para garantir que a cultura havia retornado ao estado estacionário antes da adição do próximo composto.

Após este experimento, foi realizado um cultivo contínuo com cinco concentrações $(0,038 \mathrm{~g} / \mathrm{L}, 0,076 \mathrm{~g} / \mathrm{L}, 0,152 \mathrm{~g} / \mathrm{L}, 0,304 \mathrm{~g} / \mathrm{L}, 0,608 \mathrm{~g} / \mathrm{L})$ da base nitrogenada que apresentou aumento da produção total de PS14 (PS14 $\left.{ }_{\mathrm{L}}+\mathrm{PS} 14_{\mathrm{C}}=\mathrm{PS} 14_{\mathrm{T}}\right)$ no cultivo com glicose 20g/L (CG20). Neste experimento, a solução de base nitrogenada 4 vezes concentrada em relação à concentração final desejada entrava no fermentador com vazão específica de alimentação de $0,1 \mathrm{~h}^{-1}$ e o meio de cultura completo (CG20) concentrado 1,33 vezes e sem a base entrava com vazão de $0,3 \mathrm{~h}^{-1}$, os dois meios se misturavam através de um $\mathrm{Y}$ antes da entrada no fermentador, resultando em uma vazão final de alimentação de $0,4 \mathrm{~h}^{-1}$ (Figura 6). Para a verificação da vazão de alimentação foram usadas duas balanças, uma para o meio de alimentação e outra para a base nitrogenada. Após a batelada, a primeira solução de base foi adicionada junto com o meio para a concentração final de $0,038 \mathrm{~g} / \mathrm{L}$, até que se alcançasse o estado estacionário, o que foi avaliado através da medida de DO constante por três tempos de residência, depois disso o frasco do composto em teste foi mudado para a segunda concentração e o mesmo procedimento foi repetido até o quinto frasco (concentração final de $0,608 \mathrm{~g} / \mathrm{L})$. 
Figura 6 - Esquema do cultivo contínuo para determinação da concentração não-limitante da base nitrogenada em teste.

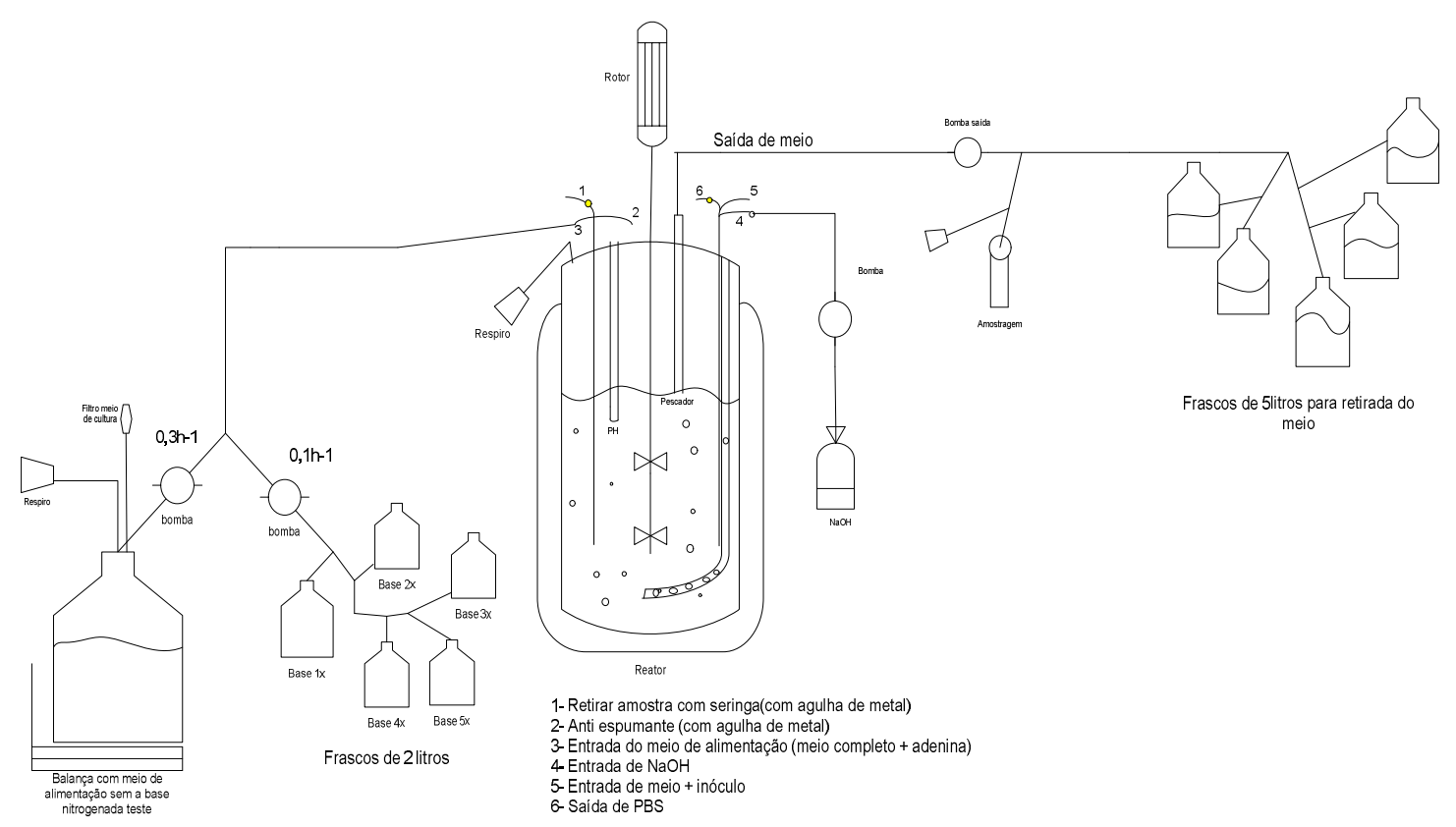

4.7 Métodos analíticos

A concentração celular foi acompanhada pela leitura DO, onde 1,0 unidade de DO corresponde a 0,366 g células/L de massa seca (GOGOLA, 2011). Quando necessário, as amostras foram diluídas em solução de $\mathrm{NaCl} 0,85 \%$ autoclavada antes da leitura da DO. As concentrações de glicose e de ácidos orgânicos no sobrenadante da cultura foram determinadas por cromatografia líquida de alta eficiência (CLAE) em equipamento Shimadzu (Class-VP), utilizando a coluna Aminex HPX-87H a $60{ }^{\circ} \mathrm{C}$ com $\mathrm{H}_{2} \mathrm{SO}_{4} 5 \mathrm{mM}$ como fase móvel a 0,6 mL/min. Os ácidos orgânicos foram detectados por UV 210nm e os açúcares por índice de refração. A concentração de sacarose foi determinada no Departamento de Engenharia Química da UFSCar por CLAE em coluna Aminex HPX-87C empregando água destilada como fase móvel. Os últimos experimentos utilizando sacarose foram medidos pela mesma coluna que foi adquirida pelo laboratório de Bioprocessos do Instituto Butantan. Os aminoácidos também foram medidos na UFSCar por CLAE (Waters) e coluna PICO-TAG a $36^{\circ} \mathrm{C}$.

A concentração de PS14 nas células e no sobrenadante foi determinada por ELISA DE CAPTURA como descrito no item 4.7.1. 


\subsubsection{ELISA DE CAPTURA para determinação da concentração de PS14 nas células e no sobrenadante}

Para realização do ELISA foi utilizada uma placa de poliestireno de fundo chato (MaxiSorp $^{\mathrm{TM}}$ - Nunc, Rochester, New York, USA) com 96 poços. Para a sensibilização foi utilizado IgG de coelho anti-PS14 (anticorpo de captura), obtido da Statens Serum Institute, Copenhagen, Dinamarca, em uma diluição 1:1000 em tampão carbonato. A placa foi sensibilizada por $14 \mathrm{~h} \mathrm{a} 4{ }^{\circ} \mathrm{C}$ e todas as lavagens foram feitas com Tween 20 a $0,05 \%$ em solução salina tamponada com fosfato (PBS-T). Após a lavagem, realizou-se o bloqueio com leite em pó desnatado a $10 \%$ em PBS durante 1 hora a $37^{\circ} \mathrm{C}$. O padrão (PS14 da ATCC) foi diluído em PBS seriadamente a 1:5 ou 1:2 partindo de $1 \mu \mathrm{g} / \mathrm{mL}$ até $1 \mathrm{ng} / \mathrm{mL}$. Após 3 horas de incubação a $37{ }^{\circ} \mathrm{C}$ ou overnight a $4{ }^{\circ} \mathrm{C}$, as placas foram lavadas com PBS-T e posteriormente foram colocados $100 \mu \mathrm{L}$ de soro de cabra imunizada com Prevenar (anticorpo secundário) a 1:200 em PBS-T-BSA (PBS-T com 0,5\% de soro albumina bovina). Após incubação por 2 horas e lavagem foi adicionado o anticorpo conjugado (anti-IgG de cabra conjugado à peroxidase) a 1:5000 em PBS-T-BSA. Para revelação foi utilizado $10 \mathrm{mg}$ de dihidrocloreto de $o$-fenilenodiamina (OPD) em 37,5 mL de tampão substrato (citrato $0,1 \mathrm{M} /$ fosfato $0,27 \mathrm{M} \mathrm{pH}$ 5 ,4). Para interromper a reação foram adicionados $50 \mu \mathrm{L}$ de $\mathrm{H}_{2} \mathrm{SO}_{4} 4 \mathrm{M}$ por poço e então a leitura foi feita em leitor de ELISA (Labsystems) a $492 \mathrm{~nm}$ (GOGOLA et al., 2012). Um esquema do ELISA de captura é apresentado na Figura 5.

A concentração de PS14 livre (PS14 ${ }_{L}$ ) foi quantificada diretamente no sobrenadante da cultura. Para medida da concentração do PS14 associado às células (PS14 $)$, o pellet de cada amostra da cultura foi ressuspendido em tampão de lise (sacarose $20 \%, \mathrm{MgSO}_{4} 50 \mathrm{mM}$ e Tris Base $50 \mathrm{mM}, \mathrm{pH}$ 7,4) para 1/10 do volume original e $4 \mathrm{U}$ de lisozima foram adicionadas. A suspensão foi incubada a $36{ }^{\circ} \mathrm{C}$ por $18 \mathrm{~h}$, centrifugada a 20.000 g por 30 minutos a $4{ }^{\circ} \mathrm{C}$ para remoção do material insolúvel e o PS14 foi medido na fração solúvel. 
Figura 7 - Esquema do ELISA de captura

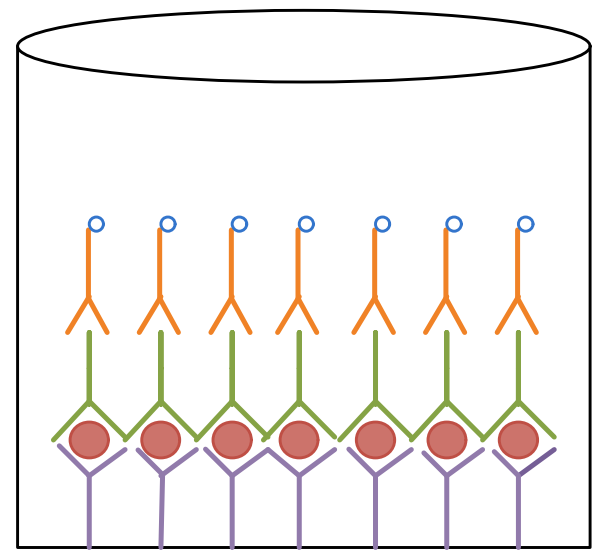

\section{Legenda}

Y IgG - Anticorpo de captura (coelho)

Y $\lg G$ - Anticorpo secundário (cabra)

b Anti-lgG de cabra ligado a proxidase

PS14 da amostra/ PS14 padrão

4.8 Cálculo dos parâmetros

Diariamente foi feita a coloração de Gram e uma amostra da cultura foi plaqueada em meio agar BHI/sangue para verificação da morfologia da colônias e da ausência de contaminantes para controle de pureza da cultura. Foi feita a coloração India Ink para visualização da cápsula (BUTT et al., 1935).

Os seguintes parâmetros foram calculados: fator de conversão da fonte de carbono em biomassa; fator de conversão da fonte de carbono em PS14; fator de conversão da fonte de carbono em ácido lático; fator de conversão da fonte de carbono em ácido acético; máxima velocidade específica de crescimento $\left(\mu_{\max }\right)$; produtividade em célula, PS14, lactato e acetato; velocidade específica de formação de PS, lactato e acetato e de consumo da fonte de carbono. Os resultados foram obtidos por cálculos utilizando dados de concentração de açúcares, massa seca, concentração de PS14, de lactato e de acetato.

A Tabela 2 ilustra como foram determinados os parâmetros tanto em cultivo contínuo como descontínuo. 
Tabela 2 - Equações para cálculo dos parâmetros de cultivos descontínuos e contínuos

\begin{tabular}{|c|c|c|}
\hline Parâmetro & Cultivo descontínuo & Cultivo contínuo \\
\hline $\begin{array}{l}\text { Fator de conversão substrato } \\
\text { em células* }\end{array}$ & $\begin{array}{l}\text { Plotando gráfico Biomassa }(\mathrm{g} / \mathrm{L}) \\
\text { por substrato consumido }(\mathrm{g} / \mathrm{L}) \text { e } \\
\text { vendo o coeficiente angular da reta }\end{array}$ & $\mathrm{Yx} / \mathrm{s}=\frac{\mathrm{X}}{\mathrm{S}_{\mathrm{a}}-\mathrm{S}}\left(\mathrm{g}_{\text {célula }} / \mathrm{g}_{\text {substrato }}\right)$ \\
\hline $\begin{array}{l}\text { Fator de conversão substrato } \\
\text { em PS14 }\end{array}$ & $\mathrm{Y}_{\mathrm{PS} / \mathrm{S}}=\frac{\mathrm{PS}-\mathrm{PS}}{\mathrm{S}_{0}-\mathrm{S}}\left(\mathrm{mg}_{\mathrm{PS} 14} / \mathrm{g}_{\text {substrato }}\right)$ & $\mathrm{Yps} / \mathrm{s}=\frac{\mathrm{PS}}{\mathrm{S}_{\mathrm{a}}-\mathrm{S}}\left(\mathrm{mg}_{\mathrm{PS} 14} / \mathrm{g}_{\text {substrato }}\right)$ \\
\hline $\begin{array}{l}\text { Fator de conversão substrato } \\
\text { em lactato }\end{array}$ & $\mathrm{Y}_{\mathrm{L} / \mathrm{S}}=\frac{\mathrm{L}-\mathrm{L}_{0}}{\mathrm{~S}_{0}-\mathrm{S}}\left(\mathrm{g}_{\text {lactato }} / \mathrm{g}_{\text {substrato }}\right)$ & $\mathrm{Y} 1 / \mathrm{s}=\frac{\mathrm{L}}{\mathrm{S}_{\mathrm{a}-\mathrm{S}}}\left(\mathrm{g}_{\text {lactato }} / \mathrm{g}_{\text {substrato }}\right)$ \\
\hline $\begin{array}{l}\text { Fator de conversão substrato } \\
\text { em acetato }\end{array}$ & $\mathrm{Y}_{\mathrm{A} / \mathrm{S}}=\frac{\mathrm{A}-\mathrm{A}_{0}}{\mathrm{~S}_{0}-\mathrm{S}}\left(\mathrm{g}_{\text {acetato }} / \mathrm{g}_{\text {substrato }}\right)$ & $\mathrm{Ya} / \mathrm{s}=\frac{\mathrm{A}}{\mathrm{S}_{\mathrm{a}}-\mathrm{S}}\left(\mathrm{g}_{\text {acetato }} / \mathrm{g}_{\text {substrato }}\right)$ \\
\hline $\begin{array}{l}\text { Fator de conversão células em } \\
\text { PS14 }\end{array}$ & $\mathrm{Y}_{\mathrm{PS} / \mathrm{X}}=\frac{\mathrm{PS}-\mathrm{PS}_{0}}{\mathrm{X}-\mathrm{X}_{0}}\left(\mathrm{mg}_{\mathrm{PS} 14} / \mathrm{g}_{\text {célula }}\right)$ & $\mathrm{Y}_{\mathrm{PS} / \mathrm{X}}=\frac{\mathrm{PS}}{\mathrm{X}}\left(\mathrm{mg}_{\mathrm{PS} 14} / \mathrm{g}_{\text {célula }}\right)$ \\
\hline Produtividade em células & $\mathrm{Q}_{\mathrm{X}}=\frac{\mathrm{X}-\mathrm{X}_{0}}{\mathrm{t}-\mathrm{t}_{0}}\left(\mathrm{~g}_{\text {célula }} \cdot \mathrm{L}^{-1} \cdot \mathrm{h}^{-1}\right)$ & $\mathrm{Qx}=\mathrm{D} \cdot \mathrm{X}\left(\mathrm{g}_{\text {célula }} \cdot \mathrm{L}^{-1} \cdot \mathrm{h}^{-1}\right)$ \\
\hline Produtividade em PS14 & 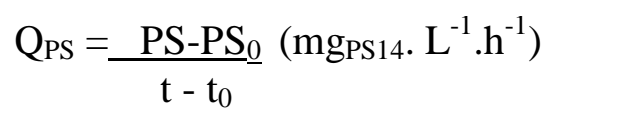 & Qps = D.PS $\left(\mathrm{mg}_{\mathrm{PS} 14 \cdot} \mathrm{L}^{-1} \cdot \mathrm{h}^{-1}\right)$ \\
\hline Produtividade em lactato & $\mathrm{Q}_{\mathrm{L}}=\frac{\mathrm{L}-\mathrm{L}_{0}}{\mathrm{t}-\mathrm{t}_{0}}\left(\mathrm{~g}_{\text {lactato }} \cdot \mathrm{L}^{-1} \cdot \mathrm{h}^{-1}\right)$ & $\mathrm{Q}_{\mathrm{L}}=\mathrm{D} \cdot \mathrm{L}\left(\mathrm{g}_{\text {lactato }} \cdot \mathrm{L}^{-1} \cdot \mathrm{h}^{-1}\right)$ \\
\hline Produtividade em acetato & $\mathrm{Q}_{\mathrm{A}}=\frac{\mathrm{A}-\mathrm{A}_{0}}{\mathrm{t}-\mathrm{t}_{0}}\left(\mathrm{~g}_{\text {acetato }} \cdot \mathrm{L}^{-1} \cdot \mathrm{h}^{-1}\right)$ & $\mathrm{Q}_{\mathrm{A}}=\mathrm{D} \cdot \mathrm{A}\left(\mathrm{g}_{\text {acetato }} \cdot \mathrm{L}^{-1} \cdot \mathrm{h}^{-1}\right)$ \\
\hline $\begin{array}{l}\text { Velocidade específica de } \\
\text { formação de PS }\end{array}$ & - & $\mu \mathrm{p}=\frac{\mathrm{PS} \cdot \mathrm{D}}{\mathrm{X}}\left(\mathrm{mg}_{\mathrm{PS} 14} \cdot \mathrm{g}_{\text {célula }}{ }^{-1} \cdot \mathrm{h}^{-1}\right)$ \\
\hline $\begin{array}{l}\text { Velocidade específica de } \\
\text { consumo de substrato }\end{array}$ & - & $\mu \mathrm{s}=\frac{\mathrm{D}}{\mathrm{Yx} / \mathrm{s}}\left(\mathrm{g}_{\text {substrato. }} \cdot \mathrm{g}_{\text {célula }}{ }^{-1} \cdot \mathrm{h}^{-1}\right)$ \\
\hline $\begin{array}{l}\text { Velocidade específica de } \\
\text { formação de lactato }\end{array}$ & - & $\mu \mathrm{l}=\frac{\mathrm{L} \cdot \mathrm{D}}{\mathrm{X}}\left(\mathrm{g}_{\text {lactato }} \cdot \mathrm{g}_{\text {célula }}{ }^{1} \cdot \mathrm{h}^{-1}\right)$ \\
\hline $\begin{array}{l}\text { Velocidade específica de } \\
\text { formação de acetato }\end{array}$ & - & $\mu \mathrm{a}=\frac{\mathrm{A} \cdot \mathrm{D}}{\mathrm{X}}\left(\mathrm{g}_{\text {acetato }} \cdot \mathrm{g}_{\text {célula }}{ }^{-1} \cdot \mathrm{h}^{-1}\right)$ \\
\hline
\end{tabular}

0: concentração da variável no início de cultivo

a: concentração da variável no meio de alimentação

\#: ou a fonte de carbono empregada

*: valores calculados durante a fase estacionária

Em cultivos descontínuos, a velocidade específica máxima de crescimento $\mu_{\text {máx }}$ foi calculada plotando-se $\ln \left(\mathrm{X} / \mathrm{X}_{0}\right)$ por tempo, na fase exponencial, onde $\mathrm{X}$ é a DO em um determinado tempo t e $\mathrm{X}_{0}$ é a DO no tempo $0 \mathrm{~h}$ (instante inicial do cultivo), por meio de uma regressão linear pode-se igualar o coeficiente angular ao $\mu_{\text {máx }}$. 
Em cultivos contínuos, foram feitas médias de três pontos em estado estacionário para se calcular os parâmetros e o $\mu_{\text {máx }}$ foi calculado através do método dinâmico. $\mathrm{O}$ valor de $\mathrm{D}$ foi ajustado para $1,0 \mathrm{~h}^{-1}$ e amostras foram tomadas a cada $10 \mathrm{~min}$. Os valores de $\ln (\mathrm{X} / \mathrm{Xi}) \mathrm{em}$ função do tempo foram plotados e o coeficiente angular da reta resultante, que é igual à $\mu_{\text {máx }}-$ $\mathrm{D}$, foi usado para calcular o valor de $\mu_{\text {máx. }}$

$\mathrm{O}$ coeficiente de manutenção $\left(\mathrm{m}_{\mathrm{s}}\right)$ e o fator de conversão verdadeiro $\left(\mathrm{Y}_{\mathrm{G}}\right)$ foram calculados pela relação de Pirt (1965), plotando-se $\mu$ s em função de D, o coeficiente angular é igual a $1 / \mathrm{Y}_{\mathrm{G}}$ e o linear é o $\mathrm{m}_{\mathrm{s}}$.

\subsubsection{Equações de formação de produtos}

De acordo com Luedeking e Piret (1959), a velocidade específica de crescimento $(\mu)$ pode ser correlacionada à velocidade específica de produção $\left(\mu_{\mathrm{p}}\right)$ de acordo com as seguintes equações:

- $\quad$ Produção associada ao crescimento: $\mu_{\mathrm{p}}=\alpha \mu$

- Produção não-associada ao crescimento: $\mu_{\mathrm{p}}=\beta$ (2)

- $\quad$ Produção parcialmente associada ao crescimento: $\mu_{\mathrm{p}}=\alpha \mu+\beta$

Onde $\alpha$ e $\beta$ são considerados constantes (SCHMIDELL et al., 2001).

Estas correlações foram utilizadas neste trabalho para avaliar a produção do produto de interesse PS14 e do lactato que é principal produto do metabolismo de S. pneumoniae.

\subsubsection{Análise estatística}

O teste $t$-Student foi usado para comparar as médias das amostras retiradas em cada condição testada em cultivos contínuos (diferentes taxas de diluição e adição de adenina, guanina e uracila). Os intervalos de confiança das médias foram obtidos através da fórmula:

$$
C I(v) 90 \%=\bar{a} \pm t \cdot n-1 \frac{\sigma}{\sqrt{n}}
$$

Onde $v$ é a população média estimada (90\% de confiança), $\bar{a}$ é a média das amostras, $t$ é o valor descrito pela distribuição $t$-Student (tabelado), $\sigma$ é o desvio padrão e $\mathrm{n}$ é a quantidade de amostras (espaço amostral). As médias foram consideradas estatisticamente 
equivalentes quando os intervalos de confiança se sobrepuseram (SCHWAAB; PINTO, 2007).

Para calcular a média e o desvio padrão de PS14 Toi usada a seguinte equação:

$$
\mathrm{R} \pm \sigma=\left(\overline{\mathrm{PS} 14_{\mathrm{L}}}+\overline{\mathrm{PS} 14_{\mathrm{C}}}\right) \pm \sqrt{\sigma_{\mathrm{PS} 14 \mathrm{~L}}^{2}+\sigma_{\mathrm{PS} 14 \mathrm{C}}^{2}}
$$

Onde $\overline{P S 14_{C}}$ e $\overline{P S 14_{L}}$ são as médias das amostras e $\sigma_{\mathrm{PS} 14 \mathrm{~L}}$ e $\sigma_{\mathrm{PS} 14 \mathrm{C}}$ são os desvios padrão das amostras (TOGINHO FILHO; ANDRELLO, 2009). 


\section{RESULTADOS E DISCUSSÃO}

\subsection{Cultivos descontínuos}

5.1.1 Influência de glicose e sacarose na produção de PS14, biomassa e ácidos orgânicos

\subsubsection{Cultivo em meio definido contendo $10 \mathrm{~g} / \mathrm{L}$ de glicose inicial (CG10)}

A Figura 8 mostra o perfil de crescimento, glicose residual, produção de PS14 $\mathrm{L}$ e PS14 ${ }_{\mathrm{C}}$ do cultivo realizado em meio contendo $10 \mathrm{~g} / \mathrm{L}$ de glicose inicial (CG10). O valor

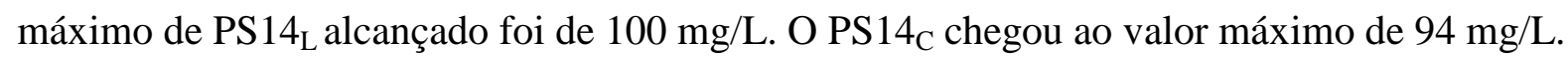

Figura 8 - Produção de biomassa, PS14 $\mathrm{L}, \mathrm{PS} 14_{\mathrm{C}}$ e glicose residual em cultivo descontínuo em reator com meio CG10

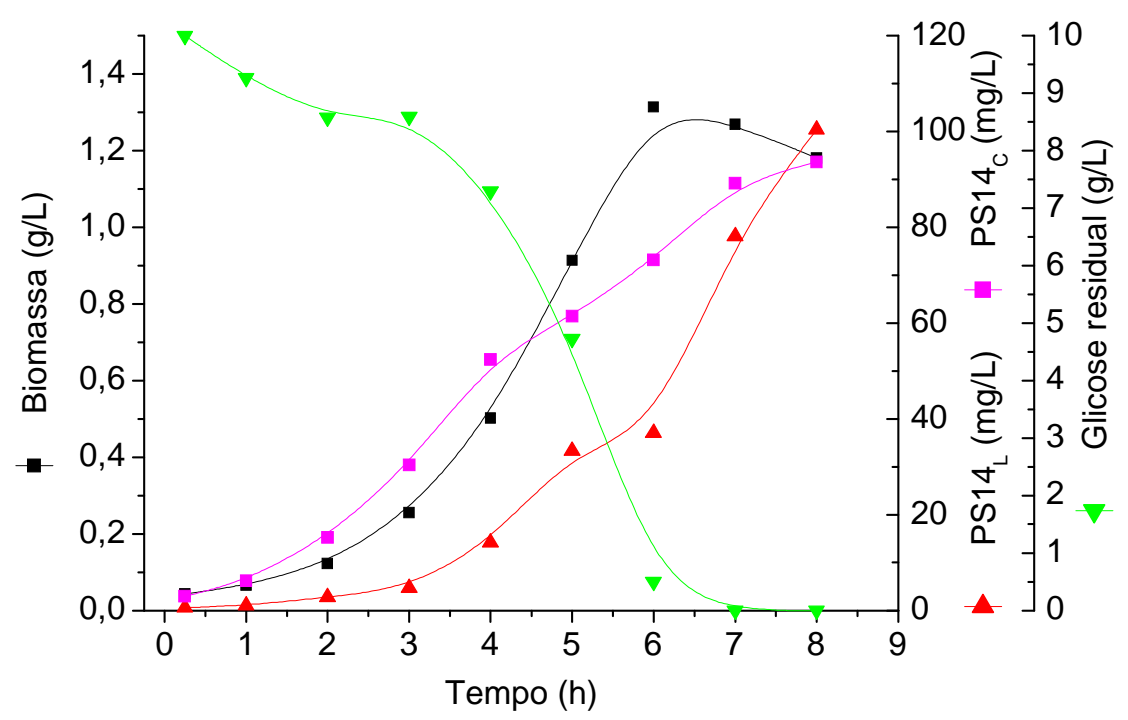

O perfil de produção de lactato mostrou-se crescente com o decorrer do cultivo, acompanhando o crescimento do microrganismo, o acetato também aumentou durante o cultivo, porém não acompanhou a curva de crescimento, como ilustrado na Figura 9. 
Figura 9 - Produção de lactato, acetato e biomassa em cultivo descontínuo em reator com meio CG10

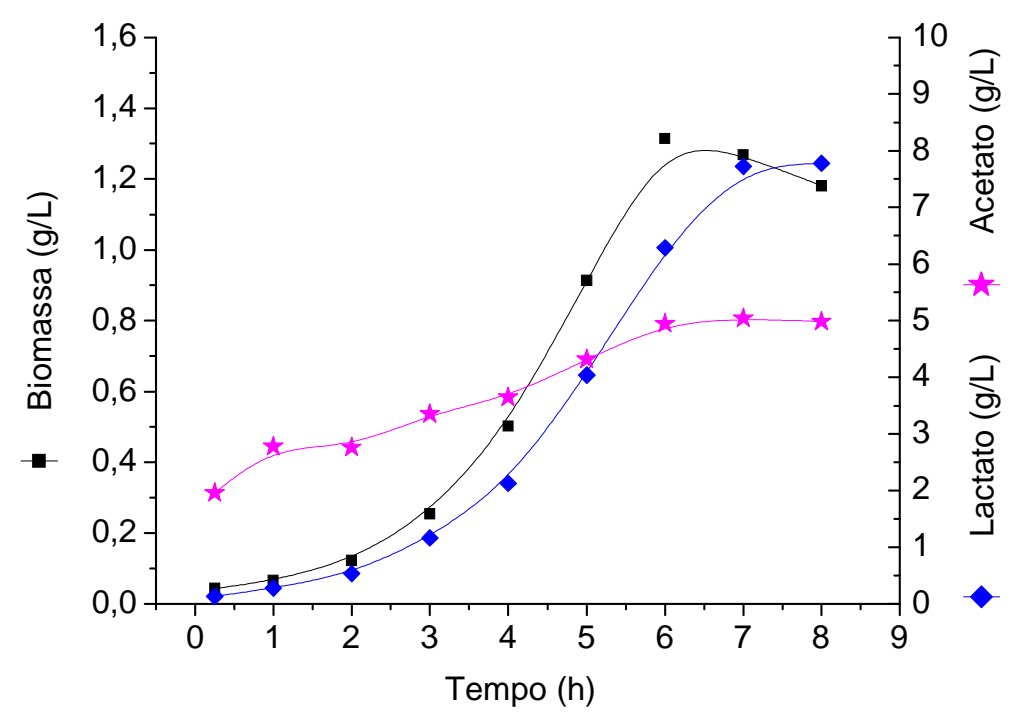

\subsubsection{Cultivo em meio definido contendo $10 \mathrm{~g} / \mathrm{L}$ de glicose inicial mais pulso de glicose $10 \mathrm{~g} / \mathrm{L}(\mathrm{CG} 10 \mathrm{P} 10)$}

A Figura 10 mostra as variáveis: biomassa, glicose residual e produção de PS14 livre no sobrenadante $\left(\mathrm{PS} 14_{\mathrm{L}}\right)$ em cultivo contendo $10 \mathrm{~g} / \mathrm{L}$ de glicose inicial, com o decorrer do tempo de cultivo. No final da fase exponencial de crescimento, entre 0 e 4 horas, realizou-se um pulso de glicose $10 \mathrm{~g} / \mathrm{L}$. O $\mu$ máx alcançado foi $0,755 \mathrm{~h}^{-1}$ e após o pulso, alcançou-se biomassa máxima de 1,46 g/L. A produção de PS14 ${ }_{\mathrm{L}}$ chegou ao valor máximo de $141 \mathrm{mg} / \mathrm{L}$, $41 \%$ maior que em cultivo contendo glicose $10 \mathrm{~g} / \mathrm{L}$ sem pulso $(100 \mathrm{mg} / \mathrm{L})$. Após $8 \mathrm{~h}$ de cultivo, a glicose foi consumida quase que totalmente, sobrando cerca de $1 \mathrm{~g} / \mathrm{L}$ no reator. 
Figura 10 - Produção de biomassa, PS14 L e glicose residual em cultivo descontínuo em reator com meio CG10P10

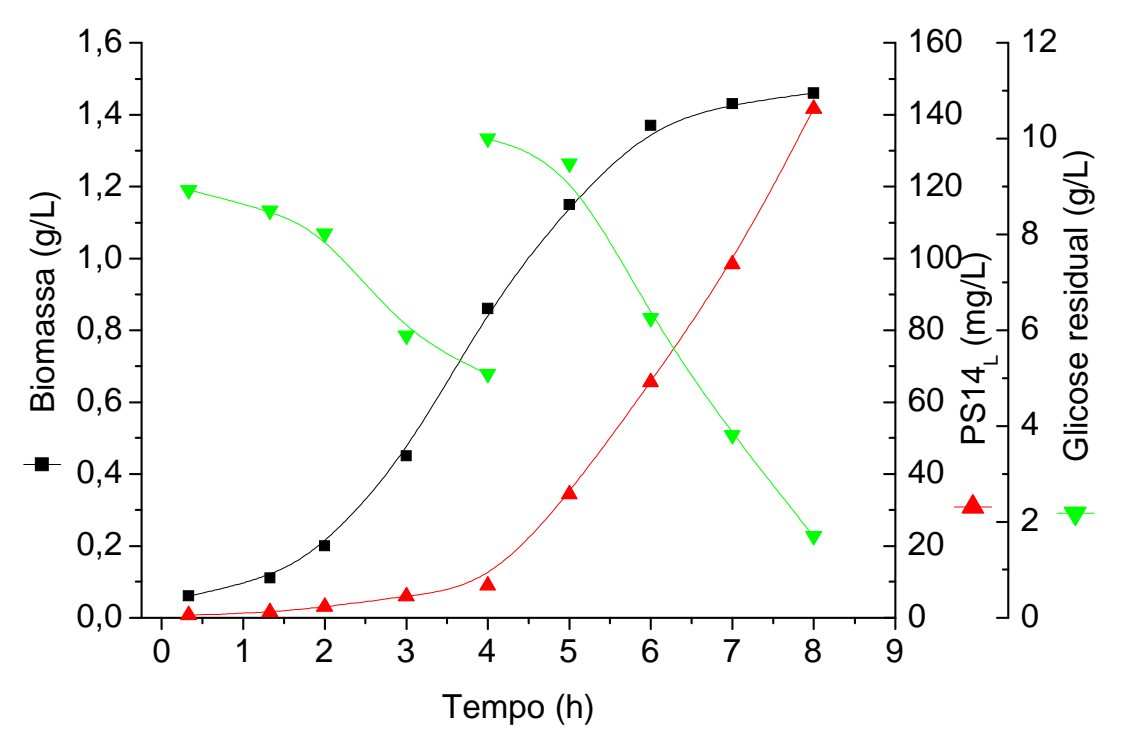

Conforme mostra a Figura 11, a produção de lactato aumentou com o decorrer do cultivo, tal como esperado pelo metabolismo, parecendo estar parcialmente associada ao crescimento, pois quando o cultivo entrou em sua fase estacionária, a produção de lactato continuou aumentando. A produção de acetato se mostrou variável e independente do crescimento, diminuindo logo após o pulso de glicose $10 \mathrm{~g} / \mathrm{L}$. Esse resultado pode ter ocorrido devido ao redirecionamento, após o pulso, do fluxo de carbono para o lactato (NEIJSSEL; SNOEP; TEIXEIRA DE MATTOS, 1997), já que neste cultivo a produção final de lactato foi $14 \mathrm{~g} / \mathrm{L}$, enquanto que sem o pulso chegou a $8 \mathrm{~g} / \mathrm{L}$ (Figura 9). Além disso, o acetato foi consumido após o pulso, passando de 4 g/L para 1 g/L (Figura 11). 
Figura 11 - Produção de lactato, acetato e biomassa em cultivo descontínuo em reator com meio CG10P10

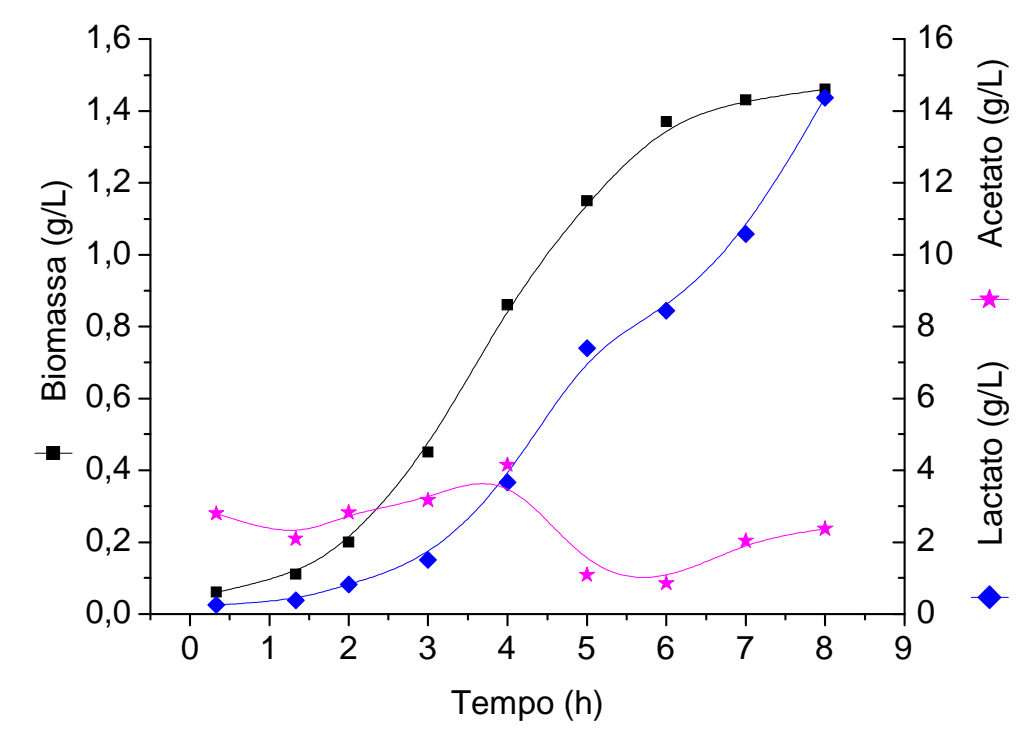

\subsubsection{Cultivo em meio definido contendo $20 \mathrm{~g} / \mathrm{L}$ de glicose inicial (CG20)}

O experimento com glicose $20 \mathrm{~g} / \mathrm{L}$ como fonte de carbono foi feito em triplicata, pois esse experimento serviu como base de comparação para os experimentos seguintes de meio modificado com ausência de aminoácidos e vitaminas (item 5.1.2 até item 5.1.5).

Neste cultivo, observou-se um perfil de crescimento muito semelhante aos anteriores, com fase exponencial de 0 a 4 horas e $\mu_{\text {máx }}$ de $0,704 \mathrm{~h}^{-1}$. Como pode ser visto na Figura 12, a produção de $\mathrm{PS} 14_{\mathrm{L}}$ máxima alcançada foi de $150 \mathrm{mg} / \mathrm{L}$, e de $\mathrm{PS} 14_{\mathrm{C}}$ foi de $95 \mathrm{mg} / \mathrm{L}$. O perfil de PS14 ligado à célula acompanhou a curva de crescimento celular, enquanto que a liberação de PS14 para o sobrenadante continuou aumentando mesmo quando a fase estacionária foi alcançada. 
Figura 12 - Produção de biomassa, PS14 L, PS14 , e glicose residual em cultivo descontínuo em reator com meio CG20.

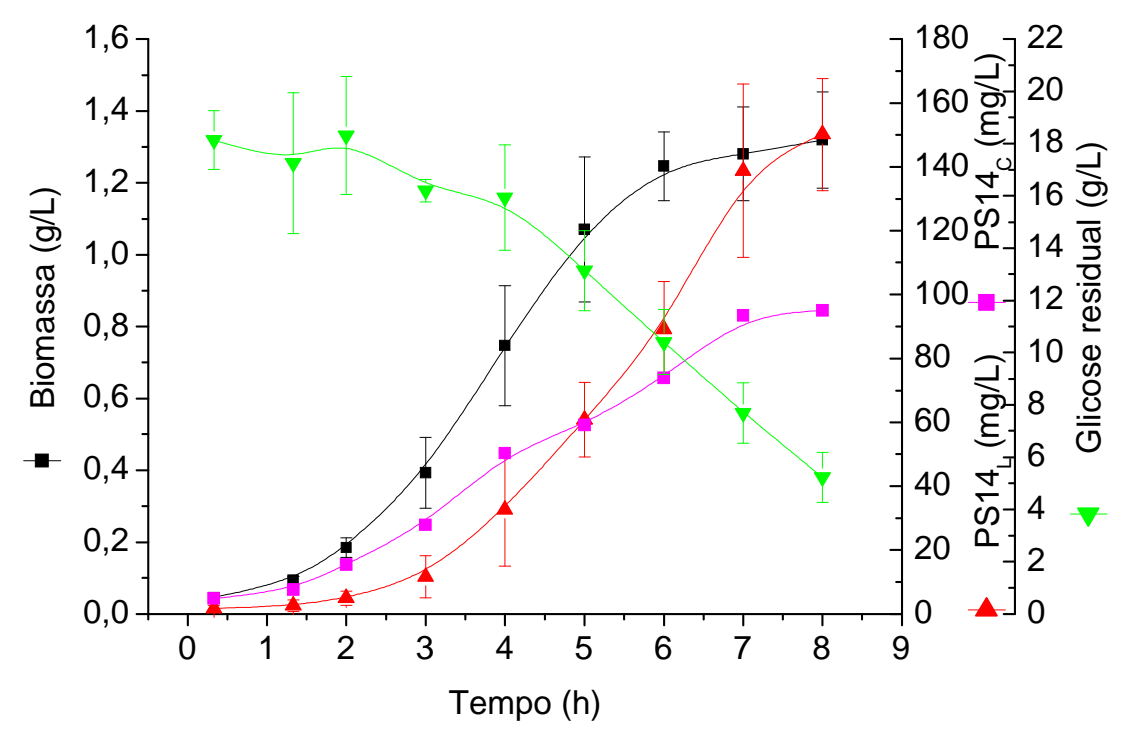

A Figura 13 mostra um perfil de lactato parcialmente associado ao crescimento, aumentando mesmo após o microrganismo entrar na fase estacionária, e um perfil de acetato aumentando com o crescimento e aparentemente diminuindo após o microrganismo atingir a fase estacionária, o que não pôde ser confirmado devido ao grande erro da medida de acetato das amostras finais dos cultivos.

Figura 13 - Produção de lactato, acetato e biomassa em cultivo descontínuo em reator com meio CG20

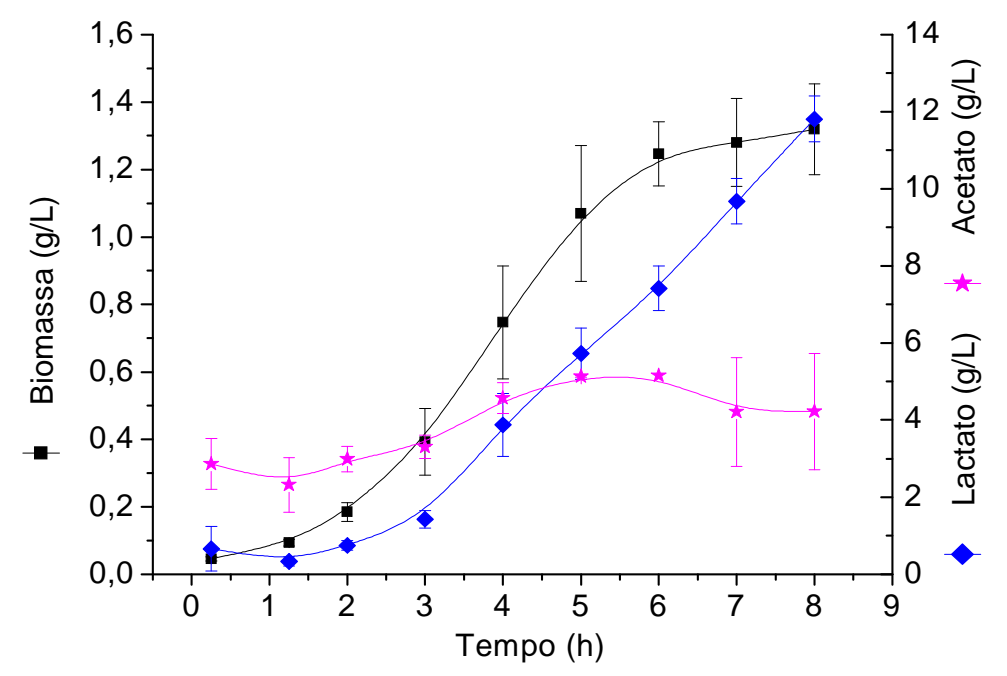


Segundo estudo prévio feito em nosso laboratório (GOGOLA, 2011), a glicose se torna limitante em cultivos contínuos quando está abaixo de $15 \mathrm{~g} / \mathrm{L}$, o que também foi comprovado nestes experimentos em batelada, já que no cultivo contendo $20 \mathrm{~g} / \mathrm{L}$ de glicose inicial, a glicose residual no fim do experimento foi de $5 \mathrm{~g} / \mathrm{L}$ (consumo de $75 \%$ ), enquanto que no experimento com $10 \mathrm{~g} / \mathrm{L}$ de glicose inicial, a glicose se esgotou após 6 horas de cultivo (consumo de 100\%).

De acordo com Neijssel; Snoep; Teixeira de Mattos (1997), altas concentrações de glicose, levam a altos níveis de intermediários glicolíticos tais como frutose-1,6-bifosfato que ativam a enzima lactato desidrogenase e inibem a piruvato formato liase. Este efeito combinado gera um maior fluxo direcionado ao lactato e, portanto ao metabolismo homofermentativo. Em limitação de glicose, a concentração intracelular desses intermediários é baixa, o que resulta em direcionamento do piruvato para diferentes ácidos orgânicos (metabolismo heterofermentativo). A princípio pensou-se que este fenômeno também tivesse ocorrido neste experimento, pois houve uma maior produção de lactato $(12 \mathrm{~g} / \mathrm{L})$ no experimento contendo excesso de glicose $(20 \mathrm{~g} / \mathrm{L})$, comparado com o experimento com 10 $\mathrm{g} / \mathrm{L}$ de glicose, onde a produção foi de $8 \mathrm{~g} / \mathrm{L}$, como pode ser visto nas Figuras 9 e 13, entretanto, quando comparadas as velocidades médias de produção de lactato na fase exponencial, vê-se que os valores foram muito semelhantes $(2,07 \mathrm{~g} / \mathrm{L}$.h para glicose $20 \mathrm{~g} / \mathrm{L} \mathrm{e}$ 2,04 g/L.h para glicose $10 \mathrm{~g} / \mathrm{L}$ ) e portanto não houve uma mudança no metabolismo do microrganismo, mais lactato foi produzido apenas porque havia mais glicose.

Segundo Cerning et al (1994) a concentração do açúcar exerce efeito sobre a produção de exopolissacarídeo (EPS) no microrganismo Lactobacillus casei. Aumentando a concentração de glicose de $10 \mathrm{~g} / \mathrm{L}$ para 20g/L houve um aumento de $120 \mathrm{mg} / \mathrm{L}$ para $160 \mathrm{mg} / \mathrm{L}$ de EPS. Do mesmo modo, para o Streptococcus pneumoniae sorotipo 14 neste trabalho, a concentração de PS14 $\mathrm{L}_{\mathrm{L}}$ aumentou de $100 \mathrm{mg} / \mathrm{L}$ para $150 \mathrm{mg} / \mathrm{L}$, quando a glicose foi aumentada de $10 \mathrm{~g} / \mathrm{L}$ para $20 \mathrm{~g} / \mathrm{L}$. Em termos de produtividade de PS14 $\mathrm{L}$, o cultivo contendo $20 \mathrm{~g} / \mathrm{L}$ de glicose inicial também foi maior chegando a 18,6 mg/L.h, enquanto que com $10 \mathrm{~g} / \mathrm{L}$ de glicose inicial chegou a 12,9 mg/L.h como mostrado na Tabela 3.

\subsubsection{Cultivo em meio definido contendo $10 \mathrm{~g} / \mathrm{L}$ de sacarose inicial (CS10)}

O cultivo utilizando sacarose como fonte de carbono foi proposto baseado na ideia de que este açúcar poderia ser a principal fonte de carboidrato para Streptococcus pneumoniae e, 
além disso, nenhum artigo ainda foi publicado utilizando sacarose no meio de cultura para avaliar a produção de PS14.

A Figura 14 mostra o perfil de crescimento e de produção de PS14 $4_{L}$ e PS14 $C$ com 10 g/L de sacarose. Observa-se que a sacarose se esgotou após 7 horas de cultivo, estando provavelmente em concentração limitante para o crescimento do pneumococo, pois a partir deste momento o pneumococo parou de crescer e intensificou a liberação de PS14 para o meio de cultura. Após 9 horas de cultivo, a produção total de PS14 $4_{\mathrm{L}}$ foi de $228 \mathrm{mg} / \mathrm{L}$ e de PS14 $\mathrm{C}$ chegou a um máximo de $140 \mathrm{mg} / \mathrm{L}$ após 7 horas de cultivo. Glicose e frutose não foram detectadas no meio de cultura através de análise de CLAE, isto ocorreu provavelmente porque a sacarose é transportada para dentro da célula e fosforilada pelo sistema PTS e uma sacarose6-fosfato hidrolase específica cliva a sacarose fosfatada em glicose-6-fosfato e frutose, não sendo assim possível detectar glicose e frutose extracelular (SALMINEN et al., 2004).

Figura 14 - Produção de biomassa, PS14 L, PS14 $\mathrm{C}$, e sacarose residual em cultivo descontínuo em reator com meio CS10

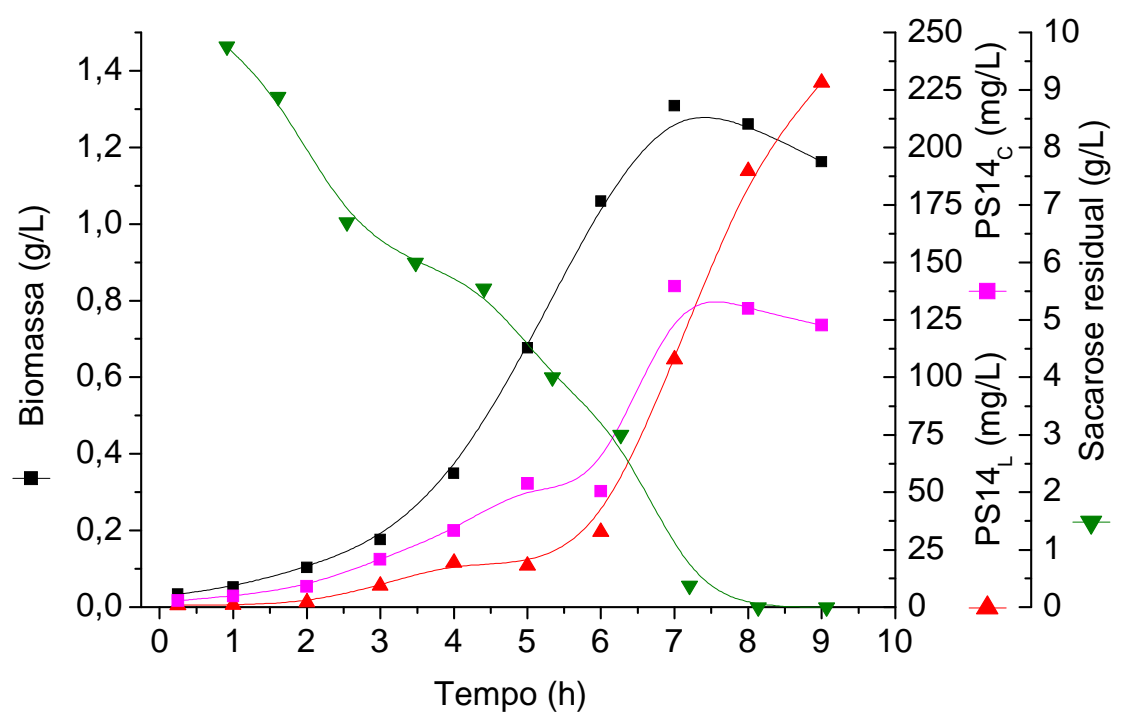

A formação de lactato se mostrou parcialmente associada ao crescimento celular tal como apresentado para os demais cultivos e a produção de acetato teve um pequeno aumento com o crescimento do microrganismo (Figura 15). 
Figura 15 - Produção de lactato, acetato e biomassa em cultivo descontínuo em reator com meio CS 10

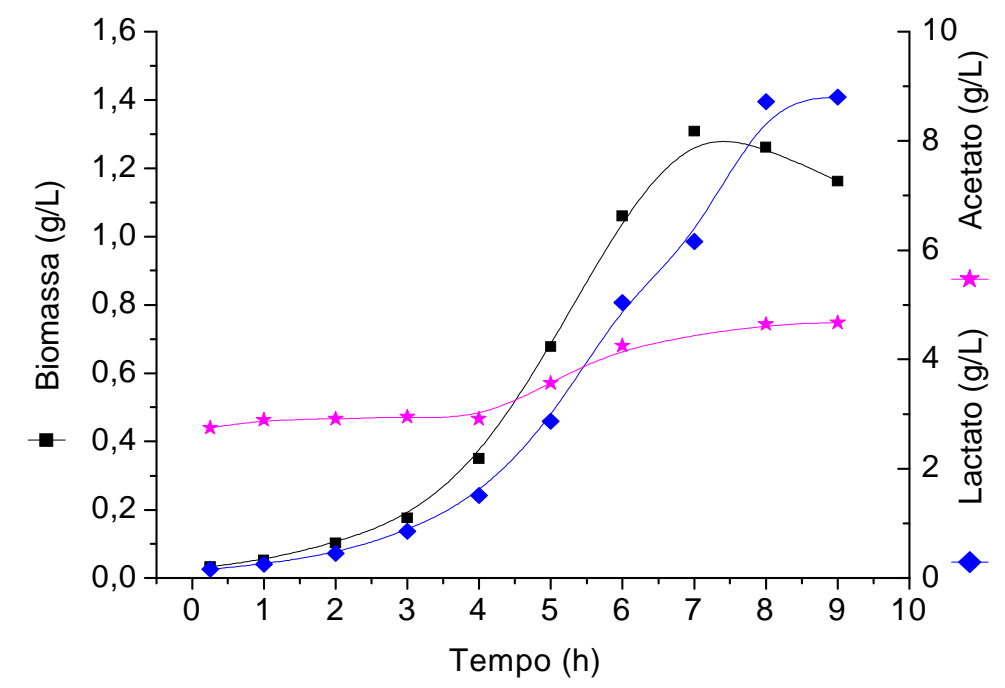

No cultivo contendo $10 \mathrm{~g} / \mathrm{L}$ de sacarose, a produção de PS14 $\mathrm{L}$ foi maior do que nos cultivos contendo glicose como fonte de carbono. A produção chegou a $190 \mathrm{mg} / \mathrm{L}$ após 8 horas de cultivo, enquanto que com glicose na mesma concentração a produção foi de apenas $100 \mathrm{mg} / \mathrm{L}$ (Figura 8 e 14), portanto ocorreu um aumento de $90 \%$ com a substituição de glicose por sacarose. Para a maioria das bactérias, a glicose é a fonte preferencial de carbono, porém, para algumas delas como Streptococcus thermophilus e Bifidobacterium longum, a lactose é a fonte preferencial e a glicose é fonte secundária de carbono e os genes para utilização da glicose são reprimidos na presença da fonte preferencial de carbono. Este é o chamado fenômeno da repressão catabólica (CCR) que será discutido adiante (GORKE; STULKE, 2008).

Segundo Iyer e Camilli (2007), a sacarose é o açúcar mais utilizado pelo $S$. pneumoniae durante a colonização, porém ainda não se tem estudos da utilização de sacarose como fonte de carbono em meio de cultura para esse microrganismo para produção de PS, sendo este o principal motivo da escolha deste açúcar para estudo do comportamento e da fonte preferencial de carbono para $S$. pneumoniae.

\subsubsection{Utilização de glicose e sacarose concomitantes como fonte de carbono (CG5S5)}

Este experimento foi realizado em frasco em duplicata, glicose e sacarose foram utilizadas juntamente $(5 \mathrm{~g} / \mathrm{L}$ de cada) para avaliar se ocorreria o fenômeno da repressão catabólica, ou seja, se essas fontes de carbono seriam cometabolizadas ou se a bactéria usaria 
preferencialmente a fonte de carbono que fosse mais acessível e permitisse o crescimento mais rápido.

Como observado na Figura 16, as duas fontes de carbono (glicose e sacarose) foram metabolizadas ao mesmo tempo, indicando que entre elas não ocorreu o fenômeno da repressão catabólica, um fenômeno regulatório pelo qual a expressão das funções para o uso da fonte preferencial de carbono e da atividade das enzimas correspondentes reprime a utilização de outras fontes na presença da fonte preferencial (GORKE; STULKE, 2008).

Figura 16 - Produção de lactato, acetato, glicose e sacarose residual em cultivo descontínuo em frasco com meio CG5S5

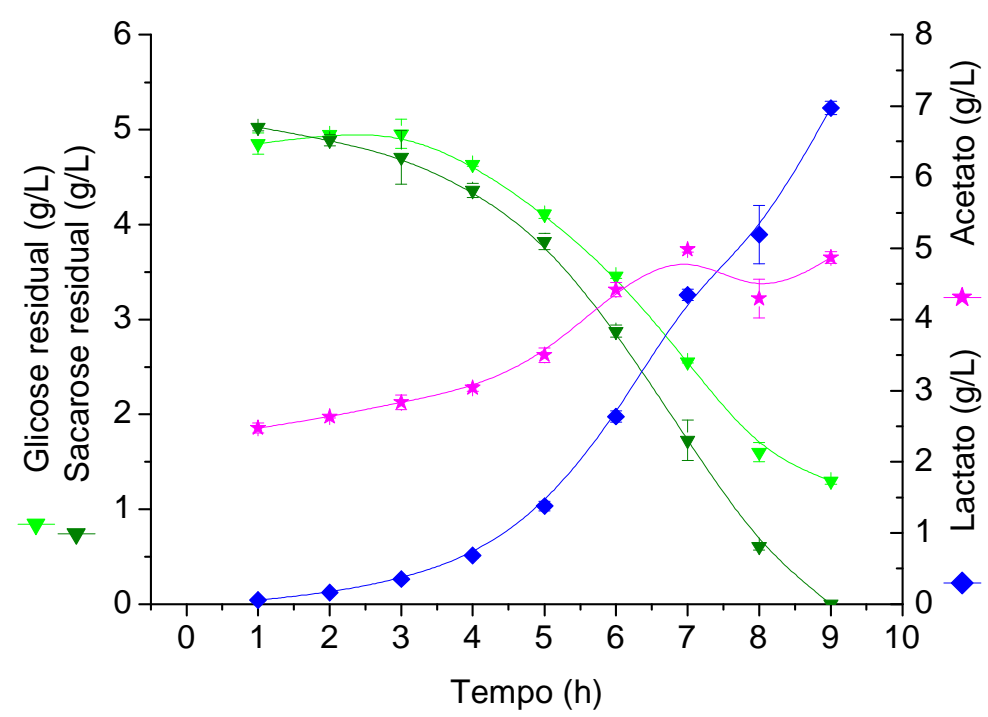

Neste cultivo em frasco, a biomassa máxima alcançada foi de 1,08 g/L e a produção máxima de PS14 $50 \mathrm{mg} / \mathrm{L}$, como mostrado na Figura 17. O $\mu_{\text {máx }}$ das curvas de crescimento em duplicata foram $0,6552 \mathrm{~h}^{-1}$ e $0,6507 \mathrm{~h}^{-1}$. 
Figura 17 - Produção de biomassa e PS14 $4_{L}$ em cultivo descontínuo em frasco com meio CG5S5

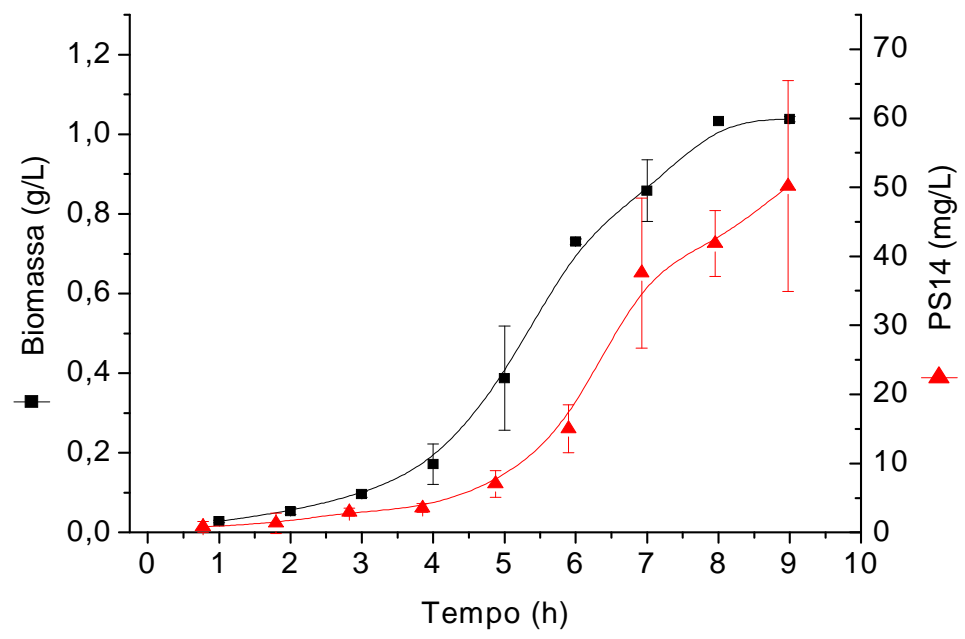

5.1.1.6 Comparação dos dados dos cultivos glicose $10 \mathrm{~g} / \mathrm{L}$ (CG10), glicose $10 \mathrm{~g} / \mathrm{L}$ mais pulso (CG10P10), glicose $20 \mathrm{~g} / \mathrm{L}$ (CG20) e sacarose $10 \mathrm{~g} / \mathrm{L}(\mathrm{CS} 10)$

A Tabela 3 mostra os parâmetros obtidos nos quatro experimentos em batelada realizados em reator citados anteriormente nos itens 5.1.1.1 a 5.1.1.4. 
Tabela 3 - Parâmetros dos cultivos batelada em reator com glicose $10 \mathrm{~g} / \mathrm{L}$, glicose $10 \mathrm{~g} / \mathrm{L}$ mais pulso, glicose $20 \mathrm{~g} / \mathrm{L}$ e sacarose $10 \mathrm{~g} / \mathrm{L}$

\begin{tabular}{|c|c|c|c|c|}
\hline Parâmetro & $\begin{array}{l}\text { Glicose } 10 \mathrm{~g} / \mathrm{L} \\
\text { (CG10) }\end{array}$ & $\begin{array}{c}\text { Glicose } 10 \mathrm{~g} / \mathrm{L} \\
\text { com pulso } \\
\text { (CG10P10) }\end{array}$ & $\begin{array}{l}\text { Glicose } 20 \mathrm{~g} / \mathrm{L} \\
\text { (CG20) }\end{array}$ & $\begin{array}{l}\text { Sacarose } 10 \mathrm{~g} / \mathrm{L} \\
(\mathrm{CS} 10)\end{array}$ \\
\hline $\mathrm{X}_{\text {máx }}(\mathrm{g} / \mathrm{L})$ & 1,31 & 1,46 & 1,32 & 1,31 \\
\hline$\mu_{\text {máx }}\left(h^{-1}\right)^{*}$ & 0,653 & 0,755 & 0,704 & 0,627 \\
\hline $\operatorname{PS} 14_{L \text { máx }}(\mathrm{mg} / \mathrm{L})$ & 100 & 141 & 150 & $228 * *$ \\
\hline $\operatorname{PS} 14_{C \text { máx }}(\mathrm{mg} / \mathrm{L})$ & 94 & - & 95 & 140 \\
\hline $\mathrm{Y}_{\mathrm{X} / \mathrm{S}}\left(\mathrm{g}_{\text {célula }} / \mathrm{g}_{\text {substrato }}\right)$ & 0,189 & $\begin{array}{l}0,21^{\#} \\
0,04^{\# \#}\end{array}$ & 0,142 & 0,204 \\
\hline $\mathrm{Y}_{\mathrm{PS} 14 \mathrm{~L} / \mathrm{S}}\left(\mathrm{mg}_{\mathrm{ps} 14} / \mathrm{g}_{\text {substrato }}\right)$ & 13,5 & $\begin{array}{l}2,15^{\#} \\
13,79^{\# \#}\end{array}$ & 11,5 & 23,3 \\
\hline $\mathrm{Y}_{\mathrm{PS} 14 \mathrm{C} / \mathrm{S}}\left(\mathrm{mg}_{\mathrm{ps} 14} / \mathrm{g}_{\text {substrato }}\right)$ & 9,8 & - & 7,0 & 14,0 \\
\hline $\mathrm{Y}_{\text {L/S }}\left(\mathrm{g}_{\text {lactato }} / \mathrm{g}_{\text {substrato }}\right)$ & 0,81 & $\begin{array}{l}0,89^{\#} \\
0,89^{\# \#}\end{array}$ & 0,86 & 0,89 \\
\hline$\%$ consumo de glicose & 100 & 91 & 75 & 100 \\
\hline$Q_{x}\left(g_{\text {célula }} \cdot \mathrm{L}^{-1} \cdot \mathrm{h}^{-1}\right)$ & 0,183 & 0,183 & 0,159 & 0,135 \\
\hline $\mathrm{Q}_{\mathrm{PS} 14 \mathrm{~L}}\left(\mathrm{mg}_{\mathrm{ps} 14} \cdot \mathrm{L}^{-1} \cdot \mathrm{h}^{-1}\right)$ & 12,9 & 18,4 & 18,6 & 26,0 \\
\hline $\mathrm{Q}_{\mathrm{PS} 14 \mathrm{C}}\left(\mathrm{mg}_{\left.\mathrm{ps} 14 \cdot \mathrm{L}^{-1} \cdot \mathrm{h}^{-1}\right)}\right.$ & 11,7 & - & 11,3 & 20,3 \\
\hline
\end{tabular}

*Foi considerada a fase exponencial para o cálculo

** Valor obtido após nove horas de cultivo. O valor equivalente a oito horas seria 190mg de PS14 L por litro de meio de cultura.

${ }^{\#}$ Valor calculado na primeira parte do experimento, antes do pulso.

\#\# Valor calculado na segunda parte do experimento, depois do pulso.

Observa-se que o cultivo contendo $10 \mathrm{~g} / \mathrm{L}$ de glicose inicial mais um pulso de $10 \mathrm{~g} / \mathrm{L}$ foi o que gerou maior biomassa $(1,46 \mathrm{~g} / \mathrm{L})$ e apresentou o maior $\mu_{\text {máx }}\left(0,755 \mathrm{~h}^{-1}\right)$. O cultivo contendo sacarose como fonte de carbono foi o que produziu maior quantidade de PS14 tanto livre $(228 \mathrm{mg} / \mathrm{L})$ quanto ligado a célula $(140 \mathrm{mg} / \mathrm{L})$ e seu $\mu_{\text {máx }}$ foi o menor $\left(0,627 \mathrm{~h}^{-1}\right)$, isso indica que uma menor velocidade de crescimento permitiria à bactéria direcionar melhor a fonte de carbono para formação do PS14.

Quando comparados ao cultivo contendo sacarose como única fonte de carbono, o fator de conversão substrato em PS14 foi menor em todas as concentrações de glicose. A produtividade em PS14 $\mathrm{L}$ também se mostrou maior utilizando a sacarose $(26,0 \mathrm{mg} / \mathrm{L} . \mathrm{h})$ ao invés da glicose tanto em concentração inicial de 10g/L (12,9 mg/L.h) como 20g/L (18,6 $\mathrm{mg} / \mathrm{L} . \mathrm{h})$. 
5.1.2 Influência da retirada de vitaminas (M1G20) na produção de PS14, biomassa e ácidos orgânicos

As vitaminas/cofatores ácido fólico, piridoxamina, ácido $p$-aminobenzóico e $\beta$-NAD foram retiradas do meio completo com o intuito de confirmar experimentos realizados anteriormente no laboratório, nos quais mesmo com a retirada dos compostos descritos acima, o crescimento e a produção de PS14 foram equivalentes aos obtidos em meio completo. Segundo análise na base de dados KEGG (2009), as vitaminas comumente requeridas pelo pneumococo sorotipo 14 como cofatores são: nicotinamida, ácido pantotênico, tiamina, biotina e piridoxal. Portanto, essas vitaminas foram mantidas no meio M1G20 neste experimento.

A Figura 18 ilustra as variáveis biomassa e produção de PS14 tanto livre quanto ligado às células. Vê-se que a biomassa alcançada foi de 1,30 g/L em M1G20, enquanto que em meio completo (CG20) foi de 1,32 $\pm 0,14 \mathrm{~g} / \mathrm{L}$, portanto valores praticamente iguais. A produção de $\mathrm{PS}_{14}$ e de PS14 $\mathrm{C}$ máximos também alcançaram valores próximos ao meio completo, 135 $\mathrm{mg} / \mathrm{L}$ e $109 \mathrm{mg} / \mathrm{L}$ respectivamente, enquanto que usando o meio CG20 a produção foi 150 $\mathrm{mg} / \mathrm{L}$ de PS14 $\mathrm{L}$ e $95 \mathrm{mg} / \mathrm{L}$ de PS14 $\mathrm{C}$.

Figura 18 - Produção de biomassa, PS14 L PS14 $\mathrm{C}$, e glicose residual em cultivo descontínuo em reator com meio contendo apenas 6 vitaminas/cofatores (M1G20)

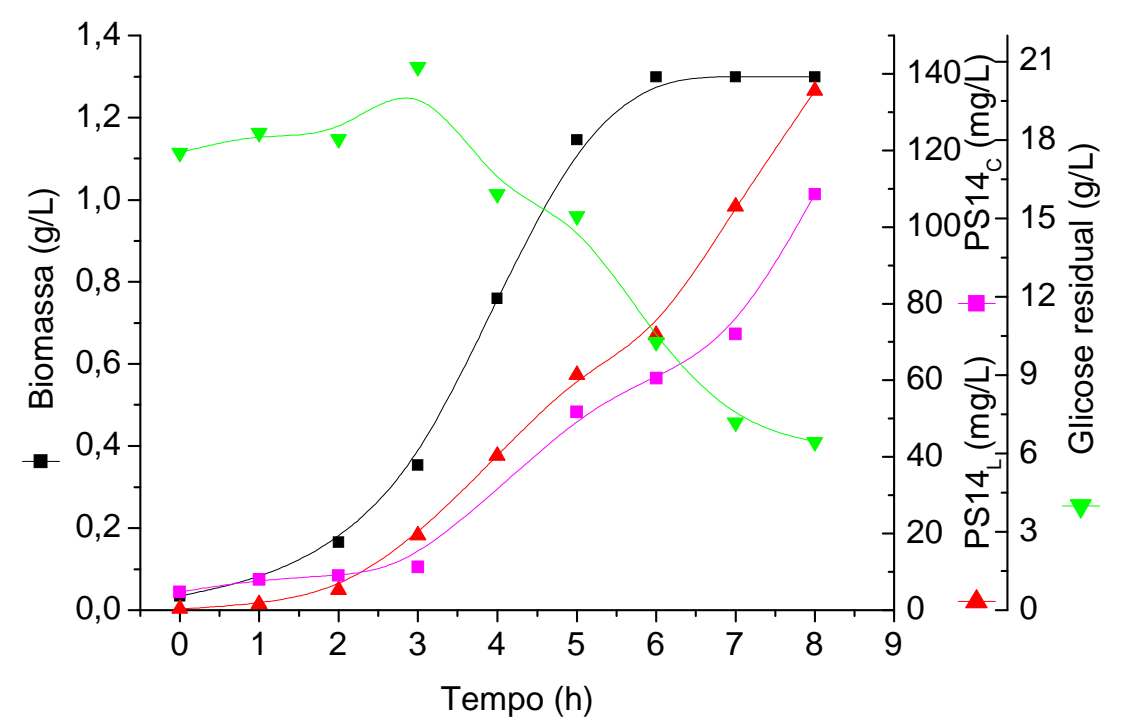


A Figura 19 mostra a produção de lactato e acetato em cultivo descontínuo com redução de vitaminas (meio $\mathrm{M} 1 \mathrm{G} 20$ ), a produção de lactato foi bem semelhante ao meio CG20 alcançando cerca de $12 \mathrm{~g} / \mathrm{L}$ para ambos, a produção de acetato também mostrou um perfil semelhante aumentando durante o cultivo, alcançando a produção máxima de 4,8 mg/L e diminuindo no final.

Figura 19 - Produção de lactato, acetato e biomassa em cultivo descontínuo em reator com meio contendo apenas 6 vitaminas/cofatores (M1G20)

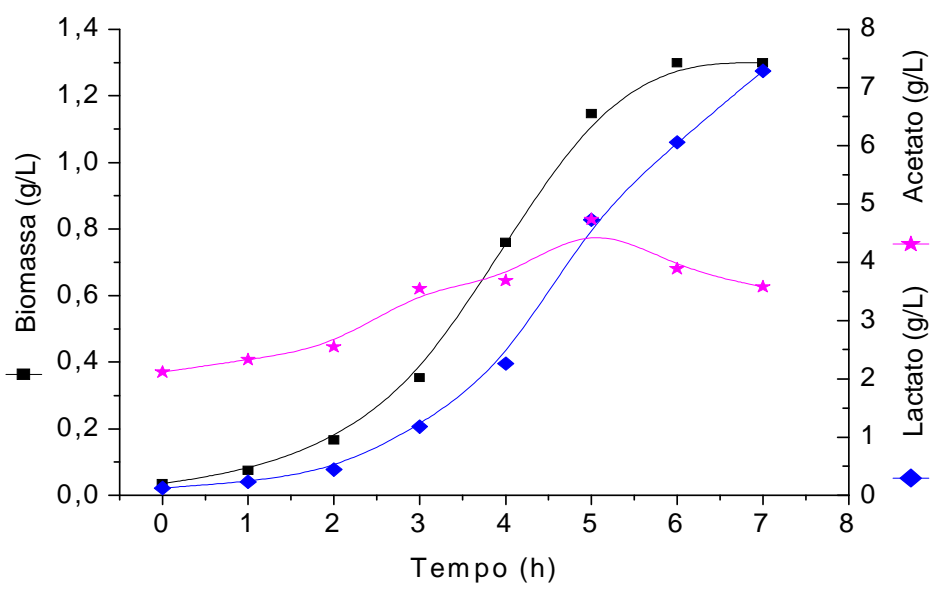

Ao contrário de carboidratos, proteínas e lipídeos, as vitaminas são requeridas na dieta em pequena quantidade, já que são precursoras de coenzimas, cujas concentrações celulares são muito pequenas por serem constantemente recicladas. As vitaminas com complexo B, por exemplo, tiamina, riboflavina, biotina, entre outras, são consideradas essenciais como transportadoras, a riboflavina atua como transportadora de $\mathrm{H}_{2}$, enquanto que a biotina como transportadora de $\mathrm{CO}_{2}$ (MARZZOCO; TORRES, 2010).

\subsubsection{Influência da retirada de aminoácidos (M2G20) na produção de PS14, biomassa e ácidos orgânicos}

Neste experimento, os aminoácidos asparagina, ácido aspártico, fenilalanina, serina, alanina, treonina, triptofano, lisina e tirosina foram retirados do meio completo, pois segundo Hartel et al. (2011) ao retirar esses aminoácidos separadamente do meio, a cepa D394cps de S. pneumoniae crescia igualmente ao meio completo. Diferentemente do publicado por Hartel et al. (2011), aqui todos os aminoácidos foram retirados de uma só vez e, como pode ser visto na Figura 20, o pneumococo apresentou menor crescimento quando 
comparado ao cultivo realizado com o meio CG20. A biomassa chegou a $0,8 \mathrm{~g} / \mathrm{L}$ enquanto que em CG20 chegou a $1,32 \pm 0,14 \mathrm{~g} / \mathrm{L}$.

Figura 20 - Produção de biomassa, PS14 L, PS14 $\mathrm{C}$, e glicose residual em cultivo descontínuo em reator com meio contendo apenas 11 aminoácidos (M2G20)

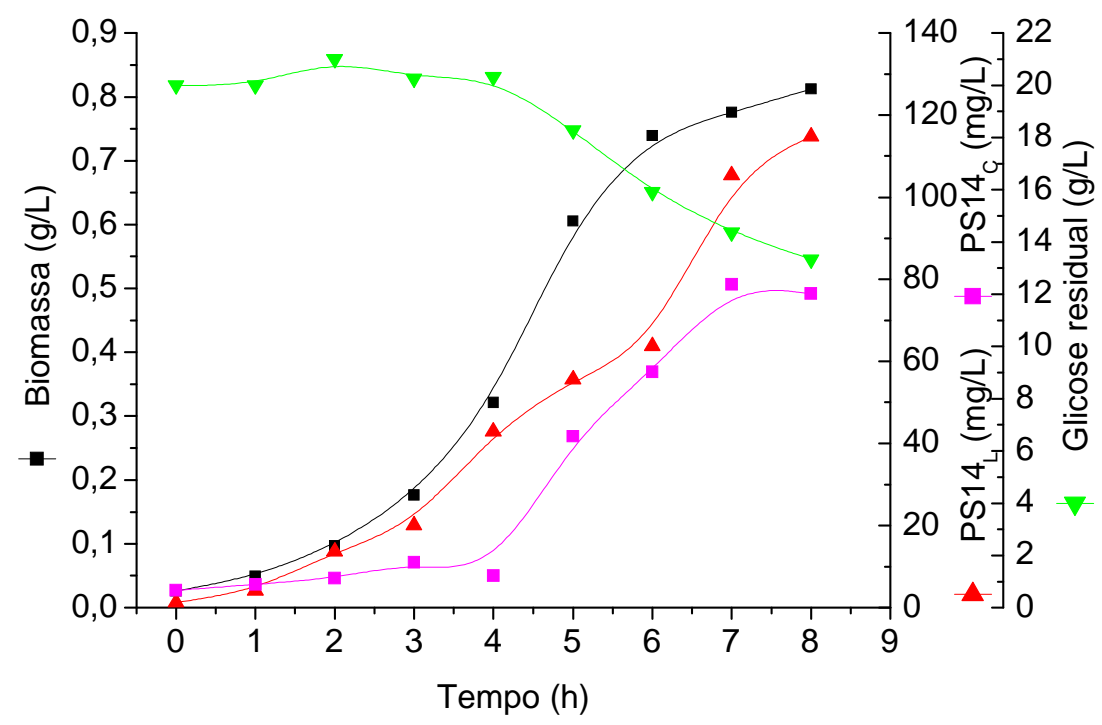

Apesar do menor crescimento, a produção de PS14 ${ }_{\mathrm{L}}$ chegou a $115 \mathrm{mg} / \mathrm{L}$ e de PS14 $\mathrm{C}$ chegou a $79 \mathrm{mg} / \mathrm{L}$. Outro fato interessante observado na Figura 20 foi o consumo de glicose, observou-se que o microrganismo começou a consumir glicose somente após 4 horas de cultivo e ainda restou uma quantidade grande de glicose no reator após o término do experimento (13 g/L). A produção de lactato foi cerca de $50 \%$ menor que em cultivo com meio CG20, visto que neste experimento a produção de lactato foi de $6 \mathrm{~g} / \mathrm{L}$ (Figura 21), enquanto que em meio completo alcançou-se $12 \mathrm{~g} / \mathrm{L}$ (Figura 13). A produção de acetato aumentou pouco com o decorrer do cultivo e mostrou pouca diferença em relação ao meio CG20, salvo o fato de não ter sido consumido no final (Figura 21). 
Figura 21 - Produção de lactato, acetato e biomassa em cultivo descontínuo em reator com meio contendo apenas 11 aminoácidos (M2G20)

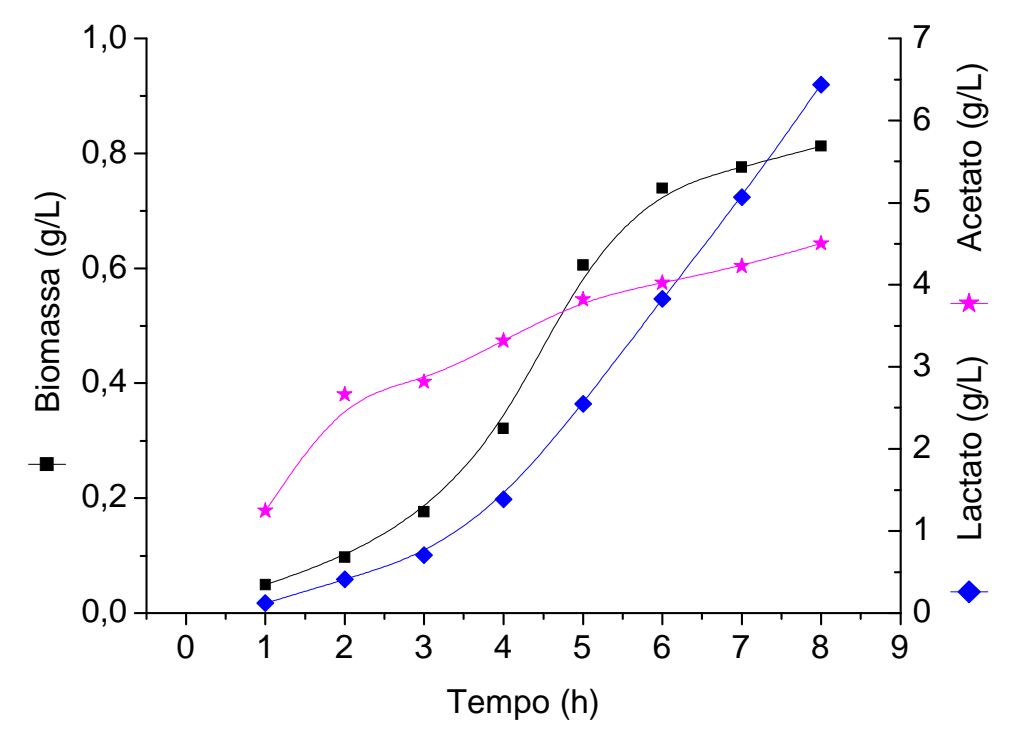

Neste cultivo, vê-se claramente que a fonte de carbono está em excesso, pois no final do cultivo ainda restaram $13 \mathrm{~g} / \mathrm{L}$ de glicose. Os fatores de conversão glicose em células e em lactato se mantiveram bem parecidos quando comparados ao cultivo em meio CG20 (Tabela 4), indicando que a proporção de consumo de glicose e produção de células e lactato foi a mesma nos dois cultivos, portanto, provavelmente a baixa biomassa se deve a limitação de nitrogênio devido à retirada dos aminoácidos. Por outro lado, o fator de conversão glicose em PS14 $\mathrm{L}$ foi maior no cultivo M2G20, indicando que houve melhor aproveitamento da fonte de carbono para produção do polissacarídeo no cultivo M2G20 e que a limitação de nitrogênio em condição de excesso de carbono levou a uma maior produção de PS14.

O fator de conversão de células em PS14 também foi maior para o cultivo com a retirada dos aminoácidos, passando de $117 \mathrm{mg} / \mathrm{g}$ em cultivo CG20 para $144 \mathrm{mg} / \mathrm{g}$ do PS14 $\mathrm{L}$ em cultivo M2G20. No trabalho de Marshall et al. (1995), em cultivo contínuo de Lactococcus lactis, o polissacarídeo neutro formado por galactose, glicose e glicosamina (composição semelhante à do PS14), foi influenciado pela temperatura e pela limitação de nitrogênio. Quando a cultura foi limitada pelo nitrogênio, a quantidade de PS produzida aumentou de $58 \mu \mathrm{g} / \mathrm{mg}$ de célula para $92 \mu \mathrm{g} / \mathrm{mg}$ de célula.

Outros trabalhos relatam que a limitação de nutrientes, tal como nitrogênio, fósforo e enxofre, na presença de excesso de carbono influencia o nível de produção de polissacarídeos. A síntese de polissacarídeo em cultivo contínuo da bactéria Klebsiella pneumoniae K1 foi maior em meio contendo baixa quantidade de nitrogênio, alta quantidade de carbono e baixa 
taxa de diluição. O aumento da produção de polissacarídeo em condições de limitação de nutrientes ou baixa taxa de diluição em cultura in vitro, segundo os autores, também ocorreria in vivo onde o substrato não estaria prontamente disponível (MENGISTU; EDWARDS; SAUDERS, 1994).

Segundo Lahtvee et al (2011), os aminoácidos são a principal fonte de nitrogênio no meio de cultura representando mais de $99 \%$ do nitrogênio consumido em um cultivo bacteriano. Um hipótese para a diminuição da biomassa de $1,3 \mathrm{~g} / \mathrm{L}$ para $0,8 \mathrm{~g} / \mathrm{L}$ seria que os aminoácidos sustentariam o crescimento e, portanto a limitação de nitrogênio levaria a uma menor produção de biomassa o que acarretaria o menor consumo de glicose.

5.1.4 Influência da retirada de aminoácidos e vitaminas (M3G20) na produção de PS14, biomassa e ácidos orgânicos

No experimento mostrado no item 5.1.2 foram retiradas as vitaminas ácido fólico, piridoxamina, ácido aminobenzóico e $\boldsymbol{\beta}$-NAD e no experimento mostrado no item 5.1.3 foram retirados os aminoácidos asparagina, ácido aspártico, fenilalanina, serina, alanina, treonina, triptofano, lisina e tirosina. Neste experimento, tanto estes aminoácidos quanto as vitaminas foram retirados de uma só vez para avaliação do comportamento da bactéria $S$. pneumoniae. Este cultivo foi realizado em duplicata.

Na Figura 22 vê-se que a biomassa atingiu somente $0,6 \mathrm{~g} / \mathrm{L}$ e a glicose residual no final do experimento foi $13,6 \mathrm{~g} / \mathrm{L}$, portanto dos $20 \mathrm{~g} / \mathrm{L}$ colocados no início do experimento, o microrganismo consumiu 6,4 g/L. Apesar da baixa biomassa, o PS14 ${ }_{\mathrm{L}}$ atingiu $114 \mathrm{mg} / \mathrm{L}$, valor semelhante ao cultivo M2G20 e o PS14 chegou a $39 \mathrm{mg} / \mathrm{L}$, valor menor que em meio de cultura com remoção de aminoácidos (M2G20) ou com remoção de vitaminas (M1G20) provavelmente devido ao menor crescimento visto que o PS14 $\mathrm{C}$ parece estar associado ao crescimento bacteriano. 
Figura 22 - Produção de biomassa, PS14 L, PS14 , e glicose residual em cultivo descontínuo em reator com meio $\mathrm{M} 3 \mathrm{G} 20$

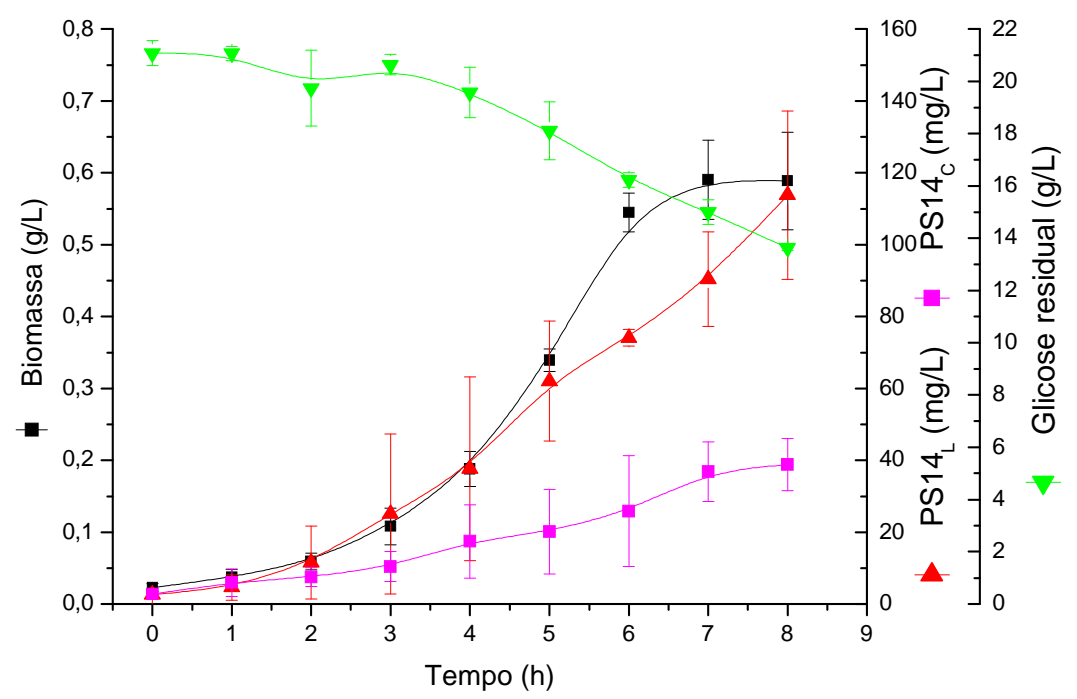

A produção de lactato alcançou $5 \mathrm{~g} / \mathrm{L}$, valor menor que os demais experimentos, como consequência do baixo consumo de glicose e da baixa biomassa. $\mathrm{O}$ acetato teve um aumento de 3,4 g/L para 4,6 g/L (Figura 23).

Figura 23 - Produção de lactato, acetato e biomassa em cultivo descontínuo em reator com meio M3G20

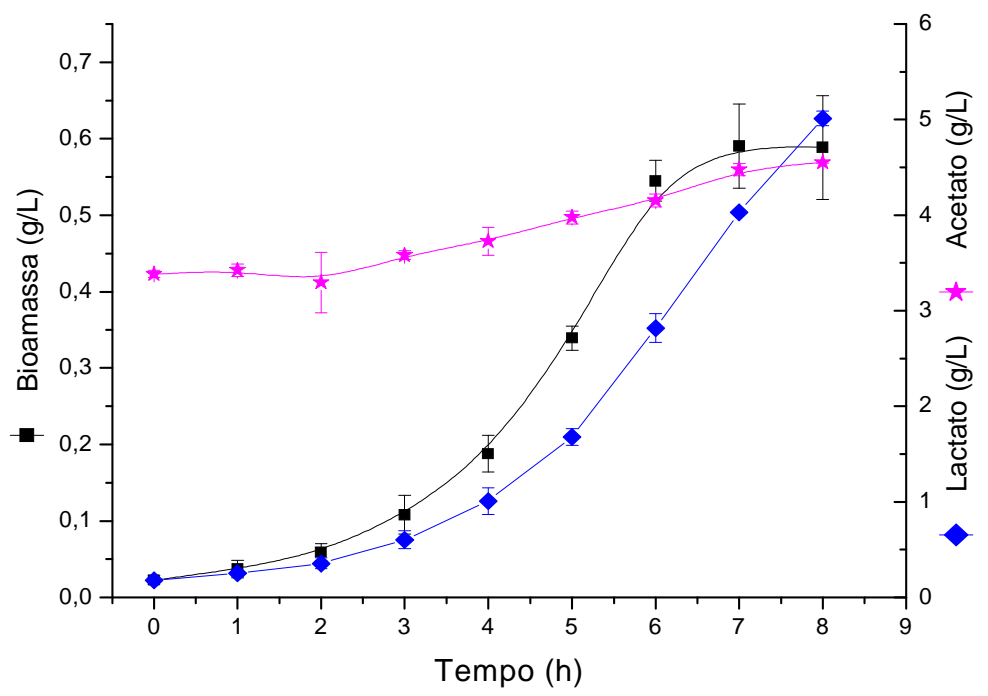


Após análise dos parâmetros (mostrados na Tabela 4) viu-se que o fator de conversão substrato em PS14 $\mathrm{L}_{\mathrm{L}}\left(14,9 \mathrm{mg}_{\mathrm{ps} 14} / \mathrm{g}_{\mathrm{glicose}}\right)$ foi semelhante ao cultivo com ausência de aminoácidos $\left(14,8 \mathrm{mg}_{\mathrm{ps} 14} / \mathrm{g}_{\text {glicose }}\right)$ e maior que no cultivo com ausência de vitaminas $(12,2$ $\mathrm{mg}_{\mathrm{ps} 14} / \mathrm{g}_{\text {glicose }}$ ), indicando que houve um bom aproveitamento da glicose para produção de PS14L mesmo sem 13 dos 34 componentes (aminoácidos e vitaminas) que compõe o meio completo. Quanto ao fator de conversão de células em PS14 observou-se um fato interessante, $\mathrm{Y}_{\mathrm{PS} 14 \mathrm{~L} / \mathrm{X}}$ foi maior (196 mg $\left.\mathrm{ps}_{14} / \mathrm{g}_{\text {célula }}\right)$ quando comparado a M1G20 (107 mg $\left.\mathrm{ps}_{\mathrm{ps} 1} / \mathrm{g}_{\text {célula }}\right)$ e M2G20 (144 mg $\mathrm{ps}_{14} / \mathrm{g}_{\text {célula }}$ ) e $\mathrm{Y}_{\mathrm{PS} 14 \mathrm{C} / \mathrm{X}}$ foi menor $\left(63 \mathrm{mg}_{\mathrm{ps} 14} / \mathrm{g}_{\text {célula }}\right)$ comparado aos mesmos experimentos (82 $\mathrm{mg}_{\mathrm{ps} 14} / \mathrm{g}_{\text {célula }}$ em M1G20 e $92 \mathrm{mg}_{\mathrm{ps} 14} / \mathrm{g}_{\text {célula }}$ em M2G20). Isso significa que ao tirar os aminoácidos e as vitaminas, proporcionalmente mais células dão origem ao PS14 livre no sobrenadante do que ligado à célula, o que seria vantajoso do ponto de vista de produção já que para indústria é muito mais interessante o PS14 $4_{\mathrm{L}}$ devido à simplicidade no processo de purificação e recuperação.

Após a realização deste experimento, descobriu-se através de uma busca pela base de dados KEGG (2012) que a vitamina Riboflavina poderia ser retirada do meio de cultura já que o microrganismo possui as enzimas necessárias para sua síntese a partir da via pentose fosfato. Portanto, mais essa vitamina foi retirada do meio quimicamente definido para avaliação do comportamento do S. pneumoniae. Os resultados são mostrados abaixo.

\subsubsection{Influência da retirada da riboflavina (M4G20) na produção de PS14, biomassa e ácidos orgânicos}

A riboflavina ou vitamina B2 faz parte de um grupo de pigmentos amarelos denominados flavinas e encontra-se amplamente distribuída na natureza, sendo produzida por bactérias, leveduras e vegetais verde escuros. Ela atua como precursora dos cofatores de flavina: FMN (flavina mononucleotídio) e FAD (flavina adenina dinucleotídio); e estes compostos servem como coenzimas em reações de oxirredução do metabolismo energético.

Neste experimento foi mantida a composição do meio assim como no item 5.1.4, ou seja, sem os mesmos aminoácidos e vitaminas além da retirada da riboflavina. Na Figura 24, observa-se que a biomassa diminuiu ainda mais, passando de $0,63 \mathrm{~g} / \mathrm{L}$ no cultivo em M3G20 para $0,56 \mathrm{~g} / \mathrm{L}$ neste. $\mathrm{O}$ consumo de glicose também foi baixo restando cerca de $11 \mathrm{~g} / \mathrm{L}$ no reator no final do experimento. Como consequência do consumo de glicose, a produção de lactato alcançou um máximo de 5,5 g/L como se pode ver na Figura 25. O acetato aumentou de $2 \mathrm{~g} / \mathrm{L}$ para $3 \mathrm{~g} / \mathrm{L}$. 
Figura 24 - Produção de biomassa, PS14 L, PS14 $\mathrm{C}$, e glicose residual em cultivo descontínuo em reator com meio M4G20

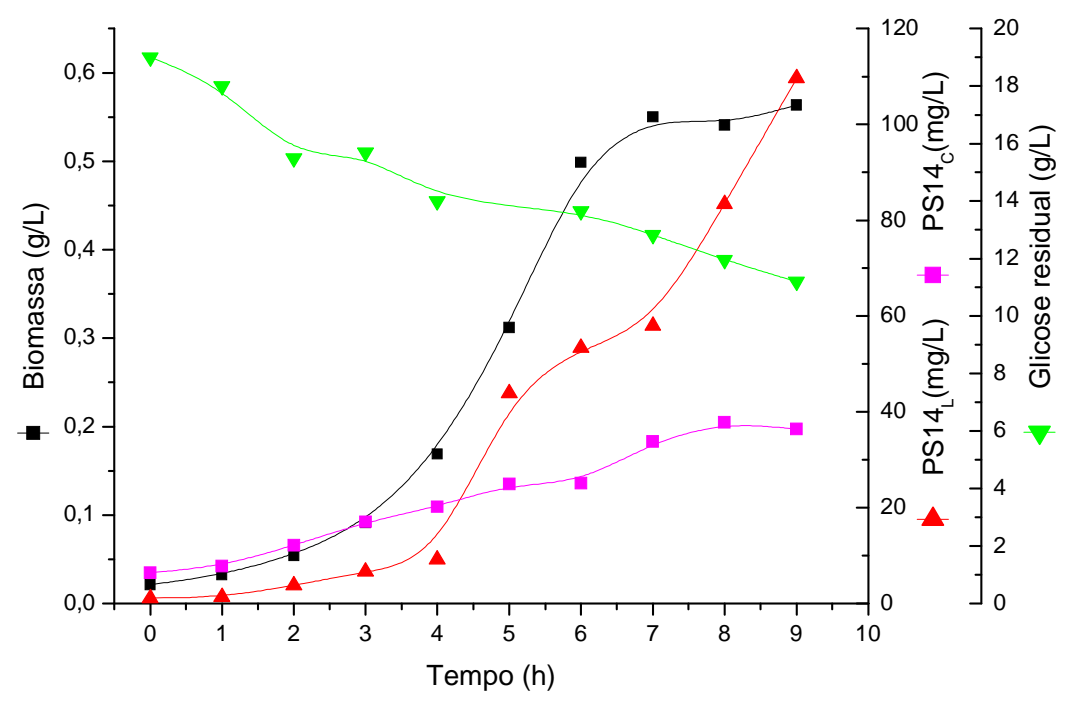

Figura 25 - Produção de lactato, acetato e biomassa em cultivo descontínuo em reator com meio M4G20

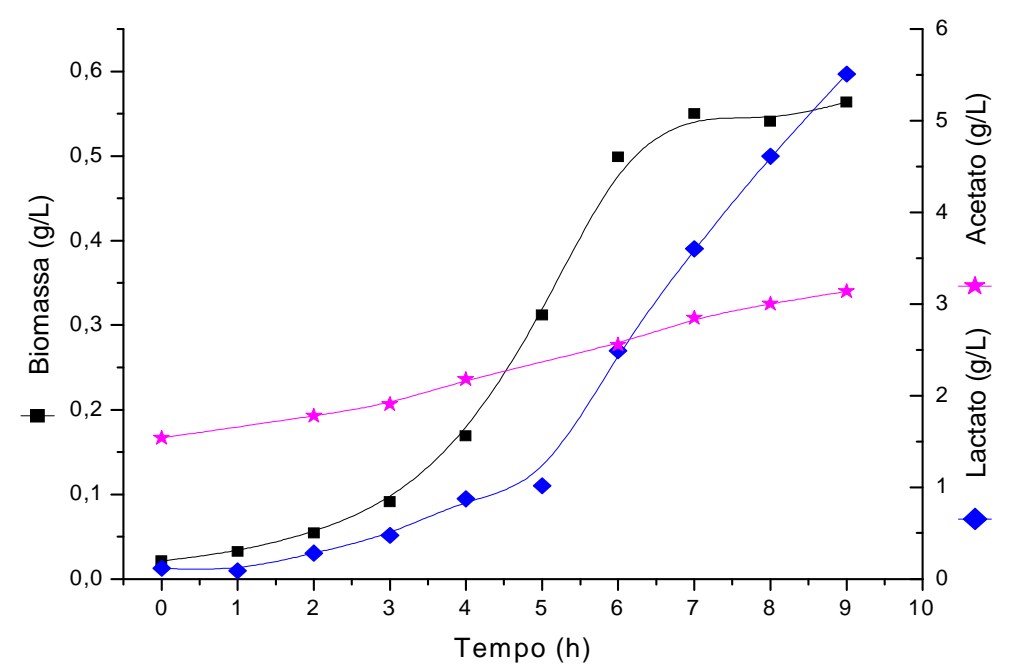

Apesar da diminuição da biomassa, a produção de PS14 $4_{L}$ permaneceu praticamente constante (110 g/L em comparação a $114 \mathrm{~g} / \mathrm{L})$ e a produção de PS14 C diminuiu de $63 \mathrm{mg} / \mathrm{L}$ em cultivo M3G20 para $55 \mathrm{mg} / \mathrm{L}$ neste cultivo, provavelmente devido a menor produção da biomassa. Assim como no experimento com meio M3G20, neste experimento também obteve-se maior $\mathrm{Y}_{\mathrm{PS} 14 \mathrm{~L} / \mathrm{X}}(200 \mathrm{mg} / \mathrm{g})$ e menor $\mathrm{Y}_{\mathrm{PS} 14 \mathrm{C} / \mathrm{X}}(55 \mathrm{mg} / \mathrm{g})$ quando comparado aos 
experimentos anteriores, confirmando que a liberação de PS14 para o sobrenadante é favorecida em condições de limitação de nutrientes.

Os resultados mostraram que a retirada da riboflavina não provocou impacto negativo na produção do polissacarídeo, podendo assim ser retirada do meio de cultura para os próximos experimentos.

A Tabela 4 mostra os parâmetros obtidos nos cultivos realizados com meio com retirada de vitaminas (M1G20), retirada de aminoácidos (M2G20), retirada de aminoácidos e vitaminas (M3G20), e retirada de aminoácidos, vitaminas e riboflavina (M4G20) comparados ao meio completo (CG20).

Tabela 4 - Parâmetros dos cultivos M1G20, M2G20, M3G20, M4G20, comparados ao meio completo com $20 \mathrm{~g} / \mathrm{L}$ de glicose inicial (CG20)

\begin{tabular}{|c|c|c|c|c|c|}
\hline Parâmetros & M1G20 & $\mathrm{M} 2 \mathrm{G} 20$ & M3G20 & M4G20 & CG20 \\
\hline $\mathrm{X}_{\text {máx }}(\mathrm{g} / \mathrm{L})$ & 1,30 & 0,81 & 0,63 & 0,56 & 1,32 \\
\hline$\mu_{\text {máx }}\left(h^{-1}\right)^{*}$ & 0,719 & 0,626 & 0,543 & 0,540 & 0,704 \\
\hline PS14 L máx $(\mathrm{mg} / \mathrm{L})$ & 135 & 115 & 114 & 110 & 150 \\
\hline $\operatorname{PS} 14_{\mathrm{C} \text { máx }}(\mathrm{mg} / \mathrm{L})$ & 109 & 79 & 39 & 38 & 95 \\
\hline $\operatorname{PS} 14_{\text {Total máx }}(\mathrm{mg} / \mathrm{L})$ & 244 & 194 & 153 & 148 & 245 \\
\hline $\mathrm{Y}_{\mathrm{X} / \mathrm{S}}\left(\mathrm{g}_{\text {célula }} / \mathrm{g}_{\text {glicose }}\right)$ & 0,114 & 0,103 & 0,076 & 0,070 & 0,099 \\
\hline $\mathrm{Y}_{\mathrm{PS} 14 \mathrm{~L} / \mathrm{S}}\left(\mathrm{mg}_{\mathrm{ps} 14} / \mathrm{g}_{\mathrm{glicose}}\right)$ & 12,2 & 14,8 & 14,9 & 13,9 & 11,5 \\
\hline $\mathrm{Y}_{\mathrm{PS} 14 \mathrm{~L} / \mathrm{X}}\left(\mathrm{mg}_{\mathrm{ps} 14} / \mathrm{g}_{\text {célula }}\right)$ & 107 & 144 & 196 & 200 & 117 \\
\hline $\mathrm{Y}_{\mathrm{PS} 14 \mathrm{C} / \mathrm{S}}\left(\mathrm{mg}_{\mathrm{ps} 14} / \mathrm{g}_{\text {glicose }}\right)$ & 9,4 & 9,4 & 4,8 & 3,9 & 7,0 \\
\hline $\mathrm{Y}_{\mathrm{PS} 14 \mathrm{C} / \mathrm{X}}\left(\mathrm{mg}_{\mathrm{ps} 14} / \mathrm{g}_{\text {célula }}\right)$ & 82 & 92 & 63 & 55 & 71 \\
\hline $\mathrm{Y}_{\mathrm{L} / \mathrm{S}}\left(\mathrm{g}_{\text {lactato }} / \mathrm{g}_{\text {glicose }}\right)$ & 1,01 & 0,82 & 0,64 & 0,69 & 0,87 \\
\hline $\mathrm{Q}_{\mathrm{x}}\left(\mathrm{g}_{\text {célula }} \cdot \mathrm{L}^{-1} \cdot \mathrm{h}^{-1}\right)^{*}$ & 0,158 & 0,102 & 0,071 & 0,060 & 0,159 \\
\hline $\mathrm{Q}_{\mathrm{PS} 14 \mathrm{~L}}\left(\mathrm{mg}_{\mathrm{ps} 14} \cdot \mathrm{L}^{-1} \cdot \mathrm{h}^{-1}\right)$ & 16,9 & 14,2 & 13,9 & 12,1 & 18,6 \\
\hline $\mathrm{Q}_{\mathrm{PS} 14 \mathrm{C}}\left(\mathrm{mg}_{\mathrm{ps} 14} \cdot \mathrm{L}^{-1} \cdot \mathrm{h}^{-1}\right)$ & 13,0 & 9,0 & 4,5 & 3,3 & 11,3 \\
\hline
\end{tabular}

*Foi considerada a fase exponencial para o cálculo

Sabe-se que a composição do meio de cultura pode afetar significativamente as variáveis do cultivo como concentração do produto, produtividade, rendimento, além do custo de operação e de purificação do produto (KENNEDY; KROUSE, 1999). Por isso, os parâmetros acima foram calculados e estão discutidos abaixo.

Em relação à produtividade, o cultivo M1G20 alcançou cerca de $90 \%$ da produtividade de PS14 $\mathrm{L}$ do cultivo contendo $20 \mathrm{~g} / \mathrm{L}$ de glicose em meio completo (CG20). No 
cultivo M2G20 a produtividade alcançou $76 \%$ e no cultivo M3G20 chegou a $75 \%$ quando comparada à do meio completo. Para o cultivo M4G20 a produtividade foi $65 \%$ comparada à do meio completo (CG20).

Observou-se que nos experimentos em meio contendo menor quantidade de aminoácidos e vitaminas (M3G20) e ausência da riboflavina (M4G20), as $\mu_{\text {máx foram menores }}$ comparadas às dos outros experimentos e os fatores de conversão de célula em PS14 $\mathrm{L}$ foram maiores, indicando que, como afirmado para a sacarose, a menor velocidade de crescimento permitiria à bactéria direcionar melhor a fonte de carbono para formação do PS14 $\mathrm{L}$.

Com o estabelecimento de um novo meio de cultura com redução de 14 componentes, sendo 9 aminoácidos e 5 vitaminas, a atenção voltou-se para sacarose como fonte de carbono, pois como mostrado no item 5.1.1.4 a utilização deste açucar levou ao aumento da produção de PS14. Assim, o próximo passo foi usar a sacarose como fonte de carbono em meio M4S10, com apenas 13 aminoácidos e 5 vitaminas.

\subsubsection{Cultivo em meio definido com retirada de aminoácidos e vitaminas contendo $10 \mathrm{~g} / \mathrm{L}$ de sacarose inicial (M4S10)}

Na Figura 26, vê-se que quando sacarose foi utilizada como fonte de carbono, houve um aumento no tempo de cultivo de 9 para 13 horas, a biomassa máxima alcançada foi de 0,37 $\mathrm{g} / \mathrm{L}$, menor que $0,56 \mathrm{~g} / \mathrm{L}$ alcançados no cultivo M4G20 onde a fonte de carbono utilizada foi a glicose 20g/L. Em contrapartida, a produção de PS14 $\mathrm{L}$ chegou a $154 \mathrm{~g} / \mathrm{L}$, que corresponde a $68 \%$ do total $(228 \mathrm{mg} / \mathrm{L})$ alcançado em meio completo utilizando sacarose $10 \mathrm{~g} / \mathrm{L}$ como fonte de carbono (CS10). O PS14 $\mathrm{C}$ chegou a $66 \mathrm{~g} / \mathrm{L}$. Observando a reta de tempo por $\operatorname{lnDO}$, vê-se que a fase exponencial foi de 4 a 11 horas, portanto, utilizando sacarose como fonte de carbono tem-se uma fase lag no reator, o que não acontecia com a glicose, e uma fase exponencial de 7 horas, enquanto que com glicose a fase exponencial foi de 5 horas, fazendo assim com que o cultivo com sacarose seja mais longo. A $\mu_{\text {máx }}\left(0,35 \mathrm{~h}^{-1}\right)$ também foi menor que a dos demais experimentos com meios modificados ( 0,54 a $0,72 \mathrm{~h}^{-1}$, Tabela 4$)$, indicando que a velocidade específica de crescimento do microrganismo foi menor utilizando a sacarose como fonte de carbono, o que, como foi dito para o experimento com meio completo e sacarose como fonte de carbono, pode ser uma vantagem quanto ao melhor direcionamento da fonte de carbono para produção de PS14. 
Figura 26 - Produção de biomassa, PS14 L, PS14 $\mathrm{C}$, e glicose residual em cultivo descontínuo em reator com meio $\mathrm{M} 4 \mathrm{~S} 10$

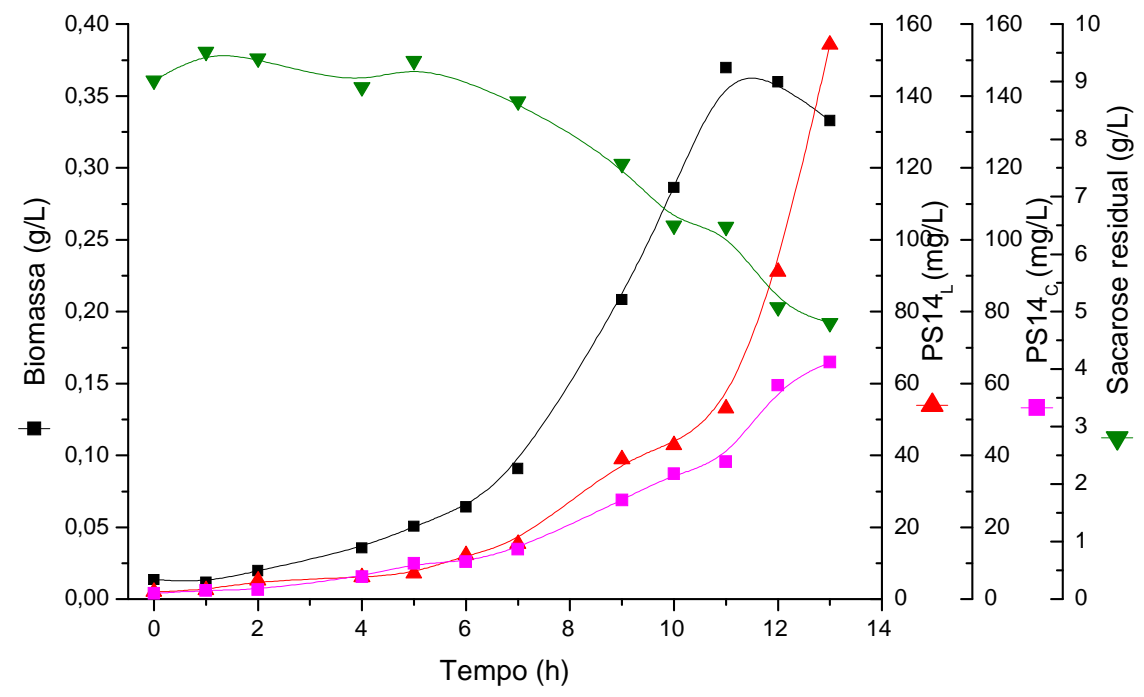

No final do experimento restaram cerca de $5 \mathrm{~g} / \mathrm{L}$ de sacarose no reator, ou seja, $5 \mathrm{~g} / \mathrm{L}$ foram consumidos e foram produzidos $4 \mathrm{~g} / \mathrm{L}$ de lactato e $1 \mathrm{~g} / \mathrm{L}$ de acetato (Figura 27).

Figura 27 - Produção de lactato, acetato e biomassa em cultivo descontínuo em reator com meio M4S 10

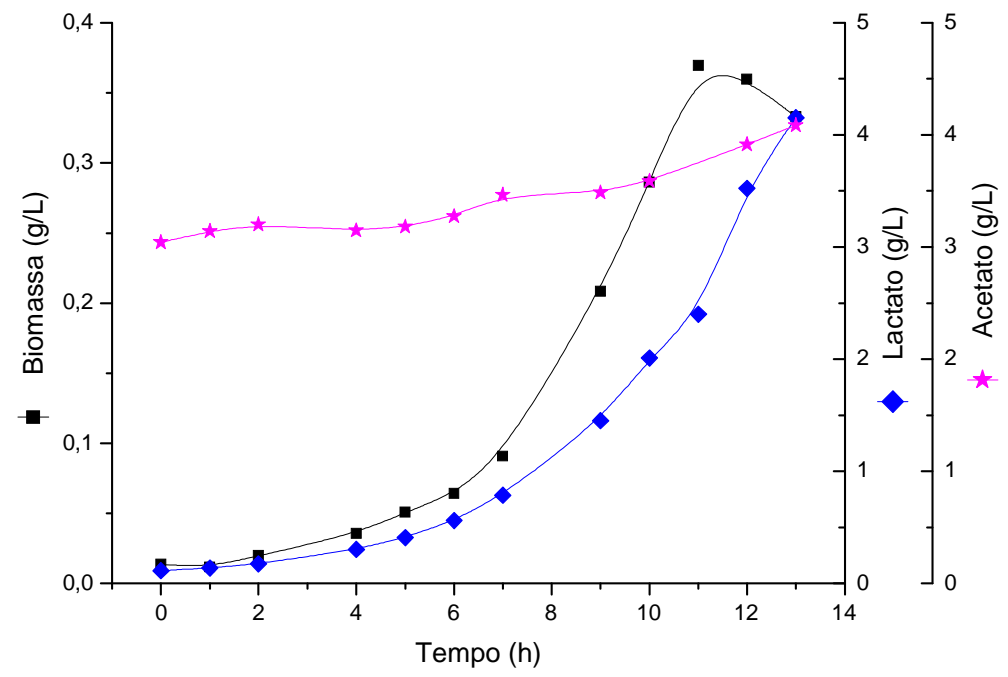


5.1.7 Cultivo em meio definido com retirada de aminoácidos e vitaminas contendo $20 \mathrm{~g} / \mathrm{L}$ de sacarose inicial (M4S20)

Um cultivo utilizando $20 \mathrm{~g} / \mathrm{L}$ de sacarose ao invés de $10 \mathrm{~g} / \mathrm{L}$ foi realizado a fim de avaliar se a concentração de sacarose exerceria efeito sobre a biomassa e a produção de PS14. Na Figura 28, observa-se que o consumo de sacarose foi um pouco maior com sacarose 20 $\mathrm{g} / \mathrm{L}(6 \mathrm{~g} / \mathrm{L})$ dando origem também a quantidade um pouco maior de lactato $(4,5 \mathrm{~g} / \mathrm{L}$, Figura 29). A biomassa alcançada $(0,42 \mathrm{~g} / \mathrm{L})$ foi apenas $0,05 \mathrm{~g} / \mathrm{L}$ maior do que no cultivo contendo sacarose $10 \mathrm{~g} / \mathrm{L}$ como fonte de carbono $(0,37 \mathrm{~g} / \mathrm{L})$. O tempo de cultivo foi de 14 horas, uma hora a mais que em cultivo utilizando sacarose $10 \mathrm{~g} / \mathrm{L}$, chegando à fase estacionária após 12 horas de cultivo. A produção de PS14 $\mathrm{C}$ chegou a $96 \mathrm{mg} / \mathrm{L}$ e foi maior que no cultivo anterior (66 mg/L), enquanto que o PS14 ${ }_{\mathrm{L}}$ foi semelhante, alcançando $158 \mathrm{mg} / \mathrm{L}$ comparados aos 154 $\mathrm{mg} / \mathrm{L}$ do cultivo anterior. Houve uma pequena produção de acetato durante o cultivo $(1 \mathrm{~g} / \mathrm{L})$ chegando a um máximo de 4 g/L (Figura 29).

Figura 28 - Produção de biomassa, PS14 1 , PS14 , e sacarose residual em cultivo descontínuo em reator com meio M4S20

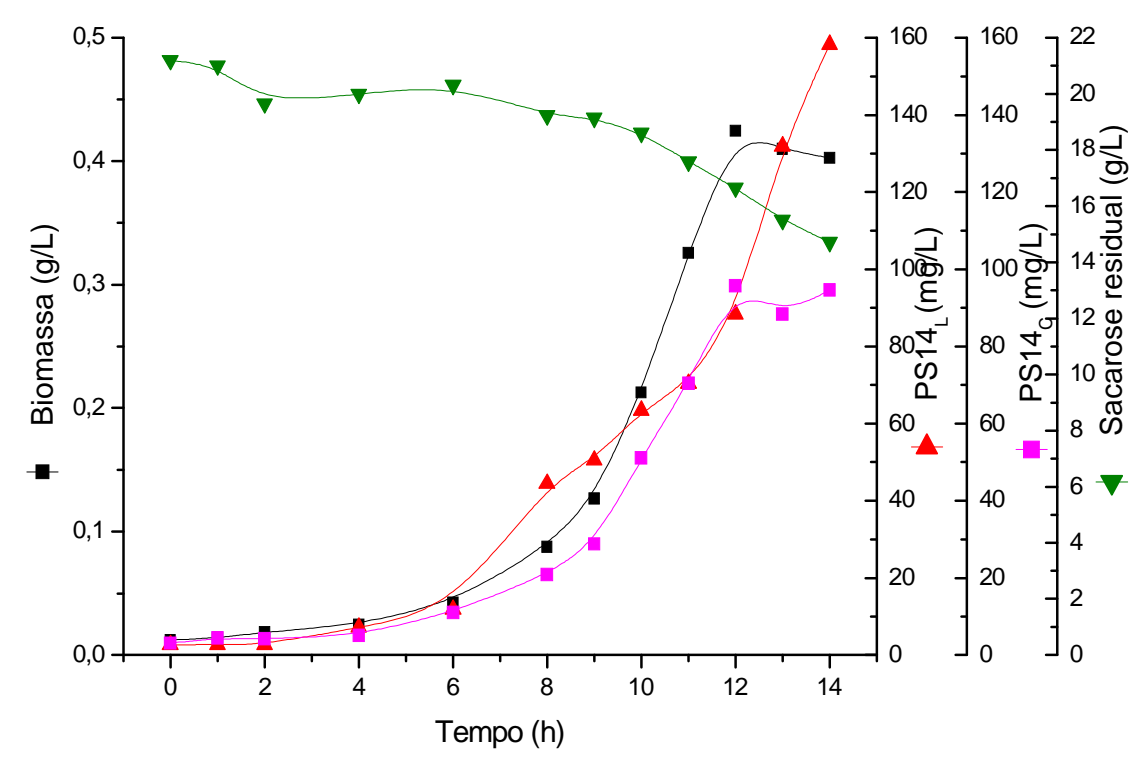


Figura 29 - Produção de lactato, acetato e biomassa em cultivo descontínuo em reator com meio M4S20

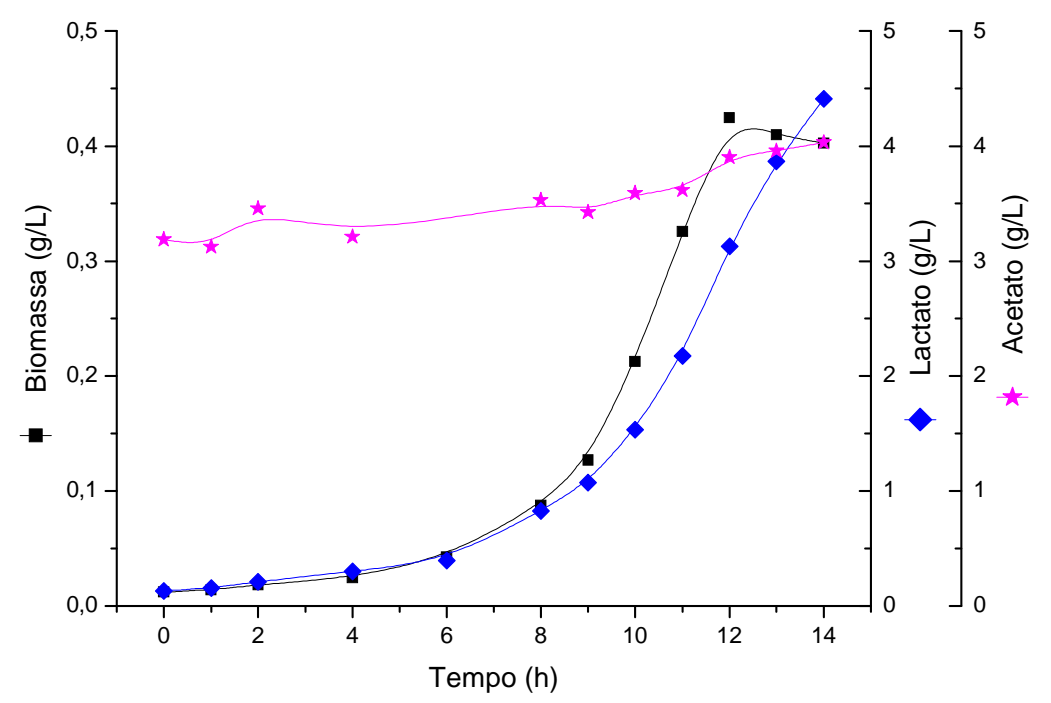

A principal diferença entre os cultivos M4S10 e M4S20, foi a produção de PS14 devido à maior produção de PS14 $\mathrm{C}$ em cultivo com sacarose $20 \mathrm{~g} / \mathrm{L}$ (M4S20), que fez com que a produção de PS14 fosse $14 \%$ maior (254 mg/L comparado a $220 \mathrm{mg} / \mathrm{L}$ ).

Após este experimento, testou-se a glicose e a frutose simultaneamente no meio de cultura para avaliar se haveria alguma diferença no transporte destes açúcares para o interior da célula comparado à sacarose.

5.1.8 Cultivo em meio definido com retirada de aminoácidos e vitaminas contendo $10 \mathrm{~g} / \mathrm{L}$ de glicose e $10 \mathrm{~g} / \mathrm{L}$ de frutose (M4G10F10)

As fontes de carbono glicose e frutose foram adicionadas ao meio de cultura na concentração de $10 \mathrm{~g} / \mathrm{L}$ cada a fim de se desvendar se seria mais vantajoso à célula transportar os açúcares separadamente ou transportar a sacarose e só então hidrolisá-la em glicose e frutose.

Na Figura 30, observa-se que glicose e frutose foram consumidas ao mesmo tempo, indicando que entre elas não há uma fonte preferencial de carbono, portanto não ocorre o fenômeno da repressão catabólica entre estes dois açúcares. Tanto para glicose quanto para frutose, restaram cerca de $5 \mathrm{~g} / \mathrm{L}$ no reator, portanto foram consumidas $5 \mathrm{~g} / \mathrm{L}$ de glicose e $5 \mathrm{~g} / \mathrm{L}$ de frutose. Vê-se que a biomassa foi maior comparada aos cultivos utilizando sacarose (M4S10 e M4S20) chegando a 0,69 g/L de massa seca. Quanto à produção de PS14, nota-se 
que PS14 1 chegou somente a $74 \mathrm{mg} / \mathrm{L}$ e PS14 $\mathrm{C}$ a $51 \mathrm{mg} / \mathrm{L}$, menor do que nos cultivos utilizando sacarose $10 \mathrm{~g} / \mathrm{L}$ (M4S10) ou $20 \mathrm{~g} / \mathrm{L}$ (M4S20).

A produção de lactato alcançou $5 \mathrm{~g} / \mathrm{L}$ e de acetato partiu de $1 \mathrm{~g} / \mathrm{L}$ até 3,5 g/L como pode ser visto na Figura 31.

Figura 30 - Produção de biomassa, PS14 $4_{L}, P S 14_{C}$, glicose e frutose residual em cultivo descontínuo em reator com meio M4G10F10

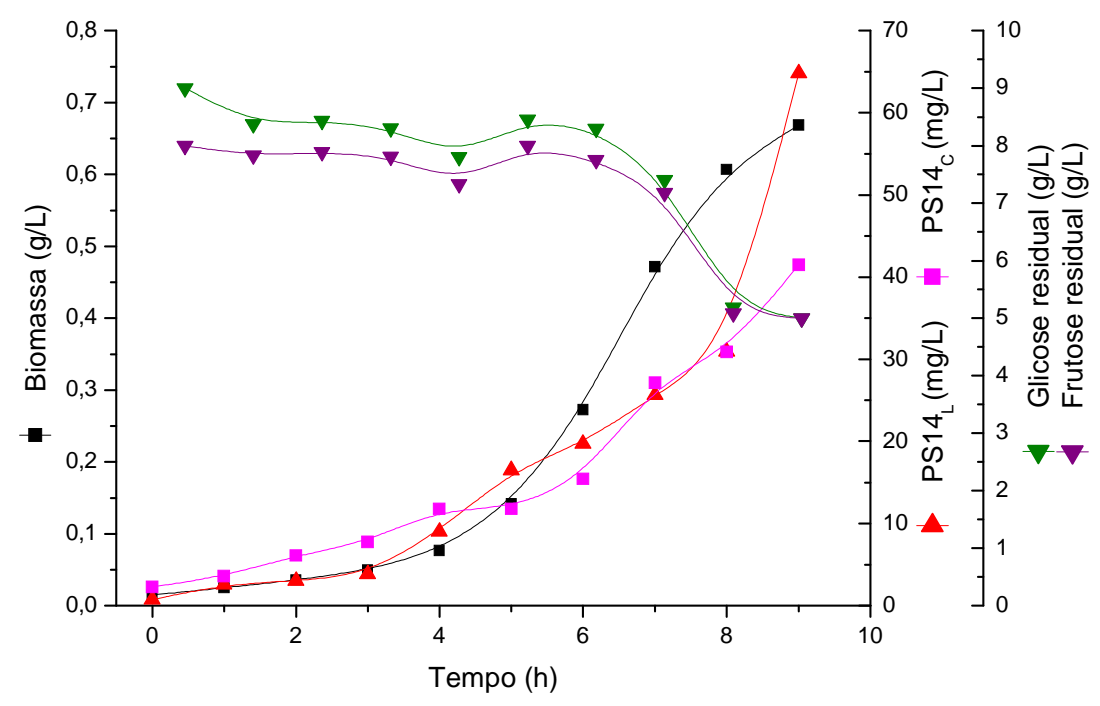

Figura 31 - Produção de lactato, acetato e biomassa em cultivo descontínuo em reator com meio M4G10F10

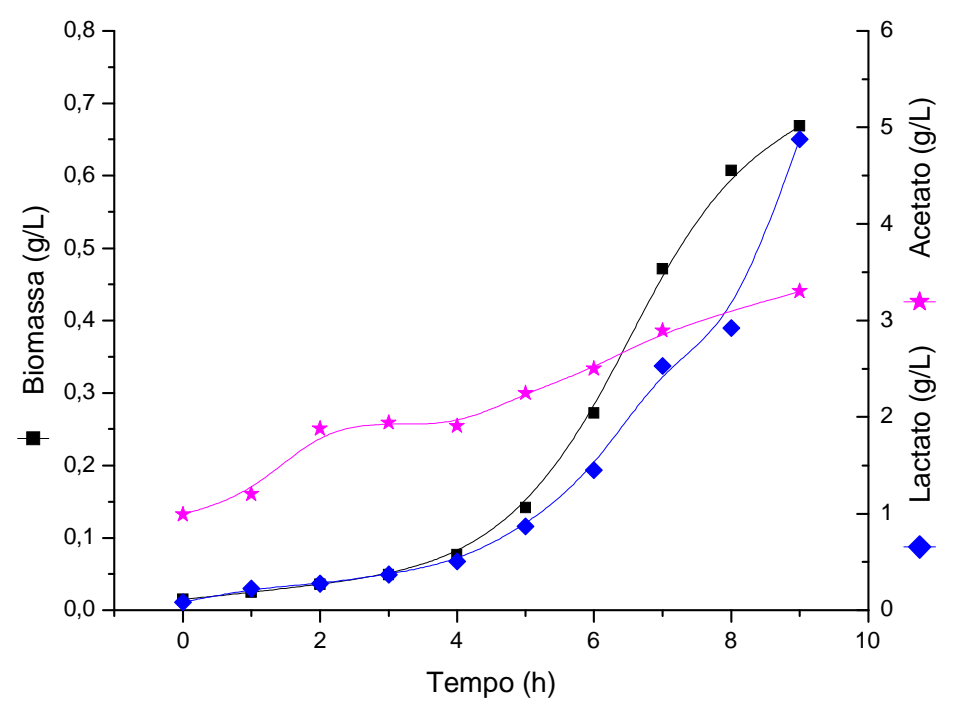


No cultivo utilizando sacarose $10 \mathrm{~g} / \mathrm{L}$ em meio completo (CS10) verificou-se através da análise por CLAE que não havia glicose nem frutose residuais, o que confirma a hipótese de que a sacarose é internalizada na forma de dissacarídeo, através dos transportadores previamente descritos por Iyer e Camilli (2007), e só dentro da célula é hidrolisada a glicose e frutose. Como o Streptococcus pneumoniae também possui um transportador para a frutose (TETTELIN et al., 2001), este experimento foi feito com o objetivo de saber se, caso a glicose e frutose fossem fornecidas diretamente, haveria algum impacto positivo na biomassa e na produção de PS14. Observando a baixa produção de PS14 neste experimento, concluiu-se que é mais vantajoso para célula internalizar a sacarose em forma de dissacarídeo e só então clivála em um monossacarídeo livre e um monossacarídeo fosfato (SALMINEN et al., 2004).

Através de uma pesquisa na base de dados KEGG (2013), verificou-se que quando a sacarose é transportada através dos transportadores chamados sus ou src e clivada dentro da célula em frutose e glicose, esta frutose segue um caminho diferente do que a frutose quando adicionada em sua forma livre. Os esquemas abaixo reproduzem resumidamente o fluxograma do KEGG e demonstram que a frutose derivada da sacarose segue um caminho em que o produto final é a UDP-glicose, que por sua vez é um precursor dos açúcares que compõe o PS14, o que explicaria a maior quantidade de PS14 formada usando sacarose como fonte de carbono. A frutose adicionada livremente é transportada pelo PTS-Fru e segue pelo caminho convencional, a via glicolítica, para produção de energia e biomassa.

Figura 32 - Esquema da via metabólica da frutose até o PS14, após sacarose ser transportada para dentro da célula.

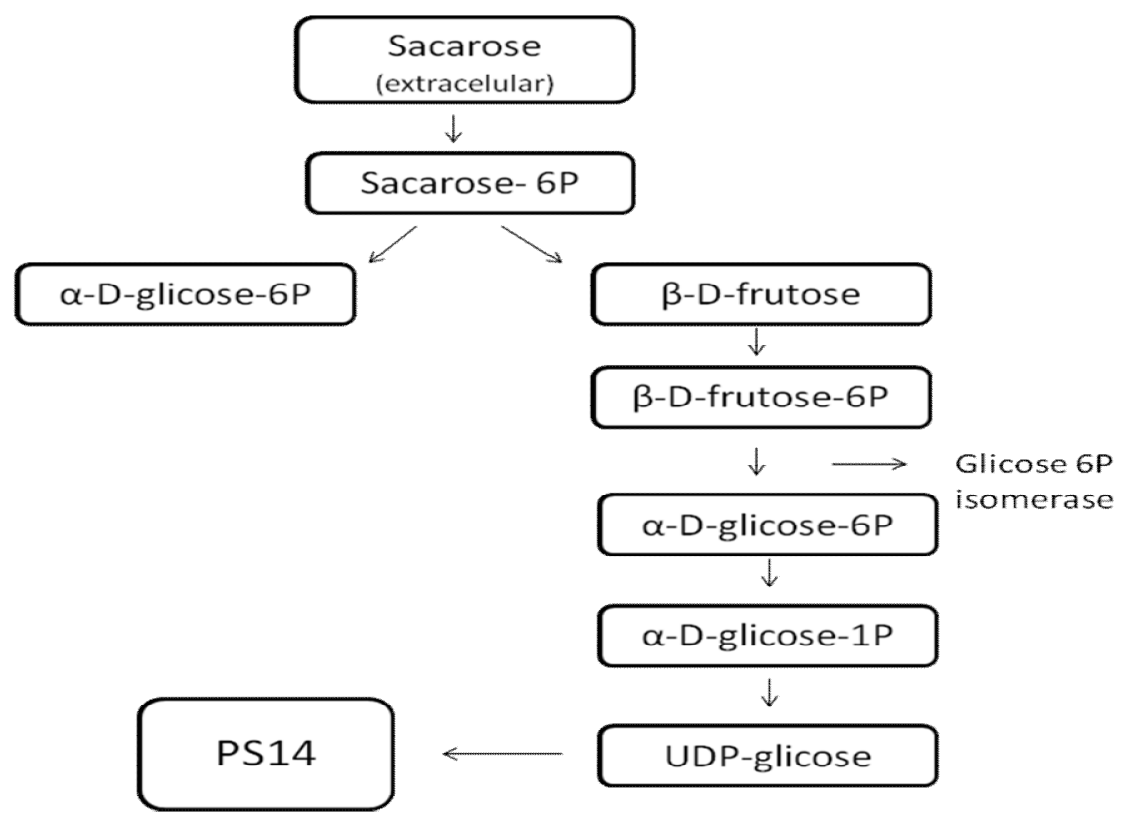


Figura 33 - Esquema da via metabólica da frutose até a glicólise, após frutose ser transportada para dentro da célula.

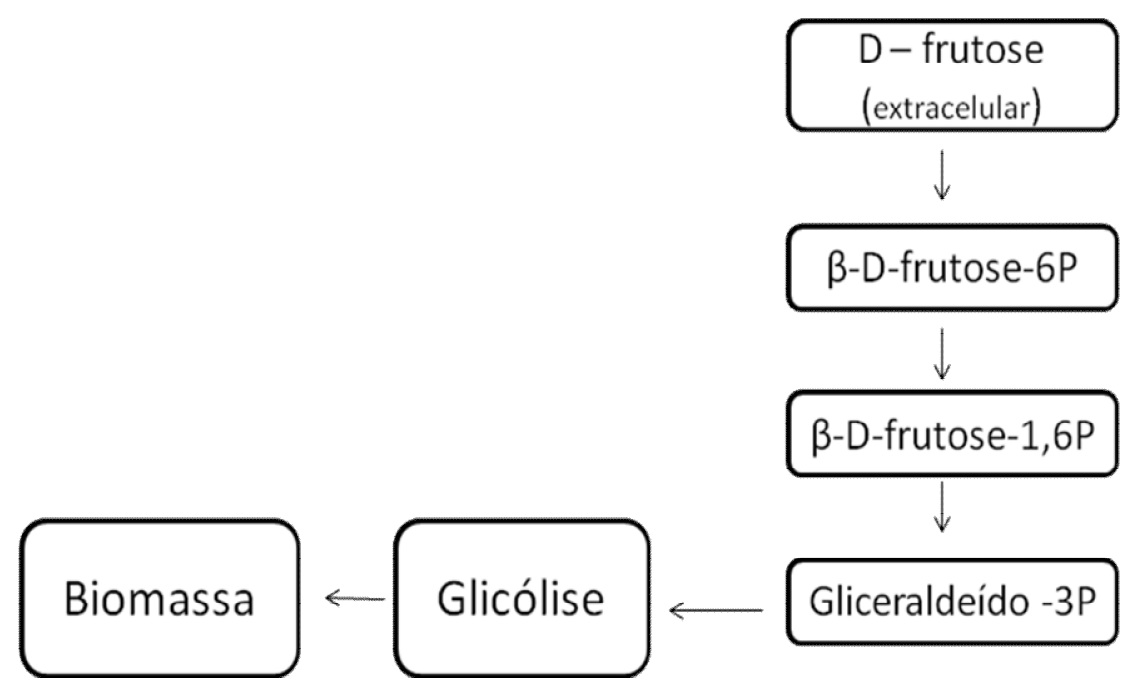

Analisando estes esquemas e também o resultado obtido, chegou-se a conclusão que a sacarose deveria continuar sendo utilizada nos demais experimentos, pois apesar da menor biomassa, a produção de PS14 alcançou valores elevados. O próximo passo foi avaliar o aumento da concentração de alguns aminoácidos que permaneceram no meio de cultura sobre a produção de biomassa e PS14.

5.1.9 Cultivo em meio definido com retirada de aminoácidos e vitaminas contendo $20 \mathrm{~g} / \mathrm{L}$ de sacarose inicial e o dobro dos aminoácidos glicina, isoleucina, leucina, valina e três vezes glutamina (M5S20)

Neste cultivo, a ideia inicial foi aumentar a concentração de alguns aminoácidos que permaneceram no meio de cultura com o objetivo de elaborar um novo meio definido, usando sacarose como fonte de carbono e a mesma quantidade de nitrogênio do meio completo original. Para que a quantidade de nitrogênio ficasse igual ao cultivo com meio de cultura completo, os aminoácidos foram acrescentados em maiores concentrações com base em uma análise de aminoácidos feita por CLAE (coluna PICO-TAG). Através desta análise, verificouse que os aminoácidos isoleucina, leucina e valina foram os mais consumidos no meio de cultura completo, o consumo em relação à quantidade inicial foi $48 \%$, $32 \%$ e $29 \%$ respectivamente. Baseado no fato de que glutamina e glicina são precursores importantes de outros aminoácidos no metabolismo do pneumocco, tais como o ácido aspártico e a serina (HARTEL et al., 2011), suas concentrações também foram aumentadas neste experimento. $\mathrm{O}$ 
experimento foi realizado em duplicata e a composição final do meio está descrita na Tabela 6.

Observa-se na Figura 34 que, assim como visto para os outros experimentos utilizando sacarose como fonte de carbono, o crescimento do pneumococco foi muito lento, levando 14 horas comparado às 9 horas utilizando glicose como fonte de carbono. Apesar disso, obtevese uma biomassa de 0,82 $\mathrm{g} / \mathrm{L}$, o dobro dos $0,41 \mathrm{~g} / \mathrm{L}$ em cultivo utilizando sacarose $20 \mathrm{~g} / \mathrm{L}$ e ausência de aminoácidos e vitaminas (M4S20). A produção de PS14 apresentou valores bem maiores que em cultivo sem o acréscimo dos aminoácidos (M4S20) e a produção de PS14 $4_{L}$ também foi maior que em cultivo com meio completo (CS10) utilizando sacarose $10 \mathrm{~g} / \mathrm{L}$, chegando a $337 \mathrm{mg} / \mathrm{L}$ enquanto que o PS14 $\mathrm{C}$ chegou a $104 \mathrm{mg} / \mathrm{L}$. Assim, a produção de PS14 foi de $441 \mathrm{mg} / \mathrm{L}$, ainda maior que os $368 \mathrm{mg} / \mathrm{L}$ produzidos em meio completo (CS10) com sacarose (Tabela 5). O consumo de sacarose foi de 12,7 $\mathrm{g} / \mathrm{L}$, bem maior que em cultivo utilizando também $20 \mathrm{~g} / \mathrm{L}$ de sacarose e sem o acréscimo dos aminoácidos remanescentes no meio (M4S20), onde o consumo de sacarose foi de apenas $6 \mathrm{~g} / \mathrm{L}$ (Figura 28).

A produção de lactato chegou a $9 \mathrm{~g} / \mathrm{L}$, enquanto que cerca de $1 \mathrm{~g} / \mathrm{L}$ de acetato foram produzidos, indo de $4 \mathrm{~g} / \mathrm{L}$ para $5 \mathrm{~g} / \mathrm{L}$ (Figura 35).

Figura 34 - Produção de biomassa, PS14 $4_{L}$, PS14 $_{C}$, sacarose residual em cultivo descontínuo em reator com meio M5S20

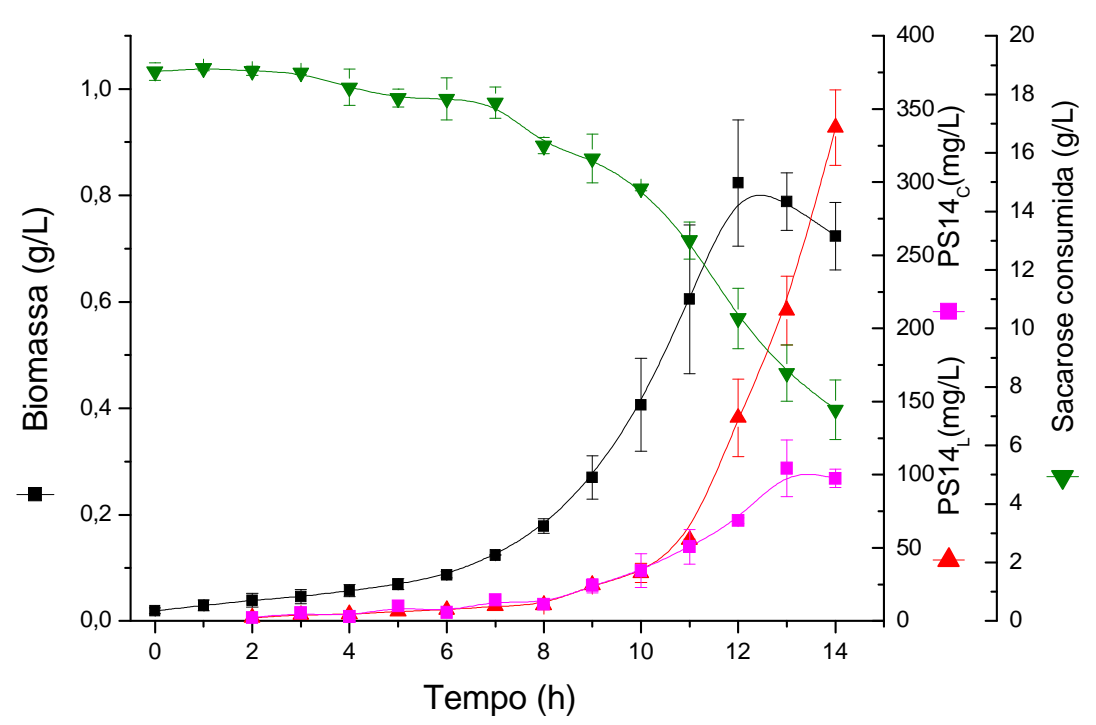


Figura 35 - Produção de lactato, acetato e biomassa em cultivo descontínuo em reator com meio M5S20

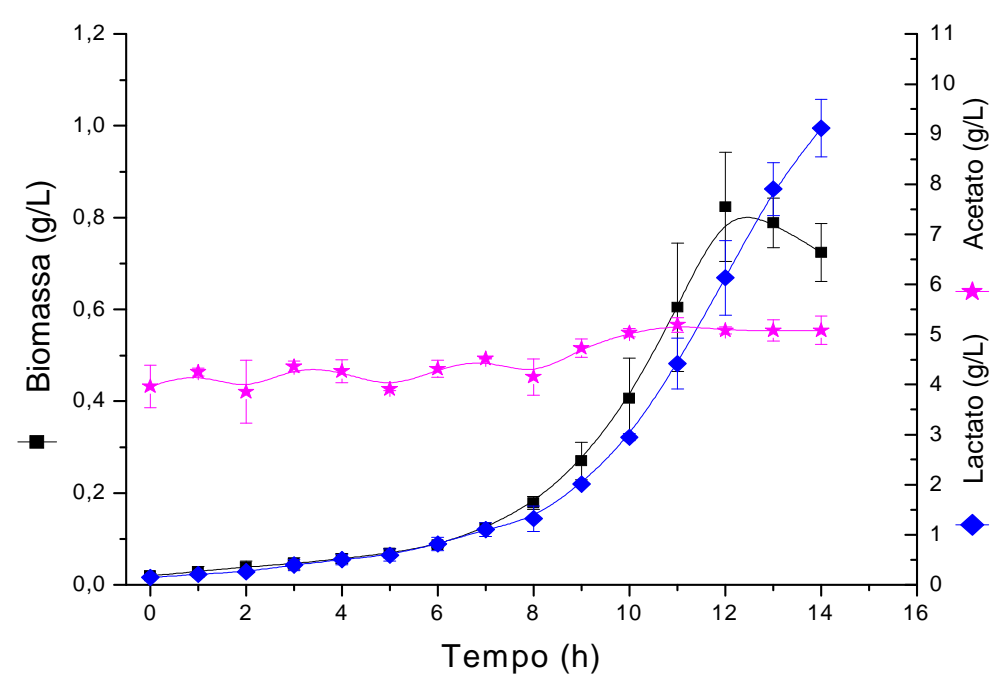

De acordo com estudos feitos por Lahtvee et al. (2011), a glutamina foi o aminoácido mais consumido pela bactéria Lactococcus lactis em cultivo contínuo, representando $50 \%$ do total de nitrogênio consumido na vazão $0,6 \mathrm{~h}^{-1}$, a glutamina é usada para síntese de proteínas relacionadas a biomassa e é doadora de aminogrupos para as bases nitrogenadas e vias de produção de aminoaçúcares. A manutenção de altas concentrações intracelulares de glutamina pode ser necessária para manter a transferência de aminogrupos efetiva (LAHTVEE et al., 2011).

Abaixo estão representados os parâmetros dos cultivos realizados com sacarose como fonte de carbono e com glicose e frutose em cultivo com ausência de aminoácidos e vitaminas. 
Tabela 5 - Parâmetros dos cultivos M4S10, M4S20, M4G10F10, M5S20 comparados ao meio completo (CS10)

\begin{tabular}{|c|c|c|c|c|c|}
\hline Parâmetros & M4S10 & M4S20 & M4G10F10 & M5S20 & CS10 \\
\hline $\mathrm{X}_{\text {máx }}(\mathrm{g} / \mathrm{L})$ & 0,37 & 0,42 & 0,69 & 0,82 & 1,31 \\
\hline$\mu$ máx $\left(h^{-1}\right)^{*}$ & 0,345 & 0,371 & 0,499 & 0,415 & 0,627 \\
\hline PS14 L máx $(m g / L)$ & 154 & 158 & 74 & 337 & 228 \\
\hline $\operatorname{PS} 14_{C \text { máx }}(\mathrm{mg} / \mathrm{L})$ & 66 & 96 & 51 & 104 & 140 \\
\hline $\operatorname{PS} 14_{\text {Total máx }}(\mathrm{mg} / \mathrm{L})$ & 220 & 254 & 125 & 441 & 368 \\
\hline $\mathrm{Y}_{\mathrm{X} / \mathrm{S}}\left(\mathrm{g}_{\text {célula }} / \mathrm{g}_{\text {glicose }}\right)$ & 0,108 & 0,092 & - & 0,061 & 0,116 \\
\hline $\mathrm{Y}_{\mathrm{PS} 14 \mathrm{~L} / \mathrm{S}}\left(\mathrm{mg}_{\mathrm{ps} 14} / \mathrm{g}_{\text {glicose }}\right)$ & 36,1 & 36,9 & - & 28,9 & 23,3 \\
\hline $\mathrm{Y}_{\mathrm{PS} 14 \mathrm{~L} / \mathrm{X}}\left(\mathrm{mg}_{\mathrm{ps} 14} / \mathrm{g}_{\text {célulal }}\right)$ & 476,6 & 398,4 & 108,8 & 481,2 & 201,5 \\
\hline $\mathrm{Y}_{\mathrm{PS} 14 \mathrm{C} / \mathrm{S}}\left(\mathrm{mg}_{\mathrm{ps} 14} / \mathrm{g}_{\mathrm{glicose}}\right)$ & 15,3 & 21,7 & - & 8,3 & 14,0 \\
\hline $\mathrm{Y}_{\mathrm{PS} 14 \mathrm{C} / \mathrm{X}}\left(\mathrm{mg}_{\mathrm{ps} 14} / \mathrm{g}_{\text {célulala }}\right)$ & 201,4 & 234,2 & 71,6 & 137,9 & 106,1 \\
\hline $\mathrm{Y}_{\text {LS }}\left(\mathrm{g}_{\text {lactato }} / \mathrm{g}_{\text {glicose }}\right)$ & 0,96 & 1,01 & - & 0,766 & 0,89 \\
\hline $\mathrm{Q}_{\mathrm{x}}\left(\mathrm{g}_{\text {célulala }} \mathrm{L}^{-1} \cdot \mathrm{h}^{-1}\right)^{*}$ & 0,03 & 0,04 & 0,07 & 0,05 & 0,135 \\
\hline $\mathrm{Q}_{\mathrm{PS} 14 \mathrm{~L}}\left(\mathrm{mg}_{\left.\mathrm{ps} 14 \cdot \mathrm{L}^{-1} \cdot \mathrm{h}^{-1}\right)}\right.$ & 13,8 & 14,1 & 7,4 & 17,2 & 26,0 \\
\hline $\mathrm{Q}_{\mathrm{PS} 14 \mathrm{C}}\left(\mathrm{mg}_{\mathrm{ps} 14 \cdot} \mathrm{L}^{-1} \cdot \mathrm{h}^{-1}\right)$ & 5,9 & 8,3 & 4,8 & 6,7 & 20,3 \\
\hline
\end{tabular}

De acordo com a Tabela 5, o cultivo M5S20 apresentou maior biomassa em comparação com os outros cultivos com meios modificados, porém apresentou menor biomassa em relação ao meio completo CS10. A produção de $\mathrm{PS} 14_{\mathrm{L}}$ foi maior que em todos os experimentos, até mesmo que nos experimentos utilizando glicose como fonte de carbono (Tabela 4). A produção de PS14 $\mathrm{C}$ também foi alta, perdendo somente para o cultivo com meio completo e $20 \mathrm{~g} / \mathrm{L}$ de glicose (CG20).

Em relação aos parâmetros, o fator de conversão substrato em PS14 foi menor em cultivo com meio M5S20 mesmo com alta produção de PS14 devido ao elevado consumo de

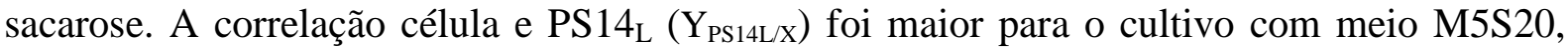
pois uma menor concentração de biomassa deu origem a maior concentração de PS14 livre no sobrenadante. Em relação à produtividade de PS14 , o cultivo com meio M5S20 apresentou valores maiores do que os demais cultivos com meio modificado e menor somente do que o cultivo com sacarose e meio completo (CS10) devido ao maior tempo de cultivo.

De acordo com esse resultado, um novo meio de cultura foi desenvolvido para cultivo de Streptococcus pneumoniae e produção de PS14, contendo sacarose como fonte de carbono no lugar da glicose e 34 dos 48 componentes do meio descrito por Van der Rjin e Kessler 
(1980), ou seja, com 14 componentes a menos, além de concentração 2 vezes maior de glicina, isoleucina, leucina e valina e 3 vezes maior de glutamina (Tabela 6).

Mais estudos precisam ser realizados com o objetivo de diminuir o tempo de cultivo utilizando sacarose como fonte de carbono, aumentar a biomassa e, consequentemente, a produção de PS14. Uma alternativa seria o uso da técnica de batelada alimentada, onde o cultivo se iniciaria com concentração baixa de sacarose e uma solução de sacarose seria alimentada durante o cultivo podendo assim gerar uma maior biomassa e aumentar ainda mais a produção de PS14, além disso, com a diminuição da concentração de sacarose no inicio do experimento poderia diminuir a fase lag, pois a sacarose em elevada concentração no início do experimento poderia estar resultando em inibição por substrato.

Tabela 6 - Composição do meio M5S20

\begin{tabular}{|c|c|c|c|c|c|}
\hline Reagente & $\mathrm{g} / \mathrm{L}$ & Reagente & $\mathrm{g} / \mathrm{L}$ & Reagente & $\mathrm{mg} / \mathrm{L}$ \\
\hline L-Glutamina & 0,6 & $\mathrm{NaHCO}_{3}$ & 2,5 & Piridoxal $\mathrm{HCl}$ & 1 \\
\hline L-Isoleucina & 0,2 & $\mathrm{Na}_{2} \mathrm{HPO}_{4}$ & 7,35 & Biotina & 0,2 \\
\hline L-Leucina & 0,4 & $\mathrm{NaH}_{2} \mathrm{PO}_{4} \cdot \mathrm{H}_{2} \mathrm{O}$ & 3,195 & Nicotinamida & 10 \\
\hline Glicina & 0,4 & Acetato de Sódio & 4,5 & Tiamina $\mathrm{HCl}$ & 2 \\
\hline L-Valina & 0,2 & $\mathrm{KH}_{2} \mathrm{PO}_{4}$ & 0,2 & Ácido pantotenico & 4 \\
\hline L-Cistina & 0,05 & $\mathrm{~K}_{2} \mathrm{PO}_{4}$ & 1 & Colina & 25 \\
\hline L-Metionina & 0,1 & $\mathrm{MgSO}_{4} \cdot 7 \mathrm{H}_{2} \mathrm{O}$ & 0,7 & $\mathrm{CaCl}_{2} \cdot 2 \mathrm{H}_{2} \mathrm{O}$ & 6,7 \\
\hline L-Histidina $\mathrm{HCl} \mathrm{H}_{2} \mathrm{O}$ & 0,14 & Sacarose & 20 & $\mathrm{Fe}\left(\mathrm{NO}_{3}\right)_{3} \cdot 9 \mathrm{H}_{2} \mathrm{O}$ & 1 \\
\hline L-Ácido Glutâmico & 0,1 & & & $\mathrm{FeSO}_{4} \cdot 7 \mathrm{H}_{2} \mathrm{O}$ & 5 \\
\hline L-Prolina & 0,2 & & & $\mathrm{MnSO}_{4} \cdot \mathrm{H}_{2} \mathrm{O}$ & 5,6 \\
\hline L-Arginina $\mathrm{HCl}$ & 0,12 & & & Adenina Sulfato & 38,3 \\
\hline L-Hidroxiprolina & 0,2 & & & Guanina $\mathrm{HCl}$ & 27,3 \\
\hline Cisteína & 0,5 & & & Uracil & 22 \\
\hline
\end{tabular}




\subsection{Cultivos contínuos}

\subsubsection{Determinação da vazão específica de alimentação mais adequada para produção} de PS14

Neste experimento, realizado com o meio de cultura com retirada de vitaminas e 10 $\mathrm{g} / \mathrm{L}$ de glicose (M1G10), o objetivo foi testar quatro vazões específicas de alimentação $(0,15$ $\mathrm{h}^{-1}, 0,3 \mathrm{~h}^{-1}, 0,4 \mathrm{~h}^{-1}$ e $0,5 \mathrm{~h}^{-1}$ ) para saber qual a melhor quanto à produção de PS14. A Figura 36 mostra as variáveis biomassa, PS14 $\mathrm{L}, \mathrm{PS} 14_{\mathrm{C}}$ e PS14 $\mathrm{T}$ em função de D. Cada ponto é a média de quatro pontos obtidos no estado estacionário após no mínimo sete tempos de residência. Vê-se que a biomassa foi menor com vazão menor e aumentou à medida que se aumentou a vazão, caindo quando se aproximou da velocidade máxima de crescimento ( $\mu_{\text {máx }}$ ). Este comportamento era esperado já que em $0,5 \mathrm{~h}^{-1}$ a vazão específica está próxima ao valor de

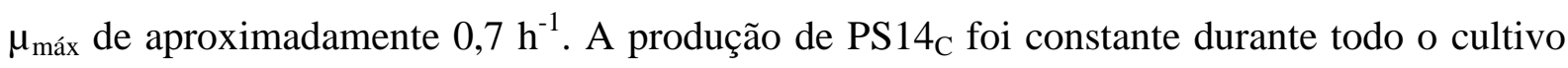
independente da vazão de alimentação, o PS14 ${ }_{\mathrm{L}}$ foi maior no menor D alcançando $114 \mathrm{mg} / \mathrm{L}$.

Figura 36 - Produção de biomassa, PS14 $4_{\mathrm{L}}, \mathrm{PS} 14_{\mathrm{C}}$ e PS14 $\mathrm{T}$ em cultivo contínuo em reator e meio M1G10 variando as vazões específicas de alimentação de 0,15 a $0,5 \mathrm{~h}^{-1}$.

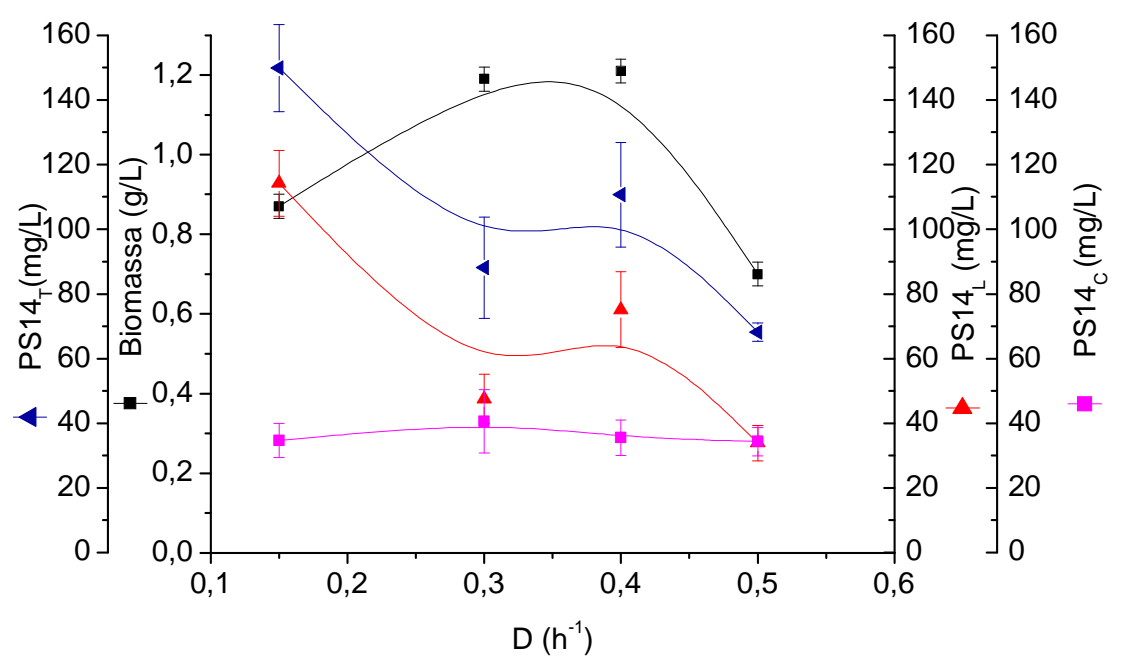

A Figura 37 ilustra a glicose residual junto com a produção de lactato e acetato. Percebe-se que nas três primeiras vazões $\left(0,15 \mathrm{~h}^{-1}, 0,3 \mathrm{~h}^{-1}, 0,4 \mathrm{~h}^{-1}\right)$ a glicose foi consumida totalmente e somente em $0,5 \mathrm{~h}^{-1}$ foi observada uma concentração de glicose residual de 3,43 $\mathrm{g} / \mathrm{L}$, isto também pode ter ocorrido devido à proximidade do $\mu_{\text {máx }}$, onde $\mathrm{S}$ residual tende ao 
infinito, ou seja, ao maior valor possível, que neste cultivo foi $10 \mathrm{~g} / \mathrm{L}$. A produção de lactato acompanhou a biomassa alcançando o máximo de $6,23 \mathrm{~g} / \mathrm{L} \mathrm{em} \mathrm{D}=0,4 \mathrm{~h}^{-1}$, o que era esperado já que o lactato é o produto principal do metabolismo primário do Streptococcus pneumoniae. A produção de acetato foi maior com o menor D e diminuiu com o decorrer do cultivo. Segundo Lahtvee et al. (2011), em cultivo com Lactococcus lactis a formação de acetato é maior em $\mu$ menores que $0,4 \mathrm{~h}^{-1}$.

Figura 37 - Produção de biomassa, glicose residual, lactato e acetato em cultivo contínuo em reator e meio M1G10 variando as vazões específicas de alimentação de $0,15 \mathrm{~h}^{-1}$ a $0,5 \mathrm{~h}^{-1}$.

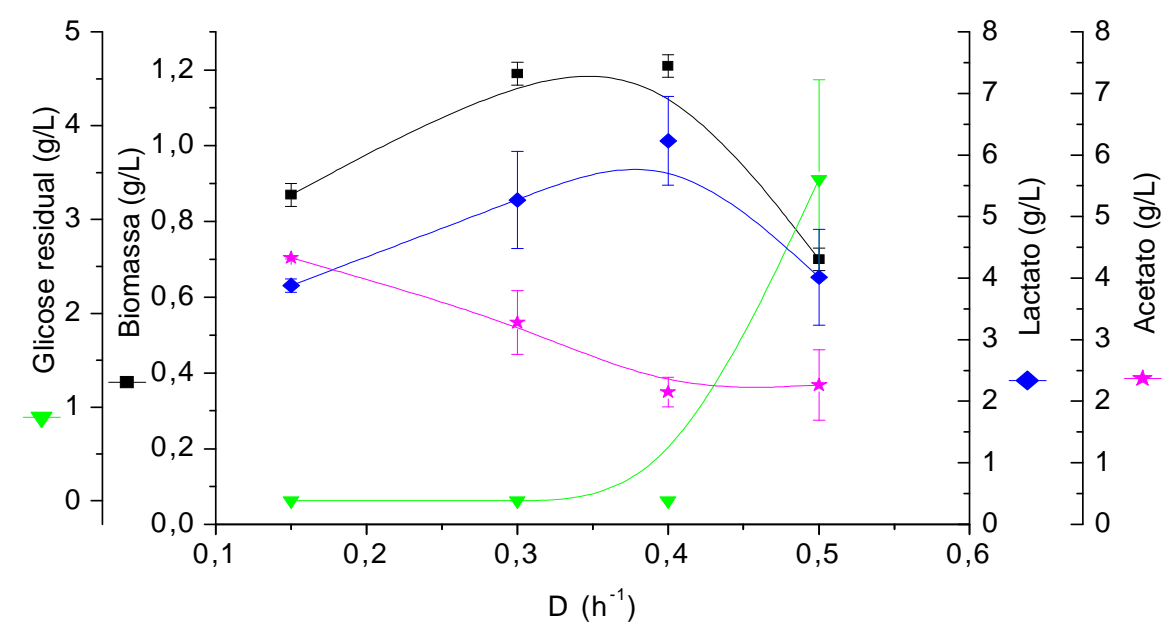

Observa-se na Tabela 7 que a maior produção de PS14 $(149 \mathrm{mg} \pm 11 \mathrm{mg}$ ) foi obtida com a menor vazão de $0,15 \mathrm{~h}^{-1}$ assim como os fatores de conversão glicose em $\operatorname{PS}_{14}(14,99$ $\mathrm{mg} / \mathrm{g})$ e célula em PS14 $\mathrm{T}(172,46 \mathrm{mg} / \mathrm{g})$ foram maiores nesta vazão, porém, quando olhamos a produtividade em PS14 $\mathrm{T}$ a melhor vazão é $0,4 \mathrm{~h}^{-1}$ produzindo um total de 44,3 mg de PS14 por litro/hora. 
Tabela 7 - Parâmetros do cultivo contínuo alterando as vazões específicas de alimentação

\begin{tabular}{|c|c|c|c|c|}
\hline \multirow[t]{2}{*}{ Parâmetros } & \multicolumn{3}{|c|}{$\mathbf{D}\left(\mathrm{h}^{-1}\right)$} & \multirow[b]{2}{*}{0,5} \\
\hline & $\mathbf{0 , 1 5}$ & $\mathbf{0 , 3}$ & $\mathbf{0 , 4}$ & \\
\hline biomassa $(\mathrm{g} / \mathrm{L})$ & $0,87 \pm 0,03$ & $1,19 \pm 0,03$ & $1,21 \pm 0,03$ & $0,70 \pm 0,03$ \\
\hline glicose residual (g/L) & 0,00 & 0,00 & 0,00 & $3,43 \pm 1,06$ \\
\hline PS14_(mg/L) & $114 \pm 10$ & $48 \pm 7$ & $75 \pm 11$ & $34 \pm 5$ \\
\hline $\mathrm{PS} 14_{\mathrm{C}}(\mathrm{mg} / \mathrm{L})$ & $35 \pm 5$ & $41 \pm 10$ & $35 \pm 5$ & $34 \pm 4$ \\
\hline $\mathrm{PS}_{14}(\mathrm{mg} / \mathrm{L})$ & $149 \pm 11$ & $88 \pm 12$ & $110 \pm 13$ & $68 \pm 7$ \\
\hline lactato $(\mathrm{g} / \mathrm{L})$ & $3,88 \pm 0,11$ & $5,27 \pm 0,79$ & $6,23 \pm 0,72$ & $4,01 \pm 0,78$ \\
\hline acetato $(\mathrm{g} / \mathrm{L})$ & $4,33 \pm 0,02$ & $3,28 \pm 0,52$ & $2,15 \pm 0,24$ & $2,26 \pm 0,57$ \\
\hline $\mathrm{Y}_{\mathrm{X} / \mathrm{S}}\left(\mathrm{g}_{\text {célula }} / \mathrm{g}_{\text {glicose }}\right)$ & 0,09 & 0,12 & 0,12 & 0,11 \\
\hline $\mathrm{Y}_{\mathrm{PS} 14 \mathrm{~L} / \mathrm{S}}\left(\mathrm{mg}_{\mathrm{ps} 14} / \mathrm{g}_{\mathrm{glicose}}\right)$ & 11,4 & 4,75 & 7,52 & 5,15 \\
\hline $\mathrm{Y}_{\mathrm{PS} 14 \mathrm{~L} / \mathrm{X}}\left(\mathrm{mg}_{\mathrm{ps} 14} / \mathrm{g}_{\text {célula }}\right)$ & 131 & 40 & 62 & 48 \\
\hline $\mathrm{Y}_{\mathrm{PS} 14 \mathrm{C} / \mathrm{S}}\left(\mathrm{mg}_{\mathrm{ps} 14} / \mathrm{g}_{\mathrm{glicose}}\right)$ & 3,47 & 4,06 & 3,55 & 5,22 \\
\hline $\mathrm{Y}_{\mathrm{PS} 14 \mathrm{C} / \mathrm{X}}\left(\mathrm{mg}_{\mathrm{ps} 14} / \mathrm{g}_{\text {célula }}\right)$ & 39,9 & 34,0 & 29,4 & 49,0 \\
\hline $\mathrm{Y}_{\mathrm{PS} 14 \mathrm{~T} / \mathrm{S}}\left(\mathrm{mg}_{\mathrm{ps} 14} / \mathrm{g}_{\mathrm{glicose}}\right)$ & 15,0 & 8,8 & 11,1 & 10,4 \\
\hline $\mathrm{Y}_{\mathrm{PS} 14 \mathrm{~T} / \mathrm{X}}\left(\mathrm{mg}_{\mathrm{ps} 14} / \mathrm{g}_{\text {célula }}\right)$ & 172 & 74 & 91 & 97 \\
\hline $\mathrm{Y}_{\text {L/S }}\left(\mathrm{g}_{\text {lactato }} / \mathrm{g}_{\text {glicose }}\right)$ & 0,39 & 0,53 & 0,62 & 0,61 \\
\hline $\mathrm{Y}_{\mathrm{A} / \mathrm{S}}\left(\mathrm{g}_{\text {acetato }} / \mathrm{g}_{\mathrm{glicose}}\right)$ & 0,43 & 0,33 & 0,21 & 0,34 \\
\hline \%consumo glicose & 100 & 100 & 100 & 65,7 \\
\hline$Q_{x}\left(g_{\text {célula }} \cdot \mathrm{L}^{-1} \cdot \mathrm{h}^{-1}\right)$ & 0,13 & 0,36 & 0,48 & 0,35 \\
\hline$Q_{P S 14 L}\left(m_{p s 14} \cdot L^{-1} \cdot h^{-1}\right)$ & 17,1 & 14,3 & 30,1 & 16,9 \\
\hline$Q_{\text {PS14C }}\left(\mathrm{mg}_{\mathrm{ps} 14 \cdot} \mathrm{L}^{-1} \cdot \mathrm{h}^{-1}\right)$ & 5,20 & 12,2 & 14,2 & 17,2 \\
\hline $\mathrm{Q}_{\mathrm{PS} 14 \mathrm{~T}}\left(\mathrm{mg}_{\mathrm{ps} 14} \cdot \mathrm{L}^{-1} \cdot \mathrm{h}^{-1}\right)$ & 28,5 & 26,4 & 44,3 & 34,1 \\
\hline $\mathrm{Q}_{\mathrm{L}}\left(\mathrm{g}_{\text {lactato }} \cdot \mathrm{L}^{-1} \cdot \mathrm{h}^{-1}\right)$ & 0,58 & 1,58 & 2,49 & 2,01 \\
\hline $\mathrm{Q}_{\mathrm{A}}\left(\mathrm{g}_{\text {acetato }} \cdot \mathrm{L}^{-1} \cdot \mathrm{h}^{-1}\right)$ & 0,65 & 0,99 & 0,86 & 1,13 \\
\hline$\mu \mathrm{PS} 14_{\mathrm{L}}\left(\mathrm{mg}_{\mathrm{PS} 14 \mathrm{~L}} \cdot \mathrm{g}_{\text {célula }}{ }^{1} \cdot \mathrm{h}^{-1}\right)$ & 19,8 & 12,6 & 23,2 & 24,2 \\
\hline$\mu \mathrm{PS} 14_{\mathrm{C}}\left(\mathrm{mg}_{\mathrm{PS} 14 \mathrm{C}} \cdot \mathrm{g}_{\text {célula }} \cdot \mathrm{h}^{-1}\right)$ & 6,01 & 10,2 & 13,9 & 20,0 \\
\hline$\mu \mathrm{PS} 14_{\mathrm{T}}\left(\mathrm{mg}_{\mathrm{PS} 14 \mathrm{C}} \cdot \mathrm{g}_{\text {célula }}{ }^{1} \cdot \mathrm{h}^{-1}\right)$ & 22,8 & 26,2 & 34,3 & 40,0 \\
\hline$\mu \mathrm{l}\left(\mathrm{gl}_{\text {actato }} \cdot \mathrm{g}_{\text {célula }}{ }^{1} \cdot \mathrm{h}^{-1}\right)$ & 0,67 & 1,32 & 2,06 & 2,86 \\
\hline$\mu \mathrm{a}\left(\mathrm{g}_{\text {acetato }} \cdot \mathrm{g}_{\text {célula }}{ }^{1} \cdot \mathrm{h}^{-1}\right)$ & 0,75 & 0,83 & 0,71 & 1,62 \\
\hline$\mu \mathrm{s}\left(\mathrm{g}_{\text {glicose }} \cdot \mathrm{g}_{\text {célula }}{ }^{1} \cdot \mathrm{h}^{-1}\right)$ & 1,73 & 2,51 & 3,30 & 4,69 \\
\hline
\end{tabular}


De acordo com Lahtvee et al. (2011), a análise do balanço de ATP mostra uma diminuição do desperdício de energia à medida que se aumenta o $\mu$, ocorrendo uma mudança gradual para uma maior eficiência do metabolismo na bactéria L. lactis.

Observando a Figura 37, o pneumococco também pareceu aumentar a eficiência do metabolismo para formação de biomassa e lactato com o aumento de $\mu$, exceto para $0,5 \mathrm{~h}^{-1}$, onde a proximidade com o $\mu_{\text {máx }}$ levou ao início da lavagem do reator.

\subsubsection{Determinação do umáx pelo método dinâmico}

Após o cultivo atingir o estado estacionário e serem recolhidas pelo menos quatro amostras para verificação de que as DO estavam constantes, a vazão foi alterada para $1,0 \mathrm{~h}^{-1}$ para que ocorresse a lavagem total do biorreator com o intuito de determinar o $\mu_{\text {máx }}$ pelo método dinâmico, onde o coeficiente angular da reta de tempo por ln de DO corresponde a $\mu_{\text {máx }}-\mathrm{D}$ como descrito no item (2.8.2). $\mathrm{O} \mu_{\text {máx }}$ alcançado foi de $0,81 \mathrm{~h}^{-1}$ (Figura 38).

Figura 38 - Determinação do $\mu_{\text {máx }}$ pelo método dinâmico em cultivo contínuo em reator com $\mathrm{D}=1,0 \mathrm{~h}^{-1}$ em meio M1G10.

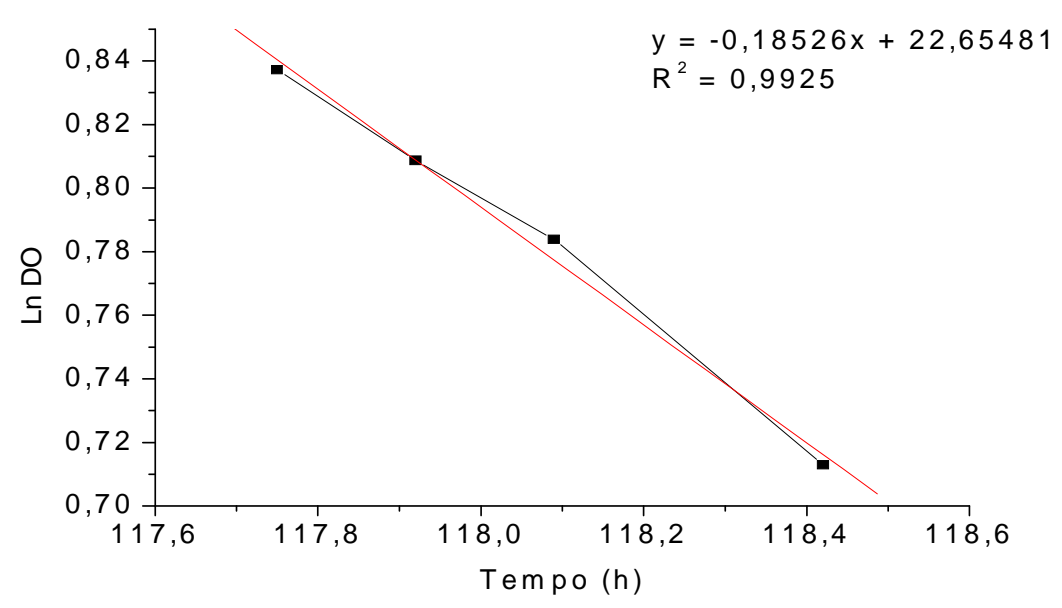

\subsubsection{Determinação do coeficiente de manutenção e do fator de conversão verdadeiro}

A Figura 39 mostra o coeficiente de manutenção da célula $\left(\mathrm{m}_{\mathrm{s}}\right)$, ou seja, o gasto energético necessário para repor os componentes celulares, transporte de moléculas para dentro e fora das células, mobilidade e osmolaridade celular. Este valor pode variar de 0,02 a $4 \mathrm{~g}_{\text {substrato }} \mathrm{g}_{\text {célula }}{ }^{-1} \cdot \mathrm{h}^{-1}$ e depende do microrganismo e das condições de cultivo (DON; SHOPARWE, 2010). 
O coeficiente de manutenção para o $S$. pneumoniae sorotipo 14 em meio completo foi $0,28243 \mathrm{~g}_{\text {substrato }} \cdot \mathrm{g}_{\text {célula }}{ }^{-1} \cdot \mathrm{h}^{-1}$ e o fator de conversão verdadeiro $\left(1 / 8,222 \mathrm{~g}_{\text {glicose }} / \mathrm{g}_{\text {célula }}\right)$ foi 0,122 $\mathrm{g}_{\text {célula }} / \mathrm{g}_{\mathrm{glicose}}$, valor bem próximo ao encontrado para $\mathrm{Y}_{\mathrm{X} / \mathrm{S}}$ para as vazões avaliadas no experimento (média das vazões: 0,11 $\mathrm{g}_{\text {célula }} / \mathrm{g}_{\text {glicose}}$ ). Foram encontrados em cultivos em batelada de $S$. zooepidemicus valores de $\mathrm{m}_{\mathrm{s}}$ de $0,514 \mathrm{~g}_{\text {substrato }} \cdot \mathrm{g}_{\text {célula }}{ }^{-1} \cdot \mathrm{h}^{-1}$ para $20 \mathrm{~g} / \mathrm{L}$ de glicose inicial e 1,564 $\mathrm{g}_{\text {substrato. }}$ gcélula $^{-1} \cdot \mathrm{h}^{-1}$ para glicose inicial de 40g/L (DON; SHOPARWE, 2010).

Figura 39 - Determinação do coeficiente de manutenção $\left(m_{s}\right)$ e do fator de conversão verdadeiro $\left(\mathrm{Y}_{\mathrm{G}}\right)$ em cultivo contínuo em reator de $S$. pneumoniae sorotipo 14 em meio M1G10.

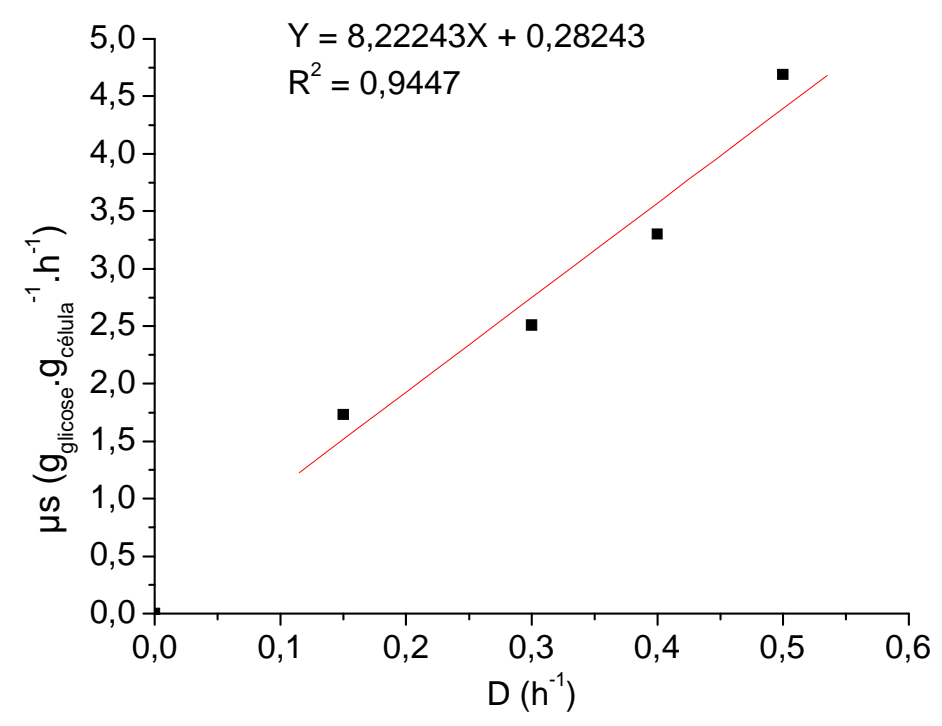

\subsubsection{Determinação do $\mu L, \mu P S 14 C, \mu P S 14 T$ e $\mu P S 14 L$}

De acordo com Luedeking e Piret (1959), o lactato é um produto parcialmente associado ao crescimento e para a bactéria Lactobacillus delbrueckii cultivada em batelada foram determinados o coeficiente linear de produção de lactato não-associada ao crescimento celular de $0,53 \mathrm{~g}_{\text {lactato }} / \mathrm{g}_{\text {célula.. }} \mathrm{h}$ e o coeficiente angular de produção de lactato associada ao crescimento celular de 2,16 $\mathrm{g}_{\text {lactato }} / \mathrm{g}_{\text {célula }}$. No trabalho de Gogola (2011) também foi observado um perfil de produto parcialmente associado ao crescimento para o lactato, com coeficiente angular de 4,671 $\mathrm{g}_{\text {lactato }} / \mathrm{g}_{\text {célula }}$ e coeficiente linear de $0,537 \mathrm{~g}_{\text {lactato }} / \mathrm{g}_{\text {célula }}$ h para $S$. pneumoniae sorotipo 14 em meio complexo. Na Figura 40 pode-se observar que o lactato está associado ao crescimento da bactéria em meio M1G10 com coeficiente angular de 4,996 $\mathrm{g}_{\text {lactato }} / \mathrm{g}_{\text {célula. Neste }}$ 
experimento foram utilizados $10 \mathrm{~g} / \mathrm{L}$ de glicose, portanto toda fonte de carbono foi consumida, assim, supõe-se que toda a glicose disponível estava sendo convertida a lactato durante o crescimento, não havendo glicose remanescente para produzir o lactato na ausência de crescimento celular, mascarando assim o perfil de produção de lactato parcialmente associado ao crescimento em condições de maior disponibilidade de glicose.

Figura 40 - Relação de $\mu_{\mathrm{L}}$ com as vazões específicas de alimentação em cultivo contínuo em reator de $S$. pneumoniae sorotipo 14 em meio M1G10.

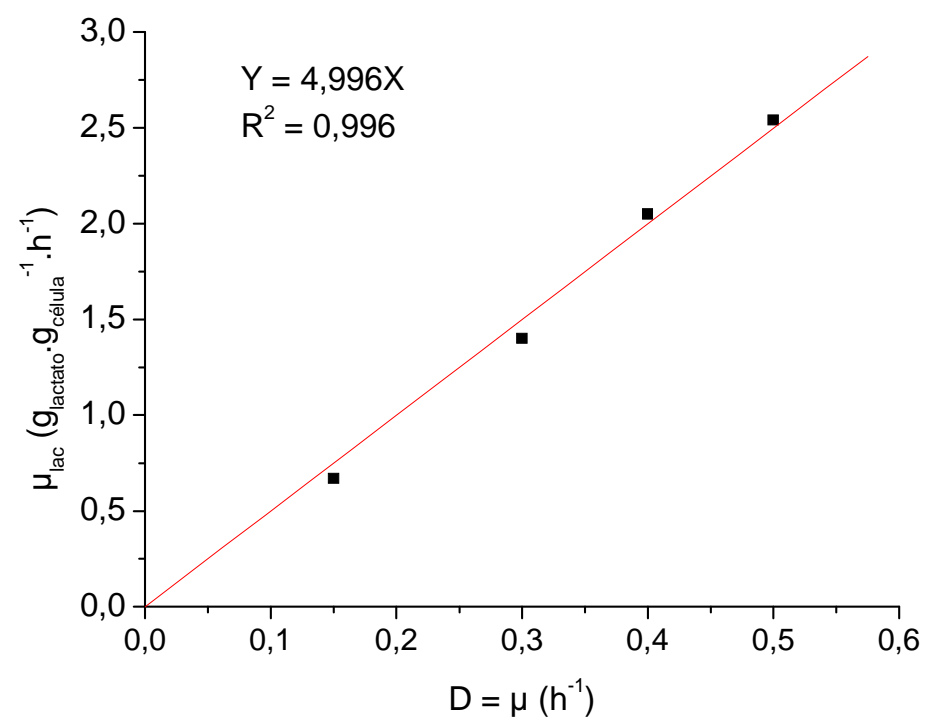

Na Figura 41, que mostra a relação entre $\mu$ e $\mu$ p, observou-se que o PS14 ligado à célula apresentou perfil associado ao crescimento (Figura 41A), enquanto que o PS14 total apresentou perfil parcialmente associado ao crescimento (Figura 41B). 
Figura 41 - Relação de $\mu_{\mathrm{PS} 14 \mathrm{C}}$ (A) e $\mu_{\mathrm{PS} 14 \mathrm{~T}}$ (B) com as vazões específicas de alimentação em cultivo contínuo em reator de $S$. pneumoniae sorotipo 14 em meio M1G10.

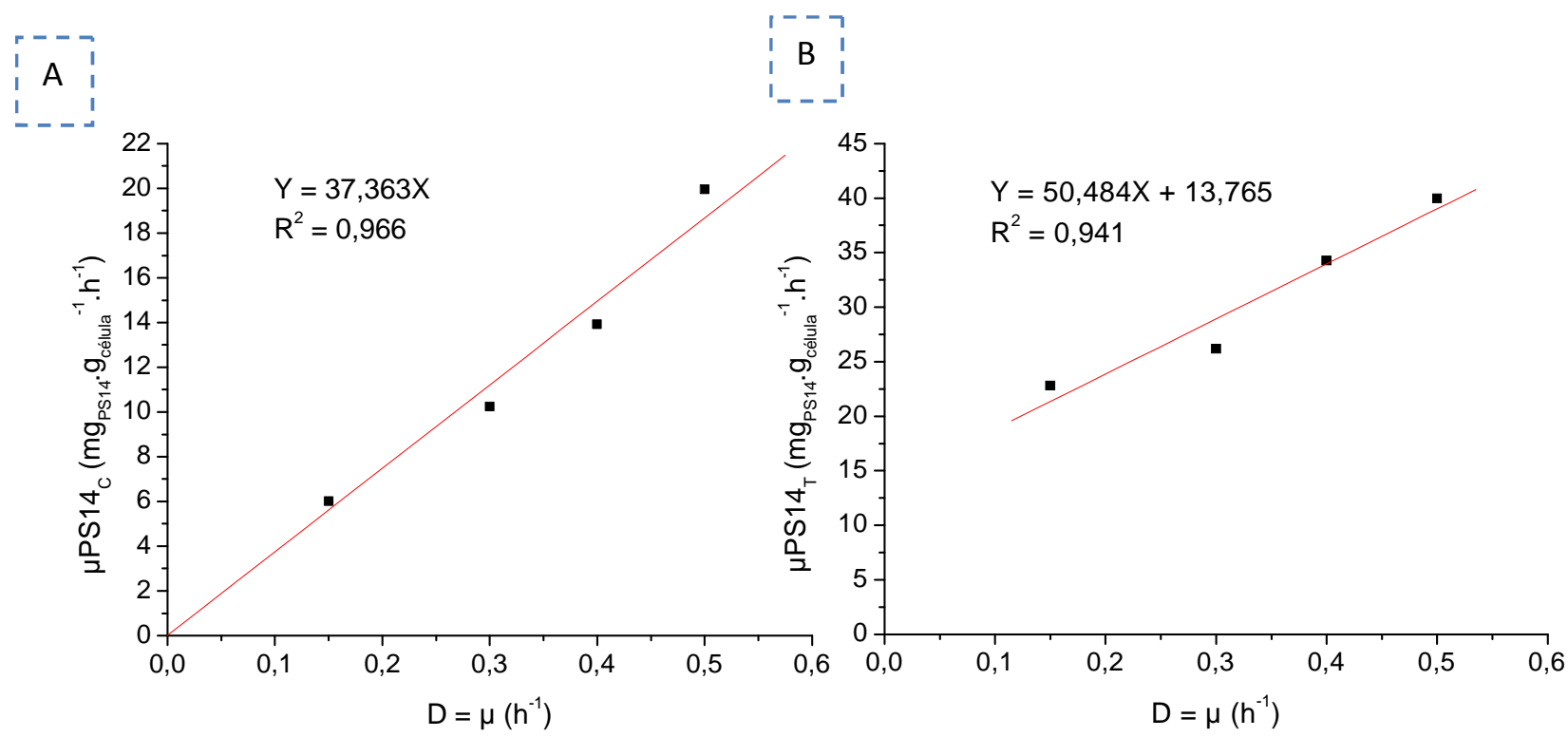

Pode-se observar na Figura 42 que, como o $\mathrm{R}^{2}$ está muito baixo, não houve correlação

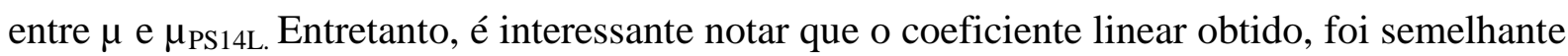
ao coeficiente linear da correlação de $\mu$ por $\mu \mathrm{PS} 14_{\mathrm{T}}$, respectivamente 14,1 e 13,8 $\mathrm{g}_{\mathrm{PS} 14 \mathrm{~L}} / \mathrm{g}_{\text {célula }}$ h, sendo assim, a produção de PS14 ${ }_{\mathrm{T}}$ não associada ao crescimento celular nas condições de cultivo estudadas provavelmente resulta da liberação de PS14 das células para o meio.

De maneira análoga, Cerning et al (1994) afirmaram que em cultivo de Lactobacillus casei o aumento da produção de PS extracelular, ou EPS, não está correlacionado com o crescimento, pois o EPS foi produzido com pouco ou até nenhum crescimento. 
Figura 42 - Relação de $\mu$ PS14 1 com as vazões específicas de alimentação em cultivo contínuo em reator de $S$. pneumoniae sorotipo 14 em meio M1G10.

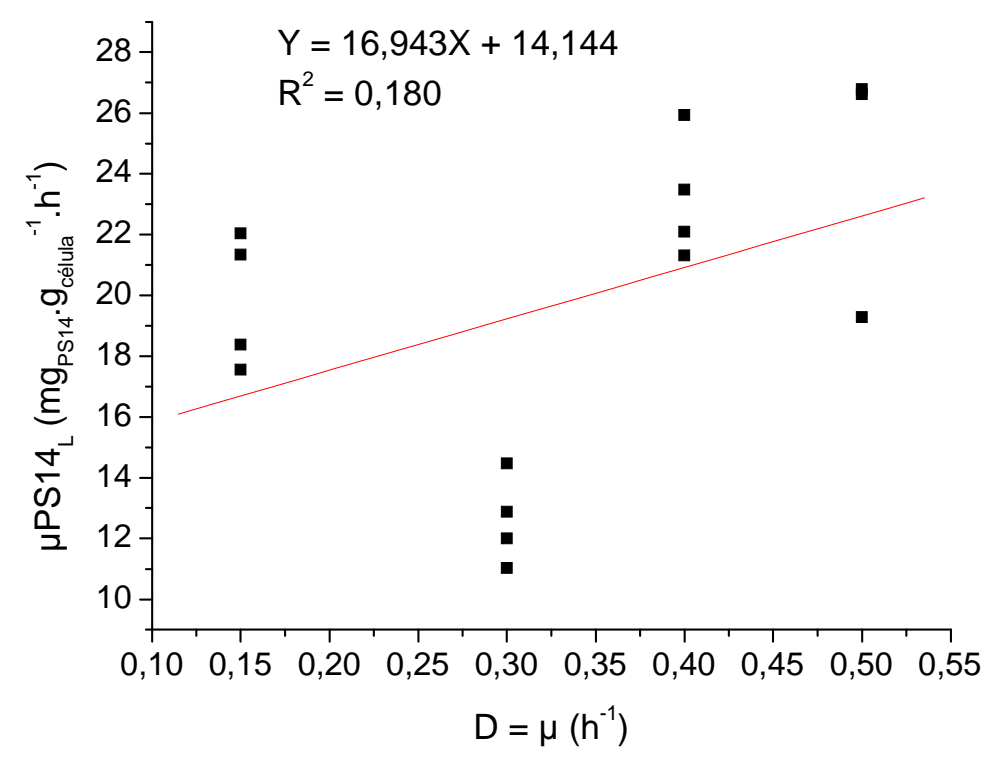

Segundo Looijesteijn et al. (2000), em meio quimicamente definido a produção específica de EPS em Lactococcus lactis foi maior na menor taxa de diluição testada e o D ótimo para produção de EPS foi encontrado em limitação de glicose. Neste cultivo de $S$. pneumoniae, a menor vazão específica de alimentação também apresentou maior fator de conversão tanto de célula a PS14 quanto de glicose a PS14. Segundo os autores, em D muito altos, mais intermediários por unidade de tempo são necessários para biossíntese do polissacarídeo e isto poderia explicar a redução da produção de PS14 em D=0,5 h ${ }^{-1}$.

Em cultivo contínuo de Klebsiella pneumoniae, a bactéria produziu maior quantidade de polissacarídeo em limitação de nitrogênio e baixa vazão específica de alimentação. Em valores baixos de $\mathrm{D}$, o tempo de residência do microrganismo aumenta e a fonte de carbono em excesso seria então utilizada para produção de polissacarídeo. Em estágios iniciais de biossíntese, as unidades repetitivas dos polissacarídeos capsulares ligam-se a lipídeos carreadores comuns a outras macromoléculas de superfície da célula, como os açúcares da peptideoglicana e do lipopolissacarídeo. Em altas taxas de diluição a síntese de peptideoglicanas e lipopolisscarídeos teria preferência sobre a produção de PS (MENGISTU; EDWARDS; SAUNDERS, 1994). Isto poderia ser devido à disponibilidade insuficiente de lipídeos isoprenóides carreadores para síntese simultânea de todos os polímeros de superfície. Apesar disto, o metabolismo do carbono ficou mais eficiente em L. lactis à medida que se aumentou o $\mu$ (CERNING et al., 1994). 
Este experimento foi feito com o objetivo de se conhecer o comportamento das variáveis de estado $\mathrm{X}, \mathrm{S}$ e $\mathrm{P}$ no estado estacionário em função da vazão específica de alimentação D, a fim de se estabelecer faixas ideais de operação do sistema tendo em vista a obtenção de alta produtividade do processo. Portanto, devido a maior produtividade em PS14 (QPS14T), a vazão $0,4 \mathrm{~h}^{-1}$ foi escolhida para os experimentos posteriores. Além disso, em D muito baixos o tempo de residência é muito grande o que leva a processos muito longos e aumenta o risco de contaminação.

Para Streptococccus pneumoniae, em um cultivo contínuo, seria possível combinar um baixo $\mu$ com o desbalanço do meio, no caso com limitação de nitrogênio, para se obter maior quantidade de PS14.

A Figura 43 mostra a cápsula de $S$. pneumoniae sorotipo 14, em lâmina corada com India Ink, de amostra retirada durante o cultivo contínuo na vazão $0,4 \mathrm{~h}^{-1}$.

Figura 43 - Cápsula de S. pneumoniae sorotipo 14 corada com India Ink

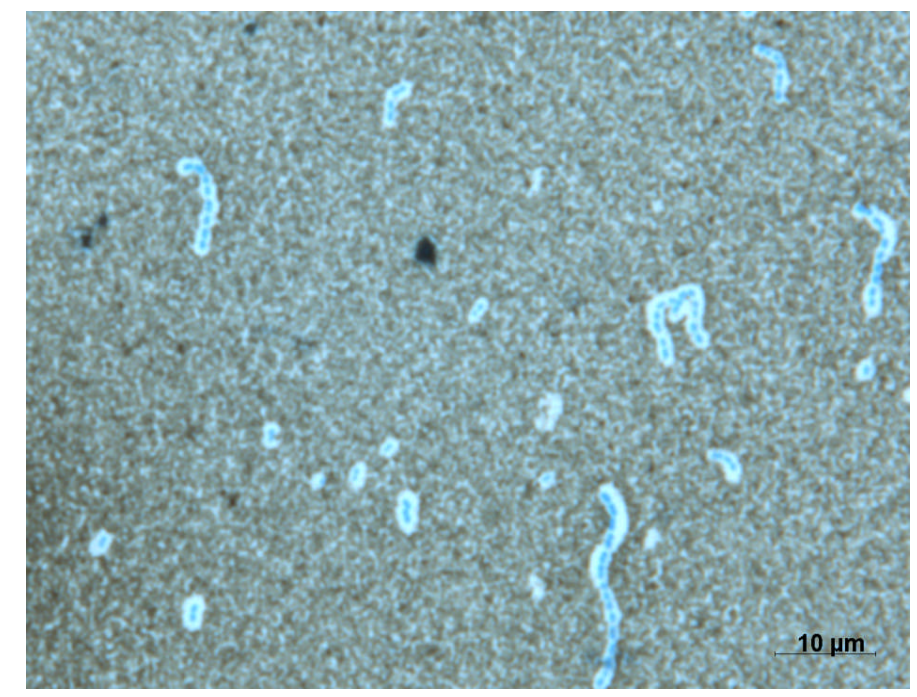

5.2.2 Influência da adição de bases nitrogenadas em cultivo contínuo na produção de $\mathrm{PS14}_{\mathrm{T}}$, biomassa e ácidos orgânicos em meio com $10 \mathrm{~g} / \mathrm{l}$ (M1G10) ou $20 \mathrm{~g} / \mathrm{l}$ de glicose (M1G20)

Os cultivos com adição de bases nitrogenadas em meio contendo tanto $10 \mathrm{~g} / \mathrm{L}$ como 20 $\mathrm{g} / \mathrm{L}$ de glicose inicial foram feitos com taxa de diluição de $0,4 \mathrm{~h}^{-1}$ devido ao fato deste $\mathrm{D}$ ter apresentado maior produtividade em PS14. As barras representadas nas figuras são médias de 
pelo menos quatro pontos retirados quando o cultivo atingiu o estado estacionário após adição de cada base nitrogenada separadamente. Na Figura 44, observa-se que em cultivo com 10 $\mathrm{g} / \mathrm{L}$ de glicose, a biomassa manteve-se constante durante todo o cultivo. A glicose residual também se mostrou aproximadamente constante durante todo o cultivo, sobrando no reator aproximadamente $1 \mathrm{~g} / \mathrm{L}$. Durante o estado estacionário e adição de adenina, as concentrações de lactato e de acetato se mantiveram constantes em $2 \mathrm{~g} / \mathrm{L}$ e $1 \mathrm{~g} / \mathrm{L}$ respectivamente, porém com adição de uracila, ambas triplicaram de valor e se mantiveram altas após a adição de guanina (Figura 44).

Os valores esperados de concentração de lactato e acetato para $\mathrm{D}=0,4 \mathrm{~h}^{-1}$, de acordo com o experimento em cultivo contínuo com diferentes vazões, seriam de aproximadamente 6,0 g/L de lactato e 2,0 g/L de acetato. Não foi possível encontrar uma explicação para os valores baixos das concentrações dos ácidos no estado estacionário e após a adição de adenina neste experimento. Após adição de uracila e guanina, os valores de lactato e acetato chegaram ao esperado, porém não houve alteração nem da biomassa e nem da glicose consumida, cujos valores foram os mesmos da primeira parte de experimento (Figura 44).

Figura 44 - Produção de biomassa, glicose residual, lactato e acetato em cultivo contínuo em reator e em meio M1G10 e adição de bases nitrogenadas.

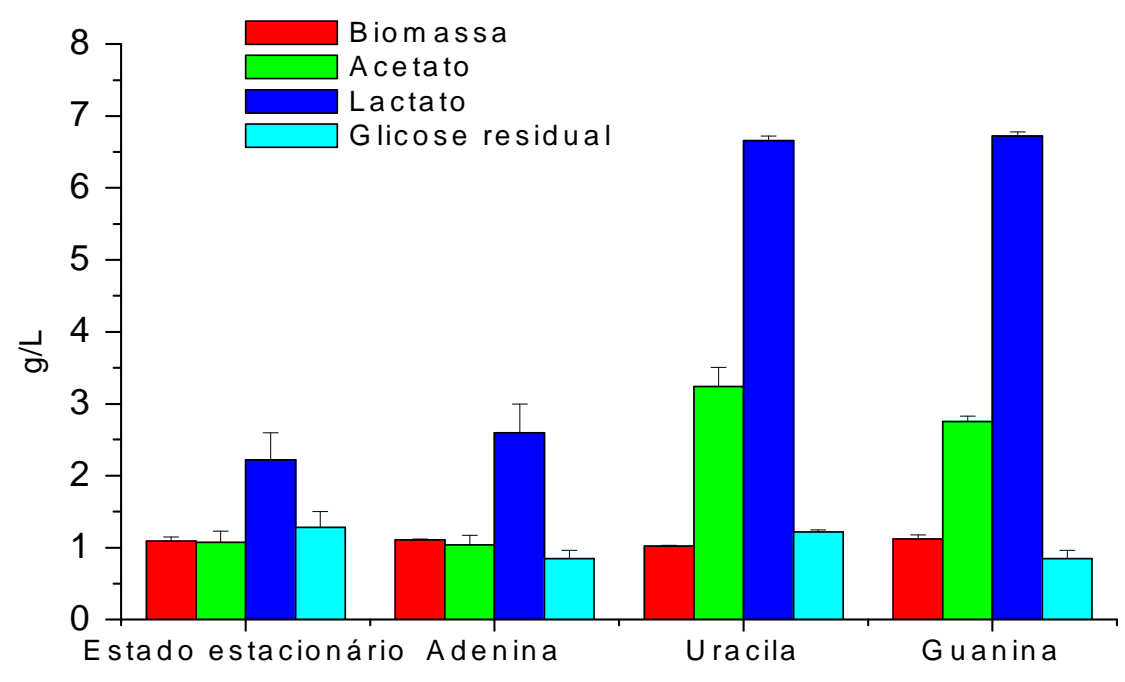

No cultivo contendo excesso de glicose (20 g/L) no meio de cultura (Figura 45), a análise da biomassa mostrou que após a adição de adenina a biomassa diminuiu levemente, continuou baixa após a adição de uracila e voltou a aumentar levemente após a adição de 
guanina. A glicose residual manteve-se constante em aproximadamente $12 \mathrm{~g} / \mathrm{L}$ diminuindo para $10 \mathrm{~g} / \mathrm{L}$ após a adição da guanina. A concentração de lactato teve uma pequena queda com adição de uracila e a produção de acetato mostrou-se constante mesmo com adição das bases nitrogenadas.

Figura 45 - Produção de biomassa, glicose residual, lactato e acetato em cultivo contínuo em reator e em meio M1G20 e adição de bases nitrogenadas.

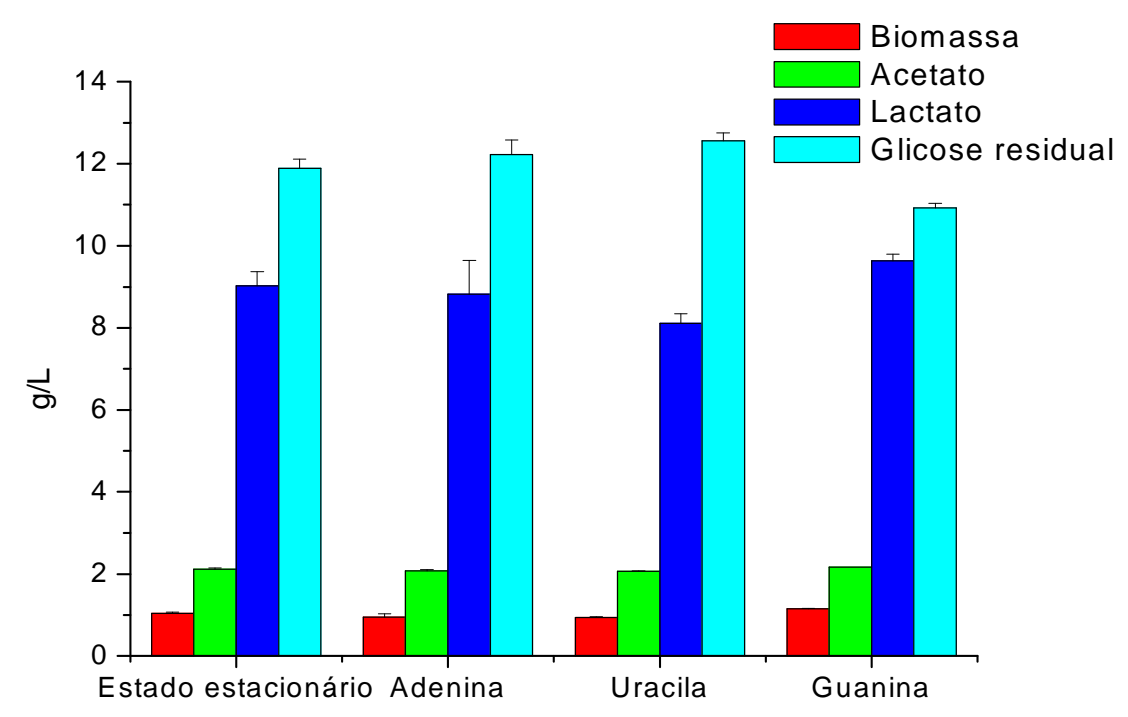

As Tabelas 8 e 9 mostram os parâmetros calculados a partir de dados dos dois experimentos de adição de bases nitrogenadas em cultivos contínuos. 
Tabela 8 - Parâmetros do cultivo contínuo com adição de bases nitrogenadas com glicose 10 $\mathrm{g} / \mathrm{L}(\mathrm{M} 1 \mathrm{G} 10)$

\begin{tabular}{|c|c|c|c|c|}
\hline & Estado & Adição & Adição & Adição \\
\hline Parâmetros & Estacionário & Adenina & Uracila & Guanina \\
\hline biomassa $(\mathrm{g} / \mathrm{L})$ & $1,09 \pm 0,06$ & $1,11 \pm 0,01$ & $1,02 \pm 0,01$ & $1,12 \pm 0,06$ \\
\hline glicose residual $(\mathrm{g} / \mathrm{L})$ & $1,28 \pm 0,22$ & $0,85 \pm 0,11$ & $1,22 \pm 0,03$ & $0,85 \pm 0,11$ \\
\hline $\mathrm{PS} 14_{\mathrm{L}}(\mathrm{mg} / \mathrm{L})$ & $41 \pm 6$ & $44 \pm 11$ & $44 \pm 13$ & $47 \pm 18$ \\
\hline $\mathrm{PS} 14_{\mathrm{T}}(\mathrm{mg} / \mathrm{L})$ & $145 \pm 15$ & $175 \pm 15$ & $139 \pm 32$ & $156 \pm 17$ \\
\hline lactato $(\mathrm{g} / \mathrm{L})$ & $2,22 \pm 0,38$ & $2,60 \pm 0,40$ & $6,66 \pm 0,06$ & $6,72 \pm 0,06$ \\
\hline acetato $(\mathrm{g} / \mathrm{L})$ & $1,07 \pm 0,16$ & $1,04 \pm 0,13$ & $3,24 \pm 0,27$ & $2,75 \pm 0,08$ \\
\hline $\mathrm{Y}_{\mathrm{X} / \mathrm{S}}\left(\mathrm{g}_{\text {célula }} / \mathrm{g}_{\text {glicose }}\right)$ & 0,13 & 0,12 & 0,12 & 0,12 \\
\hline $\mathrm{Y}_{\mathrm{PS} 14 \mathrm{~T} / \mathrm{S}}\left(\mathrm{mg}_{\mathrm{ps} 14} / \mathrm{g}_{\mathrm{glicose}}\right)$ & 16,62 & 19,12 & 15,86 & 17,07 \\
\hline $\mathrm{Y}_{\mathrm{PS} 14 \mathrm{~T} / \mathrm{X}}\left(\mathrm{mg}_{\mathrm{ps} 14} / \mathrm{g}_{\text {célula }}\right)$ & 132,92 & 157,19 & 135,94 & 138,81 \\
\hline $\mathrm{Y}_{\mathrm{L} / \mathrm{S}}\left(\mathrm{g}_{\text {lactato }} / \mathrm{g}_{\text {glicose }}\right)$ & 0,25 & 0,28 & 0,76 & 0,73 \\
\hline $\mathrm{Y}_{\mathrm{A} / \mathrm{S}}\left(\mathrm{g}_{\text {acetato }} / \mathrm{g}_{\mathrm{glicose}}\right)$ & 0,12 & 0,11 & 0,37 & 0,30 \\
\hline $\mathrm{Q}_{\mathrm{x}}\left(\mathrm{g}_{\text {célula }} \cdot \mathrm{L}^{-1} \cdot \mathrm{h}^{-1}\right)$ & 0,44 & 0,45 & 0,41 & 0,45 \\
\hline$Q_{\text {PS14T }}\left(\mathrm{mg}_{\mathrm{ps} 14} \cdot \mathrm{L}^{-1} \cdot \mathrm{h}^{-1}\right)$ & 57,9 & 70,0 & 55,7 & 62,4 \\
\hline $\mathrm{Q}_{\mathrm{L}}\left(\mathrm{g}_{\text {lactato }} \cdot \mathrm{L}^{-1} \cdot \mathrm{h}^{-1}\right)$ & 0,89 & 1,04 & 2,67 & 2,69 \\
\hline $\mathrm{Q}_{\mathrm{A}}\left(\mathrm{g}_{\text {acetato }} \cdot \mathrm{L}^{-1} \cdot \mathrm{h}^{-1}\right)$ & 0,43 & 0,42 & 1,30 & 1,10 \\
\hline$\mu \mathrm{PS} 14_{\mathrm{T}}\left(\mathrm{mg}_{\mathrm{PS} 14 \mathrm{~L}} \cdot \mathrm{g}_{\text {célula }}{ }^{1} \cdot \mathrm{h}^{-1}\right)$ & 53,2 & 62,9 & 54,4 & 55,5 \\
\hline$\mu \mathrm{l}\left(\mathrm{gl}_{\text {actato }} \cdot \mathrm{g}_{\text {célula }}{ }^{1} \cdot \mathrm{h}^{-1}\right)$ & 0,81 & 0,93 & 2,60 & 2,39 \\
\hline$\mu \mathrm{a}\left(\mathrm{g}_{\text {acetato }} \cdot \mathrm{g}_{\text {célula }}{ }^{1} \cdot \mathrm{h}^{-1}\right)$ & 0,39 & 0,37 & 1,27 & 0,98 \\
\hline$\mu \mathrm{s}\left(\mathrm{g}_{\text {glicose }} \cdot \mathrm{g}_{\text {célula }}{ }^{1} \cdot \mathrm{h}^{-1}\right)$ & 3,20 & 3,29 & 3,43 & 3,25 \\
\hline
\end{tabular}


Tabela 9 - Parâmetros do cultivo contínuo com adição de bases nitrogenadas com glicose 20 $\mathrm{g} / \mathrm{L}(\mathrm{M} 1 \mathrm{G} 20)$

\begin{tabular}{|c|c|c|c|c|}
\hline & Estado & Adição & Adição & Adição \\
\hline Parâmetros & Estacionário & Adenina & Uracila & Guanina \\
\hline biomassa $(\mathrm{g} / \mathrm{L})$ & $1,04 \pm 0,03$ & $0,94 \pm 0,08$ & $0,93 \pm 0,03$ & $1,15 \pm 0,01$ \\
\hline glicose residual (g/L) & $11,89 \pm 0,23$ & $12,23 \pm 0,36$ & $12,56 \pm 0,20$ & $10,93 \pm 0,11$ \\
\hline $\mathrm{PS}_{14}(\mathrm{mg} / \mathrm{L})$ & $63 \pm 6$ & $91 \pm 10$ & $82 \pm 4$ & $65 \pm 6$ \\
\hline $\mathrm{PS} 14_{\mathrm{T}}(\mathrm{mg} / \mathrm{L})$ & $140 \pm 24$ & $182 \pm 13$ & $146 \pm 20$ & $110 \pm 13$ \\
\hline lactato $(\mathrm{g} / \mathrm{L})$ & $9,02 \pm 0,35$ & $8,82 \pm 0,83$ & $8,11 \pm 0,24$ & $9,64 \pm 0,16$ \\
\hline acetato $(\mathrm{g} / \mathrm{L})$ & $2,12 \pm 0,02$ & $2,08 \pm 0,02$ & $2,06 \pm 0,02$ & $2,17 \pm 0,00$ \\
\hline $\mathrm{Y}_{\mathrm{X} / \mathrm{S}}\left(\mathrm{g}_{\text {célula }} / \mathrm{g}_{\text {glicose }}\right)$ & 0,13 & 0,12 & 0,13 & 0,13 \\
\hline $\mathrm{Y}_{\mathrm{PS} 14 \mathrm{~T} / \mathrm{S}}\left(\mathrm{mg}_{\mathrm{ps} 14} / \mathrm{g}_{\mathrm{glicose}}\right)$ & 17,65 & 23,47 & 19,67 & 12,11 \\
\hline $\mathrm{Y}_{\mathrm{PS} 14 \mathrm{~T} / \mathrm{X}}\left(\mathrm{mg}_{\mathrm{ps} 14} / \mathrm{g}_{\text {célula }}\right)$ & 138,41 & 195,14 & 157,21 & 95,76 \\
\hline $\mathrm{Y}_{\mathrm{L} / \mathrm{S}}\left(\mathrm{g}_{\text {lactato }} / \mathrm{g}_{\mathrm{glicose}}\right)$ & 1,11 & 1,14 & 1,09 & 1,06 \\
\hline $\mathrm{Y}_{\mathrm{A} / \mathrm{S}}\left(\mathrm{g}_{\text {acetato }} / \mathrm{g}_{\mathrm{glicose}}\right)$ & 0,26 & 0,27 & 0,28 & 0,24 \\
\hline$Q_{x}\left(g_{\text {célula }} \cdot \mathrm{L}^{-1} \cdot \mathrm{h}^{-1}\right)$ & 0,42 & 0,37 & 0,37 & 0,46 \\
\hline $\mathrm{Q}_{\mathrm{PS} 14 \mathrm{~T}}\left(\mathrm{mg}_{\mathrm{ps} 14 \cdot} \mathrm{L}^{-1} \cdot \mathrm{h}^{-1}\right)$ & 56,3 & 73,0 & 58,5 & 43,9 \\
\hline $\mathrm{Q}_{\mathrm{L}}\left(\mathrm{g}_{\text {lactato }} \cdot \mathrm{L}^{-1} \cdot \mathrm{h}^{-1}\right)$ & 3,61 & 3,53 & 3,24 & 3,85 \\
\hline $\mathrm{Q}_{\mathrm{A}}\left(\mathrm{g}_{\text {acetato }} \cdot \mathrm{L}^{-1} \cdot \mathrm{h}^{-1}\right)$ & 0,85 & 0,83 & 0,83 & 0,87 \\
\hline$\mu \mathrm{PS} 14_{\mathrm{T}}\left(\mathrm{mg}_{\mathrm{PS} 14 \mathrm{~L}} \cdot \mathrm{g}_{\text {célula }} \cdot \mathrm{h}^{-1}\right)$ & 55,4 & 78,1 & 62,9 & 38,3 \\
\hline$\mu \mathrm{l}\left(\mathrm{gl}_{\text {actato }} \cdot \mathrm{g}_{\text {célula }}{ }^{1} \cdot \mathrm{h}^{-1}\right)$ & 3,48 & 3,77 & 3,49 & 3,36 \\
\hline$\mu \mathrm{a}\left(\mathrm{g}_{\text {acetato }} \cdot \mathrm{g}_{\text {célula }}{ }^{1} \cdot \mathrm{h}^{-1}\right)$ & 0,82 & 0,89 & 0,89 & 0,76 \\
\hline$\mu \mathrm{s}\left(\mathrm{g}_{\text {glicose }} \cdot \mathrm{g}_{\text {célula }}{ }^{1} \cdot \mathrm{h}^{-1}\right)$ & 3,13 & 3,33 & 3,20 & 3,16 \\
\hline
\end{tabular}

Os dados das Tabelas 8 e 9 mostram que a produção de biomassa foi parecida tanto para o cultivo com excesso de glicose como para o cultivo com limitação de glicose. O fator de conversão de substrato em células também se mostrou semelhante em todas as condições dos dois cultivos.

Observou-se que a produção de lactato foi dependente da concentração de glicose já que a concentração alcançada foi maior com a maior concentração de glicose $(20 \mathrm{~g} / \mathrm{L})$, enquanto que a formação de acetato se mostrou independente da concentração da fonte de carbono, pois mesmo ao dobrar a concentração de glicose, a concentração de acetato produzido continuou cerca de $2 \mathrm{~g} / \mathrm{L}$. Tanto a produtividade de PS14 $4_{\mathrm{T}}$ quanto os fatores de 
conversão de glicose a PS14 $\mathrm{L}$ e a células foram maiores após a adição de adenina em meio tanto com $10 \mathrm{~g} / \mathrm{L}$ quanto com $20 \mathrm{~g} / \mathrm{L}$ de glicose.

Como mostra a Figura 46, o aumento da produção de PS14 total (soma do PS14 $4_{\mathrm{L}}$ com PS14 $)$ devido à adição de bases nitrogenadas em cultivo com limitação de glicose $(10 \mathrm{~g} / \mathrm{L})$ não foi estatisticamente significativo, com intervalo de confiança de $90 \%$, em relação ao estado estacionário.

Em cultivo contendo excesso de glicose $(20 \mathrm{~g} / \mathrm{L})$, a adição de adenina levou à produção de PS14 $4_{\mathrm{T}}$ estatisticamente significativa superior à do estado estacionário, com intervalo de confiança de 90\%: $182 \pm 13 \mathrm{mg} / \mathrm{L}$ após adição de adenina e $140 \pm 24 \mathrm{mg} / \mathrm{L}$ no estado estacionário. Deste modo, surge a hipótese de que a adenina poderia estar limitante no meio de cultura M1G20, portanto, foi realizado um cultivo contínuo com 20g/L de glicose inicial e com concentrações crescentes de adenina para definição das concentrações não-limitantes.

Figura 46 - Produção de PS14 ${ }_{\mathrm{L}}$ em cultivo contínuo em reator e em meio M1G10 e M1G20 e adição de bases nitrogenadas

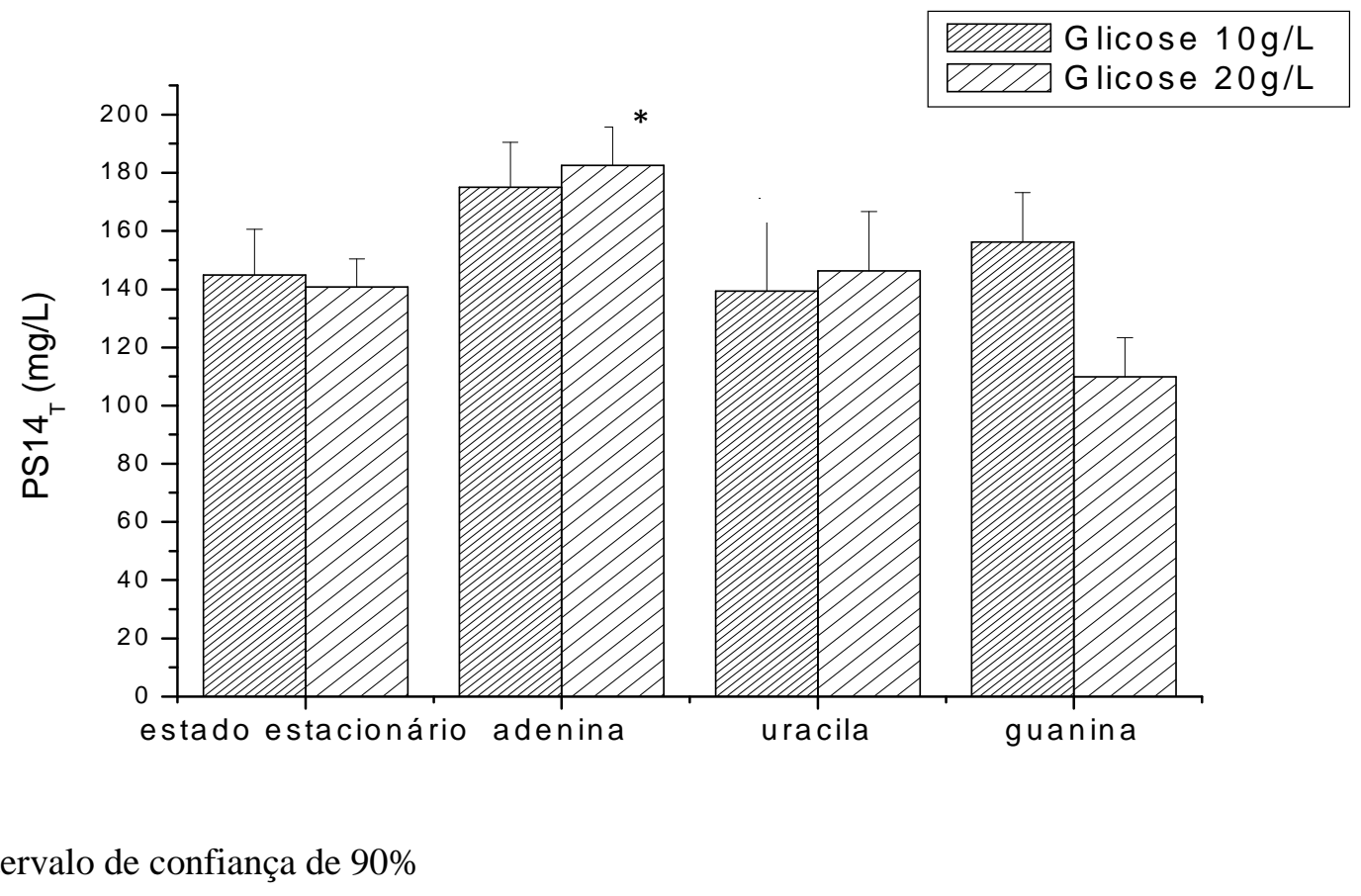

As bases nitrogenadas são compostos constantemente reciclados pelas células e exercem influência no metabolismo da bactéria $S$. pneumoniae. A uracila está diretamente relacionada com a formação dos açúcares precursores do PS14, tais como UDP-glicose, UDP-galactose, UDP-N-acetilglucosamina, e a adenina, com a formação de ATP. Um trabalho sobre o crescimento e produção de exopolissacarídeo (EPS) por Lactobacillus helveticus, em 
batelada, mostrou que em meio quimicamente definido suplementado com adenina, houve um aumento do crescimento celular e aumento também na produção de EPS, enquanto que em meio suplementado com guanina foram observados dois efeitos opostos: a diminuição do crescimento celular e o aumento da formação de EPS (TORINO et al., 2005). O mesmo fenômeno também foi observado para o $S$. pneumoniae em relação à adenina, que ao mesmo tempo mostrou uma diminuição no crescimento celular (Figura 45) e um aumento na produção de PS14 (Figura 46). Outro trabalho de produção de EPS pelo microrganismo Lactobacillus delbrueckii, mostra que adição de adenina estimulou tanto o crescimento quanto a produção de EPS (PETRY et al., 2000).

\subsubsection{Influência do aumento gradativo da concentração de adenina em cultivo contínuo, na produção de PS14 , biomassa e ácidos orgânicos em meio M1G20}

Este cultivo contínuo foi realizado com o objetivo de se estabelecer a concentração não limitante que adenina, que foi a base nitrogenada que apresentou maior produção de PS14 $\mathrm{T}$ quando adicionada como pulso no cultivo descrito no item 5.2.2. A descrição do experimento está no item 4.6.3 e o esquema na Figura 6.

A Figura 47 mostra a produção de biomassa, de acetato e lactato, além da concentração de glicose residual nas cinco concentrações de adenina testadas $(0,038 \mathrm{~g} / \mathrm{L}$ a 0,608 g/L). Observa-se que os valores foram basicamente iguais, sendo que houve uma pequena diferença somente com a concentração inicial de adenina $(0,038 \mathrm{~g} / \mathrm{L})$, onde o consumo de glicose foi menor e consequentemente a produção de lactato também. A concentração de acetato se manteve constante com todas as concentrações de adenina e a biomassa foi ligeiramente menor com a primeira concentração $(0,038 \mathrm{~g} / \mathrm{L})$, aumentando um pouco com 0,076 g/L de adenina e se mantendo para as demais concentrações. 
Figura 47 - Produção de biomassa, glicose residual, lactato e acetato em cultivo contínuo em reator e em meio M1G20 e cinco concentrações diferentes de adenina.

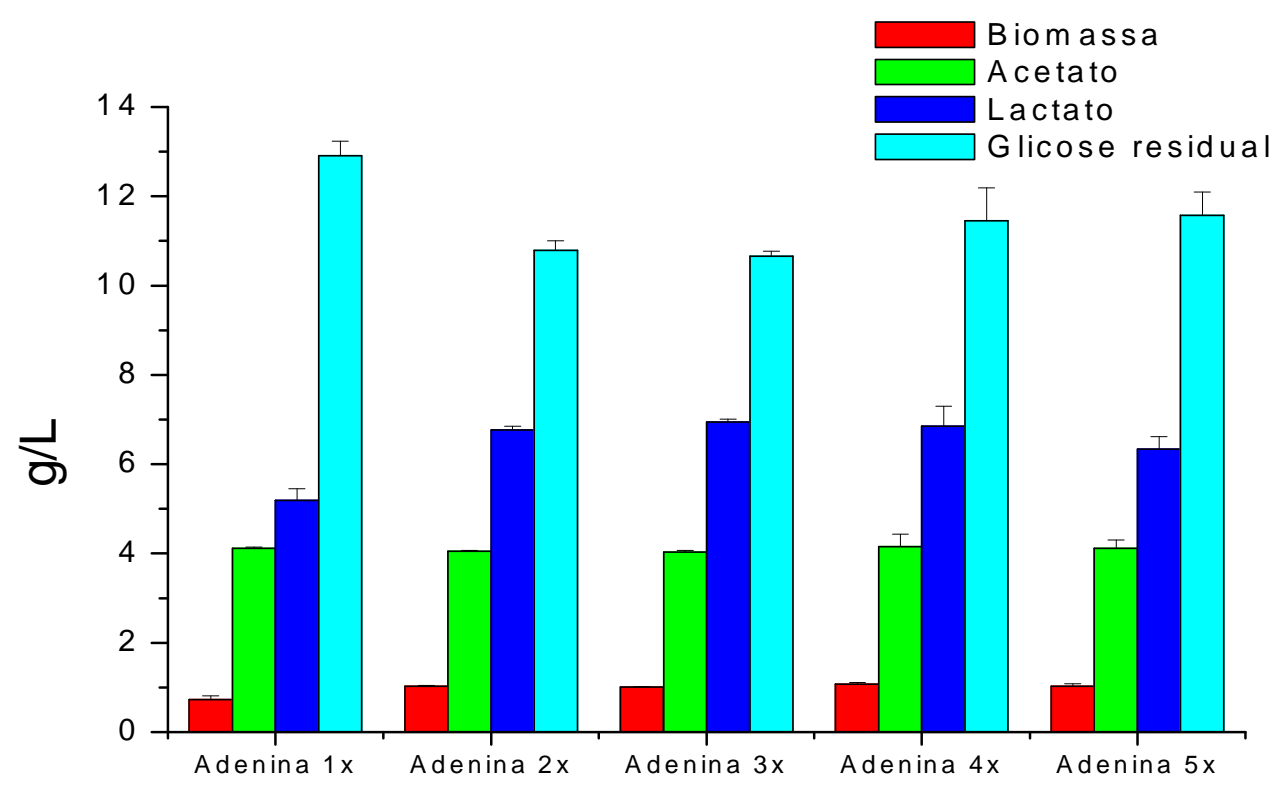

Surpreendentemente, ao avaliar-se a produção de PS14T, verificou-se que a maior produção, 158mg/L (Figura 48), ocorreu na concentração original de adenina, resultado diferente do cultivo anterior, onde a adenina foi adicionada como pulso para concentração 2 vezes superior a do meio de cultura, levando à produção de PS14T significativamente maior do que no estado estacionário (Figura 46). Porém, ao fazer o teste estatístico com $90 \%$ de confiança, verificou-se que os meios com concentrações de adenina de $1 \mathrm{x}(0,038 \mathrm{~g} / \mathrm{L}), 2 \mathrm{x}$ $(0,076 \mathrm{~g} / \mathrm{L})$ e $5 \mathrm{x}(0,608 \mathrm{~g} / \mathrm{L})$ se mostraram estatisticamente iguais, o que não nos permite através deste experimento escolher uma concentração ideal de adenina. 
Figura 48 - Produção de PS14 ${ }_{\mathrm{T}}$ em cultivo contínuo em reator e em meio M1G20 e cinco concentrações diferentes de adenina

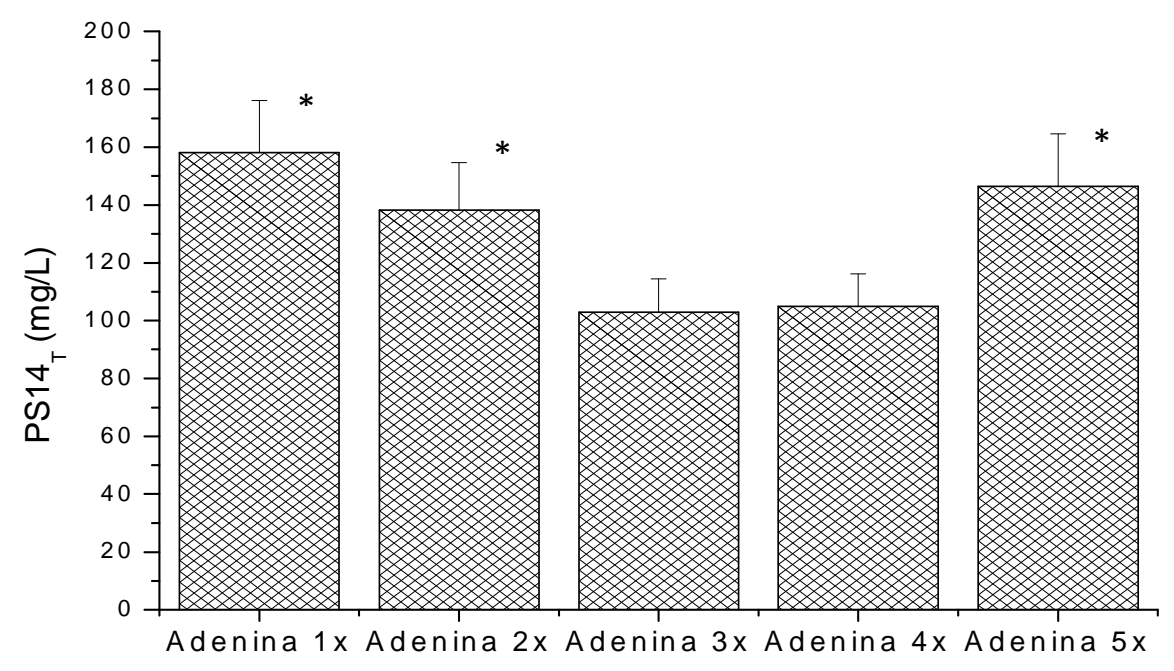

*Valores estatisticamente iguais com $90 \%$ de confiança

Pode- se observar na Tabela 10, que à medida que aumentou a concentração de adenina, a quantidade de PS14 1 diminuiu, enquanto que o PS14 $\mathrm{C}$ aumentou, o que significa que com o passar do tempo, mais PS ficou ligado às células e menos PS foi liberado para o sobrenadante. Como este fenômeno foi observado somente neste experimento concluiu-se que a menor liberação de PS14 para o sobrenadante com o decorrer do tempo poderia estar relacionado ao aumento da concentração de adenina. 
Tabela 10 - Parâmetros do cultivo contínuo com adição de adenina em cinco concentrações diferentes e glicose $20 \mathrm{~g} / \mathrm{L}$

\begin{tabular}{|c|c|c|c|c|c|}
\hline & Adenina & Adenina & Adenina & Adenina & Adenina \\
\hline Parâmetros & $0,038 \mathrm{~g} / \mathrm{L}$ & $0,076 \mathrm{~g} / \mathrm{L}$ & $0,152 \mathrm{~g} / \mathrm{L}$ & $0,304 \mathrm{~g} / \mathrm{L}$ & $0,608 \mathrm{~g} / \mathrm{L}$ \\
\hline biomassa $(\mathrm{g} / \mathrm{L})$ & $0,73 \pm 0,08$ & $1,03 \pm 0,02$ & $1,01 \pm 0,01$ & $1,18 \pm 0,03$ & $1,03 \pm 0,06$ \\
\hline glicose residual $(\mathrm{g} / \mathrm{L})$ & $12,91 \pm 0,33$ & $10,79 \pm 0,22$ & $10,66 \pm 0,12$ & $11,46 \pm 0,74$ & $11,58 \pm 0,52$ \\
\hline $\mathrm{PS} 14_{\mathrm{L}}(\mathrm{mg} / \mathrm{L})$ & $105 \pm 13$ & $83 \pm 11$ & $57 \pm 6$ & $47 \pm 2$ & $62 \pm 9$ \\
\hline $\mathrm{PS} 14_{\mathrm{C}}(\mathrm{mg} / \mathrm{L})$ & $53 \pm 6$ & $56 \pm 8$ & $45 \pm 7$ & $58 \pm 11$ & $85 \pm 12$ \\
\hline $\mathrm{PS} 14_{\mathrm{T}}(\mathrm{mg} / \mathrm{L})$ & $158 \pm 18$ & $138 \pm 16$ & $103 \pm 12$ & $105 \pm 11$ & $146 \pm 18$ \\
\hline lactato $(\mathrm{g} / \mathrm{L})$ & $5,20 \pm 0,26$ & $6,77 \pm 0,08$ & $6,95 \pm 0,06$ & $6,85 \pm 0,45$ & $6,34 \pm 0,28$ \\
\hline acetato $(\mathrm{g} / \mathrm{L})$ & $4,12 \pm 0,03$ & $4,05 \pm 0,02$ & $4,04 \pm 0,04$ & $4,16 \pm 0,27$ & $4,12 \pm 0,18$ \\
\hline $\mathrm{Y}_{\mathrm{X} / \mathrm{S}}\left(\mathrm{g}_{\text {célula }} / \mathrm{g}_{\text {glicose }}\right)$ & 0,10 & 0,11 & 0,11 & 0,13 & 0,12 \\
\hline $\mathrm{Y}_{\mathrm{PS} 14 \mathrm{~T} / \mathrm{S}}\left(\mathrm{mg}_{\mathrm{ps} 14} / \mathrm{g}_{\mathrm{glicose}}\right)$ & 22,31 & 15,01 & 11,02 & 12,29 & 17,39 \\
\hline $\mathrm{Y}_{\mathrm{PS} 14 \mathrm{~T} / \mathrm{X}}\left(\mathrm{mg}_{\mathrm{ps} 14} / \mathrm{g}_{\text {célula }}\right)$ & 217,22 & 133,92 & 102,35 & 97,37 & 142,15 \\
\hline $\mathrm{Y}_{\text {L/S }}\left(\mathrm{g}_{\text {lactato }} / \mathrm{g}_{\text {glicose }}\right)$ & 0,73 & 0,74 & 0,74 & 0,80 & 0,75 \\
\hline $\mathrm{Y}_{\mathrm{A} / \mathrm{S}}\left(\mathrm{g}_{\text {acetato }} / \mathrm{g}_{\mathrm{glicose}}\right)$ & 0,58 & 0,44 & 0,43 & 0,49 & 0,49 \\
\hline $\mathrm{Q}_{\mathrm{x}}\left(\mathrm{g}_{\text {célula }} \cdot \mathrm{L}^{-1} \cdot \mathrm{h}^{-1}\right)$ & 0,29 & 0,41 & 0,40 & 0,43 & 0,41 \\
\hline$Q_{P S 14 T}\left(\mathrm{mg}_{\mathrm{ps} 14} \cdot \mathrm{L}^{-1} \cdot \mathrm{h}^{-1}\right)$ & 63,3 & 55,3 & 41,2 & 42,0 & 58,6 \\
\hline $\mathrm{Q}_{\mathrm{L}}\left(\mathrm{g}_{\text {lactato }} \cdot \mathrm{L}^{-1} \cdot \mathrm{h}^{-1}\right)$ & 2,08 & 2,71 & 2,78 & 2,74 & 2,54 \\
\hline $\mathrm{Q}_{\mathrm{A}}\left(\mathrm{g}_{\text {acetato }} \cdot \mathrm{L}^{-1} \cdot \mathrm{h}^{-1}\right)$ & 1,65 & 1,62 & 1,62 & 1,66 & 1,65 \\
\hline$\mu \mathrm{PS} 14_{\mathrm{T}}\left(\mathrm{mg}_{\mathrm{PS} 14 \mathrm{~L}} \cdot \mathrm{g}_{\text {célula }}{ }^{1} \cdot \mathrm{h}^{-1}\right)$ & 86,9 & 53,6 & 40,9 & 39,0 & 56,9 \\
\hline$\mu \mathrm{l}\left(\mathrm{gl}_{\text {actato }} \cdot \mathrm{g}_{\text {célula }}{ }^{1} \cdot \mathrm{h}^{-1}\right)$ & 2,86 & 2,63 & 2,76 & 2,54 & 2,46 \\
\hline$\mu \mathrm{a}\left(\mathrm{g}_{\text {acetato }} \cdot \mathrm{g}_{\text {célula }} \cdot \mathrm{h}^{-1}\right)$ & 2,26 & 1,57 & 1,61 & 1,54 & 1,60 \\
\hline$\mu \mathrm{s}\left(\mathrm{g}_{\text {glicose }} \cdot \mathrm{g}_{\text {célula }}{ }^{1} \cdot \mathrm{h}^{-1}\right)$ & 3,90 & 3,57 & 3,72 & 3,17 & 3,27 \\
\hline
\end{tabular}

Na Tabela 10 também se observa que os parâmetros fator de conversão substrato/célula a PS14 , produtividade e velocidade específica de produção de $\operatorname{PS} 14_{\mathrm{T}}$ se mostraram maiores com a menor concentração de adenina, ou seja, a concentração inicial estabelecida para o meio de cultura $(0,038 \mathrm{~g} / \mathrm{L})$. Diante deste resultado, concluiu-se que é preciso ter cuidado e investigar mais a fundo as hipóteses levantadas em experimentos de pulso, uma vez que eles causam um distúrbio momentâneo no estado estacionário, o que poderia gerar resultados incongruentes. 


\section{CONCLUSÕES}

- Entre as fontes de carbono testadas em meio quimicamente definido completo para o cultivo de $S$. pneumoniae sorotipo 14 , a sacarose $10 \mathrm{~g} / \mathrm{L}$ levou à maior produção de PS14 do que a glicose em diferentes concentrações $(10 \mathrm{~g} / \mathrm{L} ; 10 \mathrm{~g} / \mathrm{L}$ com pulso e 20 g/L), chegando a $228 \mathrm{mg} / \mathrm{L}$ de PS14 livre no sobrenadante e $368 \mathrm{mg} / \mathrm{L}$ de PS14 ${ }_{\mathrm{T}}$ (livre + ligado às células).

- Não ocorreu repressão catabólica entre as fontes de carbono glicose e sacarose, nem entre glicose e frutose, pois estes açúcares foram consumidos ao mesmo tempo quando adicionados juntos ao meio de cultura.

- As vitaminas/cofatores ácido fólico, piridoxamina, ácido $\boldsymbol{p}$-aminobenzóico, $\boldsymbol{\beta}$-NAD e riboflavina e os aminoácidos asparagina, ácido aspártico, fenilalanina, serina, alanina, treonina, triptofano, lisina e tirosina podem ser retirados do meio de cultura, sem impacto drástico na produção de PS14.

- O uso do meio de cultura com a retirada dos aminoácidos e das vitaminas descritas acima e adição do dobro da concentração de glicina, isoleucina, leucina e valina, do triplo de glutamina e utilizando sacarose como fonte de carbono (M5S20) levou a maior produção de PS14 $(441 \mathrm{mg} / \mathrm{L})$ dentre todos os meios avaliados neste trabalho.

- O meio M5S20 é um novo meio quimicamente definido desenvolvido especialmente para a bactéria Streptococcus pneumoniae, ele é mais econômico que o meio completo, do qual foram retirados 14 componentes, e mais produtivo, pois a sacarose levou à maior produção de PS14. Além disso, a utilização da sacarose como fonte de carbono é uma proposta inovadora, já que ela nunca havia sido utilizada em outros trabalhos como fonte de carbono para produção de PS por S. pneumoniae. Entretanto, como a biomassa formada foi menor que no meio completo e o tempo de cultivo maior, estudos adicionais devem ser realizados para aumentar a biomassa e diminuir o tempo de cultivo.

- A vazão específica de alimentação $0,4 \mathrm{~h}^{-1}$ levou à maior produtividade de $\mathrm{PS} 14_{\mathrm{T}} \mathrm{em}$ cultivo contínuo. 
- As bases nitrogenadas não exerceram efeito positivo na produção de PS14 $4_{L}$ em meio definido com glicose 10 g/L (M1G10) provavelmente devido à limitação de glicose.

- Diferente do resultado do experimento com adição de bases nitrogenadas em cultivo contínuo em meio com glicose $20 \mathrm{~g} / \mathrm{L}$ (M1G20), no qual a injeção de adenina ao reator para concentração 2 vezes maior $(0,076 \mathrm{~g} / \mathrm{L})$ resultou em aumento da produção de PS14, o resultado do cultivo contínuo com concentrações crescentes de adenina para determinação da concentração não limitante indicou que a adenina na concentração original no meio de cultura $(0,038 \mathrm{~g} / \mathrm{L})$ produziu maior quantidade de PS14 T. 


\section{REFERENCIAS $^{1}$}

BENTLEY, S. D.; AANENSEN, D. M.; MAVROIDI, A.; SAUNDERS, D.; RABBINOWITSCH, E.; COLLINS, M.; DONOHOE, K.; HARRIS, D.; MURPHY, L.; QUAIL, M. A.; SAMUEL, G.; SKOVSTED, I. C.; KALTOFT, M. S.; BARRELL, B.; REEVES, P. R.; PARKHILL, J.; SPRATT, B. G. Genetic analysis of the capsular biosynthetic locus from all 90 pneumococcal serotypes. PLoS Genetics, v. 2, p. e31, 2006.

BIDOSSE, A.; MULAS, L.; DECOROSI, F.; COLOMBA, L.; RICCI, S.; POZZI, G.; DEUTSCHER, J.; VITI, C.; OGGIONI, M. R. A Functional Genomics Approach to Establish the Complement of Carbohydrate Transporters in Streptococcus pneumoniae. PLoS One, v. 7, p. e33320, 2012.

BLANK, L. M.; MCLAUGHLIN, R. L.; NIELSEN, L. K. Stable production of hyaluronic acid in Streptococcus zooepidemicus chemostats operated at high dilution rate. Biotechnol. Bioeng. v. 90, p. 685-693, 2005.

BRANDILEONE, M. C. C.; ANDRADE, A. L. S. S.; DI FABIO, J. L.; GUERRA, M. L. L. S.; AUSTRIAN, R. Apropriateness of pneumococcal conjugate vaccine in Brazil: potencial impacto of age and clinical diagnosis, with emphasis on meningitis. J. Infect. Dis., v. 187, p. 1206-12, 2003.

BRASIL. Ministério da Saúde. Calendário de vacinação do adulto e do idoso. Disponível em: <http://portal.saude.gov.br/portal/saude/visualizar_texto.cfm?idtxt=25806>. Acesso em: 20 ago. 2011.

BUCKWALTER, C. M.; KING, S. J. Pneumococcal carbohydrate transport: food for thought. Trends in Microbiol., v. 20, p. 517-522, 2012.

BUTT, E. M.; BONYNGE, C. W.; JOYCE, R. L. The demonstration of capsules about hemolytic streptococci with India ink or Azo blue. J. Oxfor., v. 58, p. 5-9, 1935.

CARMO, T. S. Otimização da produção de polisscarídeo capsular do Streptococcus pneumoniae sorotipo 6B em biorretaor. $2010.121 \mathrm{f}$. Tese (Doutorado em Biotecnologia) Instituto de Ciências biomédicas, Universidade de São Paulo, São Paulo, 2010.

CERNING, J.; RENARD, C. M. G. C.; THIBAULT, J. F.; BOUILLANNE, C.; LANDON, M.; DESMAZEAUD. M.; TOPISIROVIC, L. Carbon source requirements for exopolysaccharide production by Lactobacillus casei CG11 and partial structure analysis of the polymer. Appl. Envir. Microbiol., v. 60, p. 3914-3919, 1994.

DING, F.; TANG, P.; HSU, M.; CUI, P.; HU, S.; YU, J.; CHIU, C. Genome evolution driven by host adaptations results in a more virulent and antimicrobial-resistant Streptococcus pneumoniae serotype 14. BMC Genomics., v. 10, 2009, doi: 10.1186/1471-2164-10-158.

\footnotetext{
${ }^{1}$ De acordo com:

ASSOCIAÇÃO BRASILEIRA DE NORMAS TÉCNICAS. NBR 6023: informação e documentação: referências: elaboração. Rio de Janeiro, 2002.
} 
DON, M. M.; SHOPARWE, N. F. Kinetics of hyaluronic acid production by Streptococcus zooepidemicus considering the effect of glucose. Biochem. Eng. J., v. 49, n.1, p. 95-103, 2010. doi:10.1016/j.bej.2009.12.001.

DORAN, P. M. Principios de ingeniería de lós bioprocesos. Zaragoza, Espanha: Acribia, 1998.

ELBERSE, K.; WITTEVEEN, S.; VAN DER HEIDE, H.; VAN DE POL I.; SCHOT, C. Sequence Diversity within the Capsular Genes of Streptococcus pneumonia Serogroup 6 and 19. PLoS One, v. 6, n. 9, p. e25018, 2011. doi:10.1371/journal.pone.0025018

FACCIOTTI, M. C. R. Fermentação contínua. In: SCHMIDELL, W.; LIMA, U. A.; AQUARONE, E.; BORZANI, W. Biotecnologia industrial. São Paulo: Edgar Blucher, 2001. Cap. 12, p. 223-246.

FIGUEIREDO, D. B.; MARTHOS, B. V.; FERRI, A. L. S.; GOGOLA, V. M. R.; GONÇALVES V. M. Método imunoenzimático para quantificar o polissacarídeo capsular de Streptococcus pneumoniae sorotipo 1. In: CONGRESSO BRASILEIRO DE ENGENHARIA QUíMICA., 19, 2012, Foz do Iguaçu. Anais... Foz do Iguaçu, 2012.

FUNDAÇÃO OSWALDO CRUZ. Novas vacinas no calendário básico. Disponível em: $<$ http://www.bio.fiocruz.br/index.php/mais-duas-vacinas-no-calendario-basico>. Acesso em: 25 ago. 2011.

FRANCO, C. M.; ANDRADE, A. L.; ANDRADE, J. G.; ALMEIDA, E.; SILVA, S.; OLIVEIRA, C. R.; PIMENTA, F. C.; LAMARO-CARDOSO, J.; BRANDÃO, A. P.; ALMEIDA, S. C.; CALIX, J. J.; NAHM, M. H.; BRANDILEONE, M. C. Survey of nonsusceptible nasopharyngeal Streptococcus pneumoniae isolates in children attending daycare centers in Brazil. Pediatr. Infect. Dis. J., v. 29, p. 77-79, 2010.

GARAU, J,; CALBO, E. Capsular types and predicting patient outcomes in Pneumococcal bacteremia. Clin. Infect. Dis., v. 45, p. 52-54, 2007.

GOGOLA, V. M. R. Continuous cultivation of Streptococcus pneumoniae serotype 14: Metabolism and kinetics of capsular polysaccharide production. 2011. 137 p. Masters thesis - Instituto de Ciências Biomédicas, Universidade de São Paulo, São Paulo, 2011.

GOGOLA, V. M. R.; CARMO, T. S.; GERALDO, C. S. F; FIGUEIREDO, D. B.; GONÇALVES, V. M. Quantification of capsular polysaccharide of Streptococcus pneumoniae serotype 14 in culture broth samples. Anal. Biochem., v. 421, p. 250-255, 2012.

GONÇALVES, V. M.; ZANGIROLAMI, T. C.; GIORDANO, R. L. C.; RAW, I.; TANIZAKI, M. M.; GIORDANO, R.C. Optimization of médium and cultivation conditions for capsular polysaccharide production by Streptococcus pneumonia serotype 23F. Appl. Microbiol. Biotechnol., v. 59, p.713-717, 2002.

GOLÇALVES, V. M.; TAKAGI, M.; LIMA, R. B.; MASSALDI, H.; GIORDANO, R. C.; TANIZAKI, M. M. Purification of capsular polysaccharide from Streptococcus pneumoniae serotype 23F by a procedure suitable for scale-up. Biotechnol. Appl. Biochem., v. 37, p. 283287, 2003. 
GOLÇALVES, V. M.; TAKAGI, M.; CARNEIRO, S. M.; GIORDANO, R. C.; TANIZAKI, M. M. Introduction of air in the anaerobic culture of Streptococcus pneumoniae serotype $23 \mathrm{~F}$ induces the release of capsular polysaccharide from bacterial surface into the cultivation medium. J. Appl. Microbiol., v. 101, p. 1009-1014, 2006.

GONÇALVES, V. M.; TAKAGI, M.; CARMO, T. S.; LIMA, R. B.; ALBANI, S. M. F.; PINTO, J. V.; ZANGIROLAMI, T. C.; GIORDANO, R.C; TANIZAKI, M. M.; CABRERACRESPO, J. Simple and efficient method of bacterial polysaccharides purification for vaccines production using hydrolytic enzymes and tangencial flow ultrafiltration. Appl. Microbiol., p. 450-457, 2007.

GORKE, B.; STULKE, J. Carbon catabolite repression in bacteria: many ways to make the most out of nutrients. Nature Reviews, v. 6, p. 613-622, 2008.

HARTEL, T.; EYLERT, E.; SCHULZ, C.; PETRUSCHKA, L.; GIEROK, P.; GRUBMULLER, S.; LALK, M.; EISENREICH, W.; HAMMERSCHMIDT, S. Characterization of the central carbon metabolism of Streptoccus pneumoniae by isotopologue profiling. Amer. Soc. Biochem. Mol. Bio., 2011. doi: 10.1074/jbc.M111.304311.

HENRIQUES, M. X.; RODRIGUES, T.; CARIDO, M.; FERREIRA, L.; FILIPE, S. R.; Synthesis of capsular polysaccharide at the division septum of Streptococcus pneumoniae is dependent on a bacterial tyrosine kinase. Mol. Microbiol., v. 82, p. 515-534, 2011.

HOSKISSON, P. A.; HOBBS, G. Continuous culture - making a comeback? Microbiology., v. 151, p. 3153-3159, 2005.

IYER, R.; NITIN, B. S.; CAMILLI, A. Catabolite Control Protein A (CcpA) contribuites to virulence and regulation of sugar metabolism in Streptoccus pneumoniae. J. Bacteriol., v. 187, p. 8340-8349, 2005.

IYER, R.; CAMILLI, A. Sucrose metabolism contributes to in vivo fitness of Streptococcus pneumoniae. Mol. Microbiol., v. 66, p. 1-13, 2007.

KENNEDY, M.; KROUSE, D. Strategies for improving fermentation medium performance: a review. J. Ind. Microbiol. Biotechnol., v. 23, p. 456-475, 1999.

KOLKMAN, M. A. B.; WAKARCHUK, W.; NUJITEN, P. J. M.; Van der ZEJIST, B. A. M. Capsular polysaccharide synthesis in Streptococcus pneumoniae serotype 14 : molecular analysis of the complete cps locus and identification of genes encoding glycosyltransferases required for the biosynthesis of the tetrasaccharide subunit. Mol. Microbiol., v. 26, n.1, p. 197-208, 1997.

KYOTO ENCYCLOPEDIA OF GENES AND GENOMES - KEGG. Disponível em: <http://www.genome.jp/kegg>. Acesso em: 20 jan. 2013.

LAHTVEE, P.; ADAMBERG, K.; ARIKE, L.; NAHKU, R.; ALLER, K.; VILU, R. Multiomics approach to study the growth efficiency and amino acid metabolism in Lactococcus lactis at various specific growth rates. Microbial Cell Fact., v. 10 n. 12, 2011. 
LINDBERG, B.; LONNGREN, J.; POWELL, D. A. Structural studies on the specific type-14 pneumococcal polysaccharide. Carbohydr. Res., v. 58, p. 177-186, 1977.

LOOIJESTEIJN, P. J.; Van CASTEREN, W. H.; TUINIER, R.; DOESWIJK-VORAGEN, C. H.; HUGENHOLTZ, J. Influence of different substrate limitation on the yield, composition and molecular mass of exopolysaccharides produced by Lactococcus lactis subsp. Cremoris in continuous cultivation cultures. J. Appl. Microbiol., v. 89, p. 116-122, 2000.

LUEDKING, R.; PIRET, E. L. A. Kinetic study of the lactic acid fermentation. Batch Process at controlled pH. J. Biochem. Microbiol. Technol. Eng., v. 1, n. 4, p. 393-412, 1959.

MANTESE, O. C.; PAUlA, A.; MORAES, A. B.; MOREIRA, T. A.; GUERA, M. L.; BRANDILEONE, M. C. Prevalence of serotypes and antimicrobial resistance of invasive strains of Streptococcus pneumoniae. J. Pediatr., Rio da Janeiro, v. 79, p. 537-542, 2003.

MANTESE, O. C.; DE PAUlA, A.; ALMEIDA, V. V.; DE AGUIAR, P. A.; WOLKERS, P. C.; ALVARES, J. R.; ALMEIDA, S. C. G.; GUERRA, M. L. L. S.; BRANDILEONE, M. C. Prevalence of serotypes and antimicrobial resistance of invasive strains of pneumococcus in children: analysis of 9 years. J. Pediatr., Rio da Janeiro, v. 85, p. 495-502, 2009.

MARTHOS, B. V.; FERRI, A. L. S.; FIGUEIREDO, D. B.; ZANGIROLAMI, T. C.; GONÇALVES V. M. Produção de polissacarídeo capsular por Streptococcus pneumoniae sorotipo 1 em um novo meio de cultura baseado em peptona de soja. In: CONGRESSO BRASILEIRO DE ENGENHARIA QUÍMICA.,19., 2012, Foz do Iguaçu. Anais... Foz do Iguaçu, 2012.

MARSHALL, V. M.; COWIE, E.N.; MORETON, R. S. Analysis and production of two exopolysaccharides from Lactococcus lactis subsp. Cremoris LC330. J. Dairy Research, v. 62, p. 621-628, 1995.

MARZZOCO, A.; TORRES, B. B. Bioquímica básica. Rio de janeiro: Guanabara Koogan, 2007. v. 1, cap. 5.

MATELES, R. I.; BATTAT, E. Continuous culture used for media optimization. Appl. Microbiol., v. 28, p. 901-905, 1974.

MENGISTU, Y.; EDWARDS, C.; SAUNDERS, J. R. Continuous culture studies on the synthesis of capsular polysaccharide by Klebsiella pneumoniae K1. J. Appl. Bacteriol., v. 76, p. 427-430, 1994.

MITCHELL, A. M.; MITCHELL, T. J. Streptococcus pneumoniae: virulence factors and variation. Euro. Soc. of Clin. Microb. and Infect. Dis., v. 16, p. 411-418, 2010.

MUNHOZ-ELIAS, E. J.; MCKINNEY, J. D. Carbon metabolism of intracellular bacteria. Cell. Microbiol., v. 8, p. 10-22, 2006.

MUSHER, D. M. Infections caused by Streptococcus pneumoniae: clinical spectrum, pathogenesis, immunity, and treatment. Clin. Infect. Dis., v. 14, p. 801-807, 1992. 
NEIJSSEL, O. M.; SNOEP, J. L.; TEIXEIRA DE MATTOS, M. J. Regulation of energy source metabolism in streptococci. J. Appl. Microbiol. Symp. Suppl., v. 83, p. 12S-19S, 1997.

O'BRIEN, K. L.; WOLFSON, L. J.; WATT, J. P.; HENKLE, E.; DELORIA-KNOLL, M.; McCALL, N.; LEE, E.; MULHOLlAND, K.; LEVINE, O. S.; CHERIAN, T. Burden of disease caused by Streptococcus pneumoniae in children younger than 5 years: global estimates. Lancet, v. 374, p. 893-902, 2009.

PETRY, S.; FURLAN, S.; CREPEAU, M.; CERNING, J.; DESMAZEAUD, M. Factors affecting exocellular polysaccharide production by Lactobacillus delbrueckii subsp. Bulgaricus grown in a chemically defined medium. Appl. Envir. Micobiol., v. 66, p. 34273431, 2000.

PIRT, S. J. The maintenance energy of bacteria in growing cultures. Proc. R. Soc. Lond., B, Biol. Sci., v. 163, n. 991, p. 224-231, 1965.

RANE, L.; SUBBAROW, Y. Nutritional requirements of the pneumococcus 1. Growth factors for types I, II, V, VII, VIII. J.Bacteriol., v. 40, p. 695-704, 1940.

SALMINEN, S.; VON WRIGHT, A.; OUWEHAND, A. Lactic acid bacteria: microbiological and functional aspects. New York: Board, 2004. v. 1, p. 18-25.

SAN MARTIN, R.; BUSHELL, D.; LEAK, D. J.; HARTLEY, B. S. Development of a synthetic medium for continuous anaerobic growth and ethanol production with a lactate dehydrogenase mutant of Bacillus stearothermophilus. J. Gen. Microbiol., v. 138, p. 987 996, 1992.

SCHMIDELL, W.; LIMA, U. A.; AQUARONE, E.; BORZANI, W. Biotecnologia Industrial. São Paulo: Edgard Blucher, 2001. v. 2, p. 242-245.

SCHWAAB, M.; PINTO, J. C. Análise de dados experimentais I: fundamentos de estatística estimação de parâmetros. Rio de Janeiro: E-papers Editora, 2007.

SHELBURNE. S. A.; DAVENPORT, M. T.; KEITH, D. B.; MUSSER, J. M. The role of complex carbohydrate catabolism in the pathogenesis of invasive streptococci. Trends in Microbiol., v. 16, p. 318-325, 2008.

SIREVA (Organizacao Pan-Americana de Saude). Informe Regional De Sireva II: datos por pais y por grupos de edad sobre las caracteristicas de los aislamientos de Streptococcus pneumoniae, Haemophilus influenzae y Neisseria meningitidis, en procesos invasores. Documentos Tecnicos. Tecnologias Esenciales de Salud, 2011.

SINGLETON, R. J.; HENNESSY, T. W.; BULKOW, L. R.; HAMMITT, L. L.; ZULZ T., HURLBURT, D. A.; BUTLER, J. C.; RUDOLPH, K.; PARKINSON, A. Invasive pneumococcal disease caused by nonvaccine serotypes among Alaska native children with high levels of 7-valent pneumococcal conjugate vaccine coverage. JAM, v. 297, p. 17841792, 2007. 
SNAPPER, C. M.; SHEN, Y.; KHAN, A. Q.; COLINO, J.; ZELAZOWSKI, P.; MOND, J. J.; GAUSE, W. C.; WU, Z. Distinct types of T-cell help for the induction of a humoral immune response to Streptococcus pneumoniae. Trends in Immunol., v. 22, p. 308-311, 2001.

SPELLERBERG, B.; CUNDELL, D. R.; SANDROS, J.; PEARCE, B. J.; IDANPAANHEIKKILA, I.; ROSENOW, C.; MASURE, H. R. Pyruvate oxidase, as a determinant of virulence in Streptococcus pneumoniae. Mol. Microbiol., v. 19, p. 803-813, 1996.

TETTELIN, H.; NELSON, K. E.; PAULSEN, I. T.; EISEN, J. A.; READ, T. D.; PETERSON, S.; HEIDELBERG, J.; DEBOY, R. T.; HAFT, D. H.; DODSON, R. J. Complete genome sequence of a virulent isolate of Streptococcus pneumoniae. Science, v. 293, p. 498$506,2001$.

TODA, K. Theoretical and methodological studies of continuous microbial bioreactors. J. Gen. Appl. Microbiol., v. 49, p. 219-233, 2003.

TOGINHO FILHO, D. O.; ANDRELLO, A. C. Catálogo de experimentos do laboratório integrado de física geral. Departamento de física. Universidade Estadual de Londrina. Mar. 2009.

TORINO, M. I.; HÉBERT, E. M.; MOZZI, F.; FONT DE VALDEZ, G. Growth and exopolysaccharide production by Lactobacillus helveticus ATCC 15807 in an adeninesupplemented chemically defined medium. J. Appli. Microbiol., v. 99, p. 1123-1129, 2005.

VAN DER RIJN, C. L, KESSLER, R. E. Growth characteristics of group A streptococci in a new chemically defined medium. Infect. Immun., v. 27, p. 444-448, 1980.

VENTURA, C. L.; CARTEE, R. T.; FORSEE, W. T.; YOTHER, J.; Control of capsular polysaccharide chain length by UDP-sugar substrate concentrations in Streptococcus pneumoniae. Mol. Microbiol., v. 61, p. 723-733, 2006.

WORLD HEALTH ORGANIZATION (WHO). Pneumonia. 2011. Disponível em: <http://www.who.int/immunization/topics/pneumococcal_disease/en/>. Acesso em: 10 jun. 2012.

YOTHER, J. Capsules of Streptococcus pnuemoniae and other bacteria: paradigms for polysaccharides biosynthesis and regulation. Annu. Rev. Microbiol., v. 65, p. 563-581, 2011.

ZHANG, J.; GREASHAM, R. Chemically defined media for commercial fermentations. Appl. Microbiol. Biotechnol., v. 51, p. 407-421, 1999. 


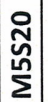

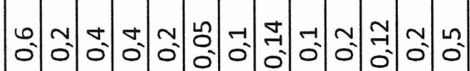

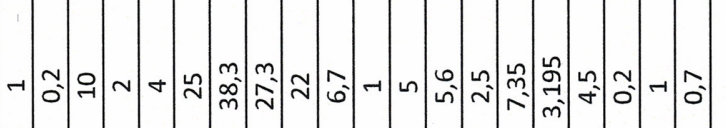

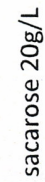

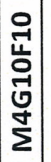

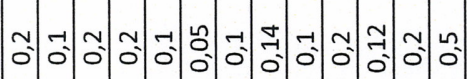

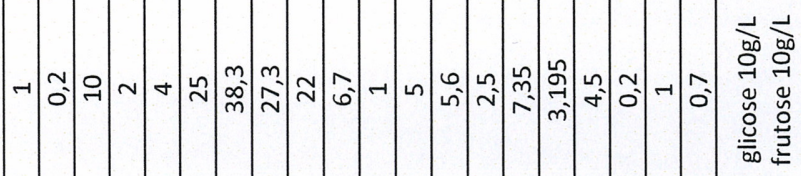

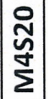

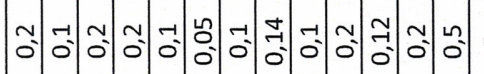

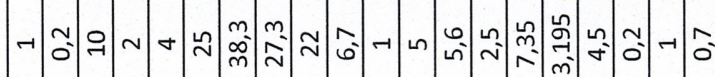
㠃

袲

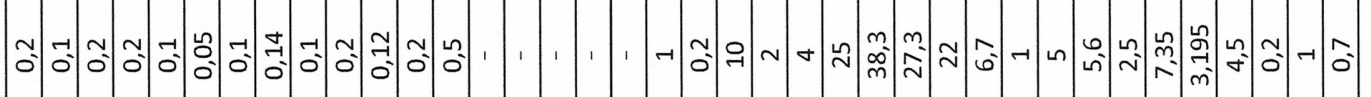

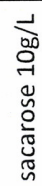

衷 :

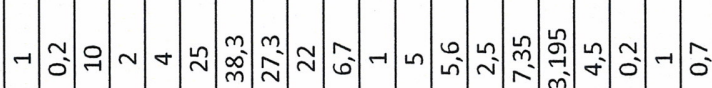

ָั్ָ

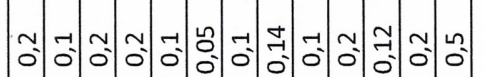

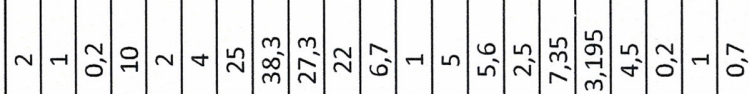

胥

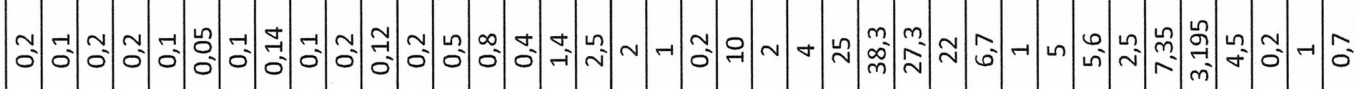

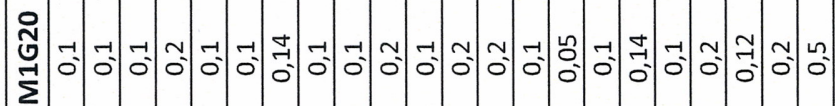

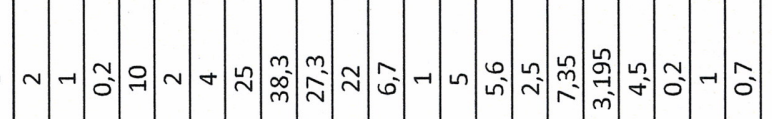

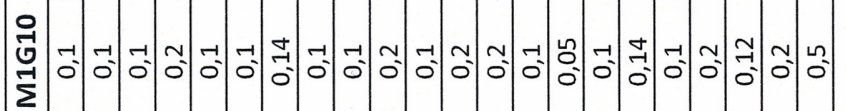

